\title{
EMPREGO DE ESPÉCIES TROPICAIS ALTERNATIVAS NA PRODUÇÃO DE ELEMENTOS ESTRUTURAIS DE MADEIRA LAMINADA COLADA
}

André Luiz Zangiácomo

Dissertação apresentada à Escola de Engenharia de São Carlos, da Universidade de São Paulo, como parte dos requisitos para obtenção do título de Mestre em Engenharia de Estruturas.

Orientador: Prof. Dr. Francisco Antonio Rocco Lahr

São Carlos

2003 


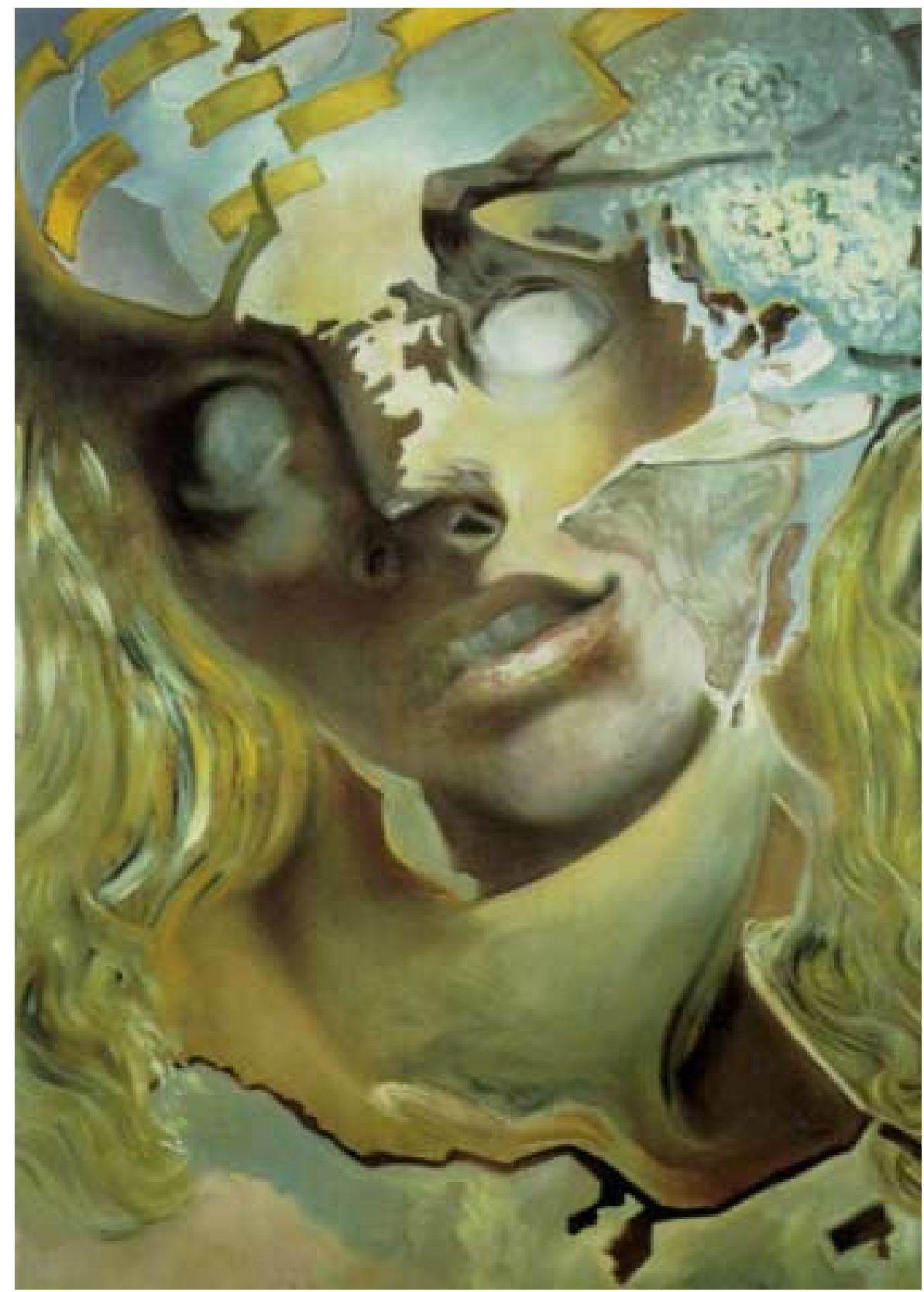

Cabeça Explodida!- Salvador Dali

Aos meus pais Odécio e Dinivanda e aos meus irmãos Daniel e Kelly. 


\section{$\Lambda^{\text {GRADECIMENTOS }}$}

Este trabalho é o fruto de cada sorriso, de cada palavra, de cada olhar, enfim, é o resultado da relevante contribuição destas pessoas, as quais eu faço questão de tornar pública. Os meus sinceros agradecimentos:

Aos meus pais Odécio e Dinivanda (Décio e Vanda), por serem os primeiros professores de minha vida e por terem me dado a oportunidade de estudar. Ao meu irmão Daniel (Mi) pelo companheirismo e pela boa música de sua bateria, e à minha irmã Kelly, pela sua carinhosa companhia e pelos momentos de risadas juntos.

Ao Professor Doutor Francisco Antonio Rocco Lahr pela sua valiosíssima amizade e orientação nesta pesquisa. Acima de tudo, Ser Humano.

À Tia Maria, e às primas Marlene e Marli, pelo incentivo. Desculpem a ausência.

Aos funcionários do LaMEM, Jaime, Arnaldo, Silvio, Cido, Samuel, Bragatto, Roberto e Tânia, pela enorme ajuda durante o desenvolvimento deste trabalho.

Ao colega Mariano, pela fundamental contribuição no planejamento e na análise estatística.

Aos companheiros do LaMEM pelas amizades, trocas de informações, colaborações, piadas e todos os dias de convivência.

Ao Centro Acadêmico "Armando de Salles Oliveira" (CAASO), pelo convívio político, social e cultural. Aos amigos do Grupo de Som - CAASO, do MTB FOR FUN - CAASO e do Bando de Expressão Cômico Cultural do CAASO.

Aos amigos e moradores da "República dos Cachassauros Largados", engenheiros Marú, Bicudo, Farelo, Sardinha, Fernandinho, Spin e Tonho. Pelos momentos de devaneios, pelas alegrias, diversões, etc. E por sempre compartilharem comigo das 
seguintes frases: "De quem é essa louça suja?" e "Quem é que lava o banheiro essa semana ?".

Aos amigos de Americana por me apoiarem e me receberem nos finais de semana.

Aos membros integrantes da banca do Exame de Qualificação professores José Samuel Giongo e Raquel Gonçalves pelas valiosas sugestões.

Ao professor Gilberto e aos funcionários do Laboratório de Química Analítica e Tecnologia de Polímeros do IQSC - USP pelo auxílio e preparação do poliol e do prepolímero empregados nesta pesquisa.

À Fundação Coordenação de Aperfeiçoamento de Pessoal de Nível Superior (CAPES), pela bolsa de estudos concedida.

E a todos aqueles que de uma forma ou de outra depositaram suas ajudas anonimamente na composição desta obra. 


\section{SUMÁRIO}

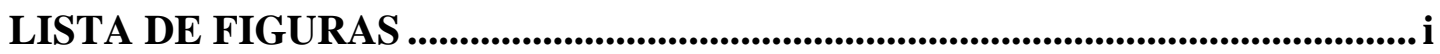

LISTA DE TABELAS .............................................................................................

ABREVIATURAS E SIGLAS ............................................................................................. iv

LISTA DE SÍMBOLOS....................................................................................

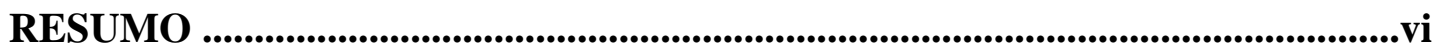

ABSTRACT ............................................................................................................ vii

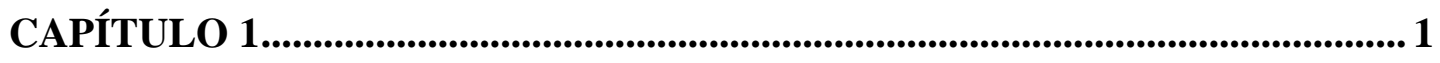
INTRODUÇÃO

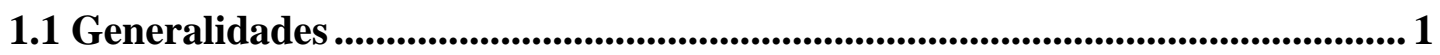

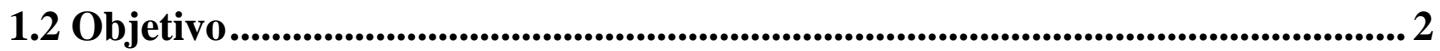

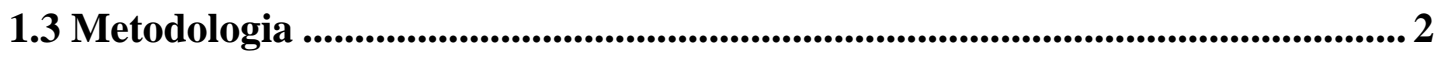

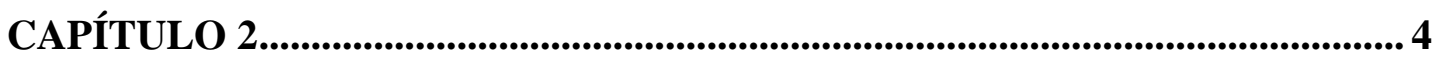

REVISÃO BIBLIOGRÁFICA

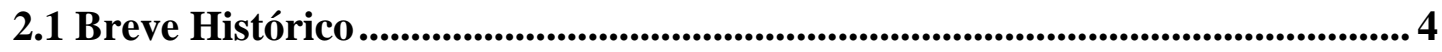

2.2 Algumas pesquisas a respeito da MLC no Brasil...........................................8

2.3 Vantagens da MLC ..............................................................................................................9

2.4 Madeiras da Floresta Amazônica ....................................................................9

2.5 Ensaios Não Destrutivos ................................................................................. 10

2.6 Conclusões da Revisão Bibliográfica................................................................... 11

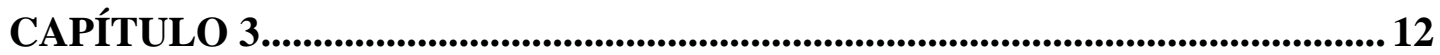

ENSAIOS PRELIMINARES

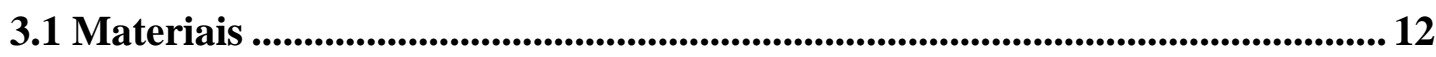

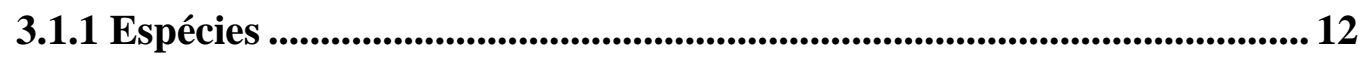

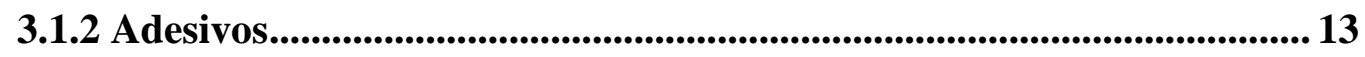


3.1.3 Equipamentos ................................................................................................................. 13

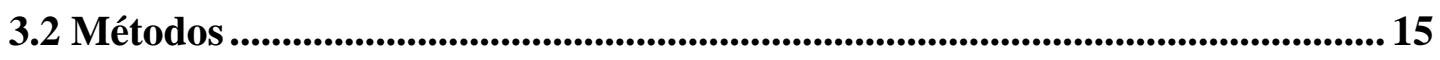

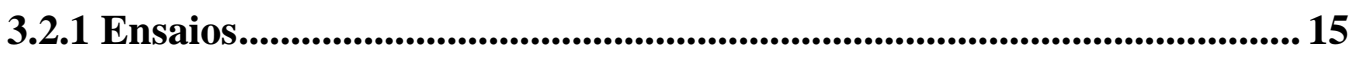

3.2.2 Obtenção dos corpos-de-prova.................................................................... 15

3.2.3 Preparo dos adesivos e processo de colagem ............................................ 17

3.3 Planejamento estatístico .............................................................................................. 18

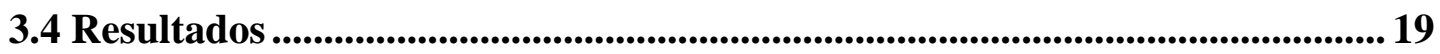

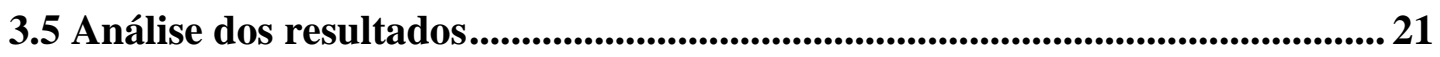

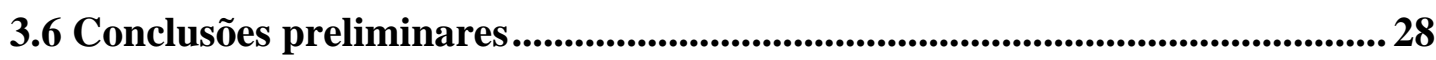

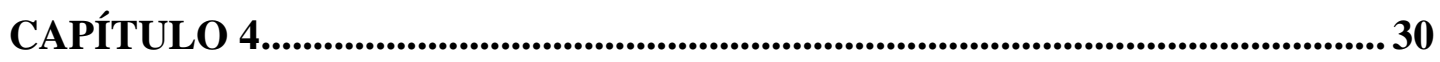

ENSAIOS PRINCIPAIS

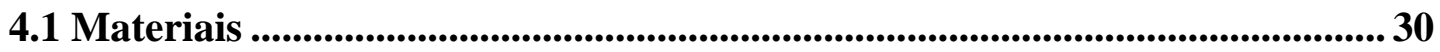

4.1.1 Espécie .................................................................................................................. 30

4.1.2 Adesivos.................................................................................................. 31

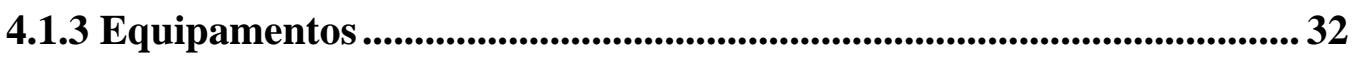

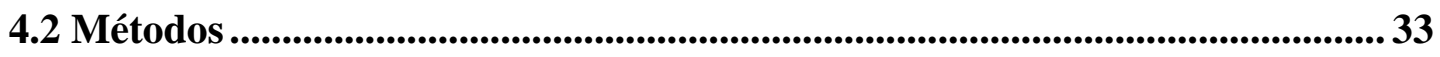

4.2.1 Obtenção das lâminas ........................................................................................ 33

4.2.2 Ensaios das lâminas ................................................................................34

4.2.2.1 Flexão estática nas lâminas .................................................................. 35

4.2.2.2 Vibração transversal .............................................................................36

4.2.2.3 Ultra-som ............................................................................................. 38

4.2.3 Critérios para a montagem dos elementos estruturais ......................... 40

4.2.4 Colagem das vigas ...................................................................................................... 41

4.2.5 Ensaios das vigas ............................................................................................. 43

4.2.5.1 Flexão estática................................................................................43

4.2.5.2 Vibração transversal .................................................................................. 46

4.2.5.3 Ultra-som .......................................................................................4 4

4.2.6 Planejamento estatístico .......................................................................48 
CAPÍtULO 5.

APRESENTAÇÃo E ANÁLISE DOS RESULTADOS

5.1 Valores obtidos nos ensaios com as lâminas ...............................................51

5.1.1 Flexão estática............................................................................... 51

5.1.2 Vibração transversal..........................................................................5 52

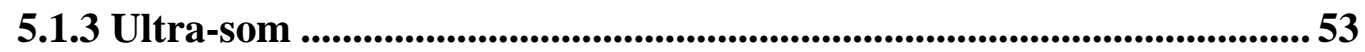

5.1.4 Análises dos resultados obtidos para as lâminas..................................54

5.1.4.1 Flexão estática versus vibração transversal.....................................55

5.1.4.2 Flexão estática versus ultra-som ...................................................56

5.1.4.3 Vibração transversal versus ultra-som ...........................................5 57

5.2 Resultados obtidos para as vigas .......................................................................5 57

5.2.1 Disposição das lâminas nas vigas .............................................................. 61

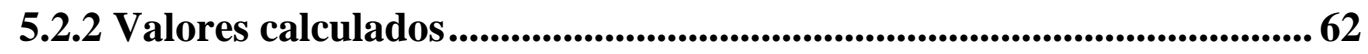

5.2.3 Valores obtidos nos ensaios ..............................................................64 64

5.2.3.1 Flexão estática............................................................................6 64

5.2.3.2 Vibração transversal .......................................................................66

5.2.3.3 Ultra-som ........................................................................................66

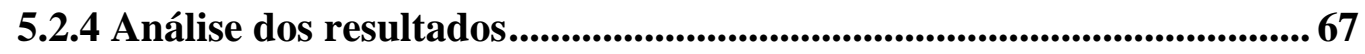

5.2.4.1 Análise fatorial ..............................................................................68

5.2.4.2 Correlações e análises de variância ................................................... 72

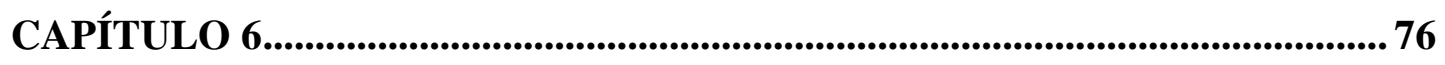

CONCLUSÕES

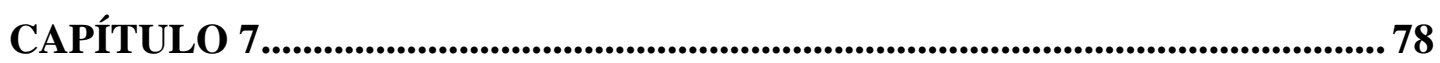

7.1 REFERÊNCIAS BIBLIOGRÁFICAS ...................................................... 78

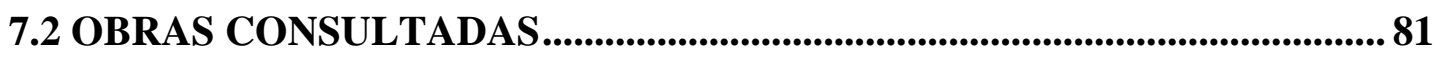

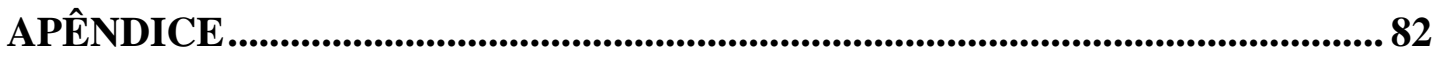




\section{LISTA DE FIGURAS}

Figura 1 - Esquema de uma viga de MLC ...........................................................5

Figura 2 - Ponte em arco construída com madeira laminada colada ..................... 7

Figura 3 - Estrutura de cobertura em madeira laminada colada ......................... 7

Figura 4 - Serra utilizada no corte das peças...................................................................14

Figura 5 - Cortador tipo asa para emendas dentadas........................................... 14

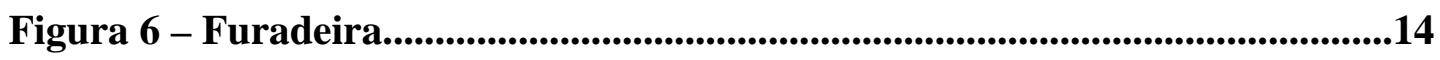

Figura 7 - Máquina Universal de ensaios AMSLER................................................ 14

Figura 8 - Máquina Universal de ensaios Dartec ....................................................... 15

Figura 9 - Confecção de corpo-de-prova para ensaio de tração normal............... 16

Figura 10 - Aplicação de adesivo..............................................................18

Figura 11 - Processo de colagem ................................................................................. 18

Figura 12 - Corpo-de-prova submetido a ensaio de tração paralela .................... 20

Figura 13 - Corpo-de-prova submetido a ensaio de cisalhamento.......................20

Figura 14 - Corpo-de-prova submetido a ensaio de tração normal...................... 21

Figura 15- Aspecto da madeira Cedrinho ................................................................... 31

Figura 16 - Tábuas de Cedrinho ..................................................................................... 31

Figura 17 - Adesivos utilizados nas colagens ....................................................... 32

Figura 18 - Esquema de corte das tábuas para obtenção das lâminas ................ 34

Figura 19 - Esquema de ensaio de flexão estática para as lâminas....................... 35

Figura 20 - Esquema do ensaio de determinação do módulo de elasticidade por meio de vibração transversal ......................................................................... 37

Figura 21 - Detalhe do equipamento de vibração transversal................................37

Figura 22 - Equipamento de vibração transversal .............................................. 37

Figura 23 - Lâmina em ensaio..............................................................................38

Figura 24 - Detalhe da célula de carga .................................................................... 38

Figura 25 - Esquema de ensaio para determinação da constante dinâmica por

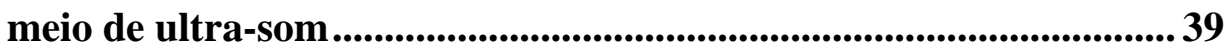

Figura 26 - Aparelho de ultra-som Sylvatest .............................................................. 39 
Figura 27 - Lâminas para montagem da peça estrutural...........................................42

Figura 28 - Dispositivo para prensagem das vigas ............................................ 42

Figura 29 - Distribuição do adesivo nas lâminas..........................................................42

Figura 30 - Detalhe da distribuição ..................................................................................... 42

Figura 31 - Aplicação da pressão com uso de torquímetro.....................................43

Figura 32 - Vigas sob pressão ......................................................................................... 43

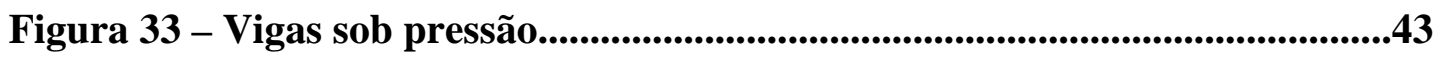

Figura 34 - Vista lateral de uma viga colada ................................................................. 43

Figura 35 - Esquema de ensaio de flexão estática de 4 pontos ............................. 45

Figura 36 - Ensaio de flexão estática de 4 pontos em uma viga ........................... 45

Figura 37 - Detalhe de aplicação de força no ensaio..................................................46

Figura 38 - Vista lateral do ensaio de flexão estática. .......................................... 46

Figura 39 - Elemento estrutural preparado para ensaio de vibração transversal 46

Figura 40 - Viga sofrendo impacto em ensaio de vibração transversal................ 47

Figura 41 - Esquema de ensaio de ultra-som em viga de MLC ..........................48

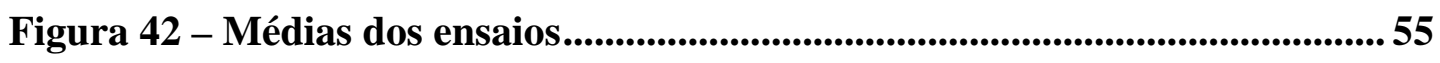

Figura 43 - Correlação para as lâminas: flexão x vibração.................................56

Figura 44 - Correlação para as lâminas: flexão x ultra-som ..............................56

Figura 45 - Correlação para as lâminas: ultra-som x vibração ............................. 57

Figura 46 - Esquema da viga sem colar........................................................58

Figura 47 - Distribuição das lâminas nas vigas ......................................................62

Figura 48 - Gráfico dos resíduos contra valores estimados da tabela 17 ........... 69

Figura 49 - Gráfico de probabilidade normal para os resíduos da tabela 17 .... 70

Figura 50 - Gráfico dos resíduos contra os escores normais (tabela 17)............. 70

Figura 51- Dados obtidos na análise fatorial ......................................................... 71

Figura 52 - Correlação para as vigas: flexão x vibração .......................................... 73

Figura 53 - Correlação para as vigas: flexão x ultra-som........................................ 73

Figura 54 - Correlação para as vigas: ultra-som x vibração .............................. 74 


\section{LISTA DE TABELAS}

Tabela 1 - Tensões médias obtidas para a Envira branca (em MPa) 19

Tabela 2 - Tensões médias obtidas para o Cambará (em MPa)........................... 19

Tabela 3 - Tensões médias obtidas para a Castanheira (em MPa) ...................... 19

Tabela 4 - Tensões médias obtidas para o Cedrinho (em MPa)............................ 20

Tabela 5 - Análise de variância da Envira Branca ................................................. 22

Tabela 6 - Análise de variância do Cambará...........................................................23

Tabela 7 - Análise de variância da Castanheira ....................................................25

Tabela 8 - Análise de variância do Cedrinho.....................................................227

Tabela 9 - Matriz planejamento para análise estatística ................................... 49

Tabela 10 - Módulos de elasticidade das lâminas obtidos por flexão estática ... 52

Tabela 11 - Módulos de elasticidade das lâminas, obtidos por vibração

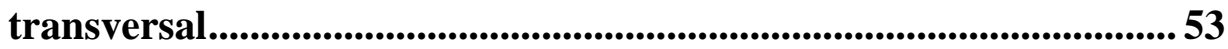

Tabela 12 - Constantes dinâmicas das lâminas obtidas por ultra-som ................54

Tabela 13 - Resultados calculados obtidos para as vigas ...................................63

Tabela 14 - Valores obtidos por ensaios de flexão estática .................................65

Tabela 15 - Valores obtidos nos ensaios de vibração transversal ....................... 66

Tabela 16 - Valores obtidos em ensaios por ultra-som .........................................6 67

Tabela 17 - Resultados obtidos nos ensaios, matriz planejamento, valores estimados, resíduos e escores normais............................................... 68

Tabela 18 - Valores de $\mathbf{E}$ obtidos nos ensaios de flexão estática e vibração transversal e de $C_{L L}$ obtidos nos ensaios de ultra-som ....................... 72

Tabela 19 - Análises de variância das médias dos ensaios versus calculados .... 75 


\title{
ABREVIATURAS E SIGLAS
}

\author{
ABNT - Associação Brasileira de Normas Técnicas \\ ASTM - American Society for Testing and Materials \\ DIN - Deutsches Institut für Normung \\ EESC - Escola de Engenharia de São Carlos \\ EUA - Estados Unidos da América
}

IBAMA -Instituto Brasileiro do Meio Ambiente e dos Recursos Naturais Renováveis INPA - Instituto Nacional de Pesquisas da Amazônia

INPE - Instituto Nacional de Pesquisas Espaciais

IPT - Instituto de Pesquisas Tecnológicas

IQSC - Instituto de Química de São Carlos

LaMEM - Laboratório de Madeiras e de Estruturas de Madeira

LPF - Laboratório de Produtos Florestais

MLC - Madeira Laminada Colada

NBR - Norma Brasileira Registrada

SET - Departamento de Engenharia de Estruturas

USP - Universidade de São Paulo 


\section{LISTA DE SÍMBOLOS}

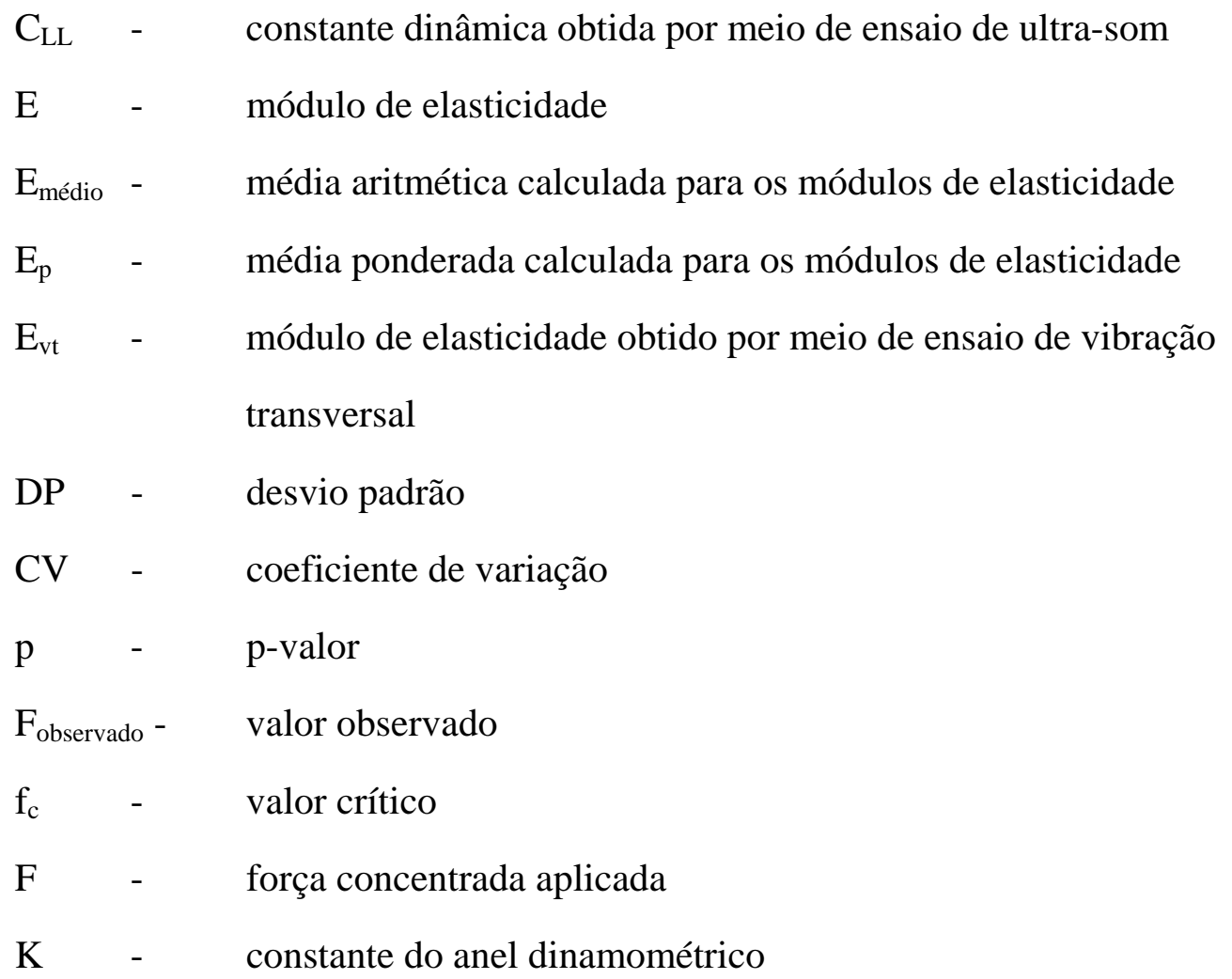




\section{$\mathrm{R}^{\mathrm{ESUMO}}$}

ZANGIÁCOMO, A. L. (2003). Emprego de espécies tropicais alternativas na produção de elementos estruturais de madeira laminada colada. São Carlos, 2003. 78p. Dissertação (Mestrado) - Escola de Engenharia de São Carlos, Universidade de São Paulo.

Apesar da versatilidade da madeira, seu emprego fica, às vezes, dificultado por não serem totalmente conhecidas as suas propriedades e seu desempenho em diferentes condições de serviço. Neste trabalho, procura-se contribuir para um melhor aproveitamento das espécies tropicais alternativas, em especial no emprego para produção de elementos estruturais de madeira laminada colada, uma vez que o Brasil possui grande potencial dessas espécies, mas ainda sub-utilizadas. Neste contexto, realiza-se a determinação das propriedades físicas, de resistência e de rigidez de algumas espécies e determinam-se também as rigidezes de elementos estruturais obtidos da espécie cujos corpos-de-prova apresentam os melhores resultados. Ensaiam-se vigas montadas com dois tipos de adesivos, duas intensidades de pressão e duas distribuições de lâminas. Adota-se a metodologia experimental recomendada no ANEXO B da NBR 7190:1997 - Projeto de Estruturas de Madeira, da Associação Brasileira de Normas Técnicas (ABNT). Analisam-se os resultados obtidos a partir de conceitos estatísticos. A espécie Cedrinho (Erisma sp) apresentou as melhores respostas, das quais pode-se concluir que os adesivos Cascophen e à base de mamona não influenciaram as propriedades de rigidez das vigas, o mesmo acontecendo para as duas intensidades de pressão, 0,8 $\mathrm{MPa}$ e 1,2 $\mathrm{MPa}$. As propriedades de rigidez das vigas de MLC podem ser influenciadas pela distribuição das lâminas ao longo da altura da seção transversal.

Palavras-chave: madeira, estruturas de madeira, madeira laminada colada. 


\section{$\mathrm{A}^{\mathrm{BSTRACT}}$}

ZANGIÁCOMO, A. L. (2003). Employment of alternative tropical timber species in glued laminated timber structural elements production. São Carlos, 2003. 78p. Dissertação (Mestrado) - Escola de Engenharia de São Carlos, Universidade de São Paulo.

Despite the wood versatility, its application is, sometimes, difficult because of its properties and performances under differents work conditions are not completely known. The present work seeks to contribute for a better utilization of the alternative tropical wood species, especially in the employment to the production of structural elements of glued laminated timber, once that Brazil has a great potential of these species which are under applicated. In this context, the determination of the physical properties, the strength and the stiffness of some alternative tropical species are realized, and the stiffness of structural elements made of the specie wich presented the best results in specimens tests are determinated. Beams are tested with two adhesives classes, two pressure intensities and two ways of lamination. Experimental methods suggested in ANEXO B, NBR 7190:1997 - Timber Structures Design (Brazilian Technical Codes Association) were used. The specie Cedrinho (Erisma sp) presents the best results, and conclusions are made: Cascophen and castor oil adhesives did not influence the beams stiffness properties; the same thing happens for the two pressure intensities, $0,8 \mathrm{MPa}$ and 1,2 $\mathrm{MPa}$. The glulam beams stiffness properties can be influenced by the ways of lamination.

Keywords: wood, timber structures, glued laminated timber 
"Queira, basta ser sincero e desejar profundo, você será capaz de sacudir o mundo, vai, tente outra vez.

Tente, e não diga que a vitória está perdida, se é de batalhas que se vive a vida, tente outra vez."

Raul Seixas (1975)

\section{INTRODUÇÃO}

\subsection{Generalidades}

O emprego da madeira na construção de estruturas, no Brasil, nem sempre ocorre em condições satisfatórias no tocante à tecnologia agregada ao material, apesar de sua versatilidade e de sua disponibilidade. Mesmo considerando estes aspectos favoráveis, seu emprego fica, às vezes, dificultado por não serem totalmente conhecidas suas propriedades físico-mecânicas e seu desempenho em diferentes condições de serviço.

Para o adequado aproveitamento da madeira como material estrutural, é indispensável o conhecimento das suas características de resistência e de rigidez. Isto deve ocorrer com todas as espécies, inclusive as alternativas, cujo potencial seja mais promissor, consideradas as múltiplas possibilidades de uso. Entre estes usos, vem ganhando cada vez mais espaço no mercado internacional, com reflexos imediatos na construção civil brasileira, o emprego de elementos estruturais de madeira laminada colada (MLC), solução compatível para uma vasta gama de problemas estruturais. 
Paralelamente, vem sendo observada a conscientização da necessidade de um melhor aproveitamento dos recursos naturais provenientes das Florestas Tropicais, em particular no que concerne à Floresta Amazônica, com a disseminação dos conceitos de manejo sustentado e comercialização de material certificado. Cada vez menos se compactua com a exploração seletiva e predatória, que conduziu à exaustão diversas espécies de uso consagrado. Também está sendo gradativamente abandonado o procedimento desaconselhável de se queimar, nos próprios locais de extração, as numerosas árvores de espécies pouco conhecidas, ou mesmo desconhecidas, em particular as que fornecem madeira com densidade inferior a $0,75 \mathrm{~g} / \mathrm{cm}^{3}$, a $12 \%$ de umidade. Deve ser lembrado que é nesta faixa de densidades que se encontram as espécies potencialmente indicadas para emprego na produção de elementos estruturais de madeira laminada colada.

Informações publicadas pelo Instituto Nacional de Pesquisas Espaciais - INPE (1998) mostram um significativo decréscimo na taxa de desmatamento na Floresta Amazônica. No período compreendido entre 1978 e 1987, $21.130 \mathrm{~km}^{2}$ foram consumidos por ano. Nos dez anos seguintes, este número caiu para $16.777 \mathrm{~km}^{2}$, e as perspectivas são de que se reduza ainda mais esta taxa nos próximos anos. Assim sendo, passa a crescer a disponibilidade de espécies de menor densidade, evidenciando a urgência para o desenvolvimento de trabalhos de pesquisa, seja de cunho teórico, seja de abordagem teórico-experimental, que permitam o adequado conhecimento de sua aplicabilidade às mais diversificadas situações práticas, incluindo-se entre elas a MLC.

\subsection{Objetivo}

O trabalho aqui proposto tem como objetivo gerar subsídios que contribuam para o emprego de espécies tropicais, com densidade até $0,75 \mathrm{~g} / \mathrm{cm}^{3}$, a $12 \%$ de umidade, valor de referência da NBR 7190:1997, na produção de peças estruturais de MLC.

\subsection{Metodologia}

Esta pesquisa foi dividida em duas fases. $\mathrm{Na}$ primeira, são realizados ensaios em corpos-de-prova colados obtidos de quatro espécies de madeira: são determinadas a 
resistência à tração das emendas dentadas, a resistência da lâmina de cola à tração normal e a resistência ao cisalhamento da lâmina de cola. Para efeito de comparação, são realizados também ensaios para a determinação da resistência à tração paralela às fibras, resistência à tração normal às fibras e resistência ao cisalhamento em corposde-prova de madeira maciça. Na segunda fase, determinam-se por meio de ensaios de flexão estática, de vibração transversal e de ultra-som, as rigidezes de elementos estruturais obtidos da espécie cujos corpos-de-prova apresentam os melhores resultados. São ensaiadas vigas montadas com dois tipos de adesivos, duas intensidades de pressão e duas distribuições de lâminas. Os experimentos são conduzidos de acordo com a metodologia recomendada no ANEXO B da NBR 7190:1997 - Projeto de Estruturas de Madeira, da Associação Brasileira de Normas Técnicas (ABNT), e os resultados obtidos são analisados a partir de conceitos estatísticos (análises de variância das médias, correlações e análise fatorial). 
"Quarenta anos de idade: velho demais para trabalhar, jovem demais para se aposentar."

Homem desempregado em entrevista na TV

\section{REVISÃO BIBLIOGRÁFICA}

\subsection{Breve Histórico}

Elementos estruturais de madeira laminada colada (MLC) são formados por peças de madeira obtidas com lâminas de determinada seção, solidarizadas entre si sob pressão, com o emprego de adesivos (figura 1).

A MLC tem seus usos mais freqüentes em estruturas de cobertura, elementos estruturais principais para pontes, torres de transmissão, edifícios, embarcações, banzos de escadas e corrimão, equipamentos decorativos planos ou em relevos, esquadrias e móveis. Isto se deve ao fato da MLC adaptar-se a uma significativa variedade de formas e apresentar alta resistência a solicitações mecânicas em função de seu peso próprio relativamente baixo.

A técnica de laminar peças de madeira com pequenas dimensões para se obter elementos estruturais mais avantajados teve origem na Alemanha, no final do século XIX, quando Hetzer obteve a primeira patente deste processo de produção. No entanto, o Sistema Hetzer, como passou a ser conhecido, ganhou evidência apenas a partir de 1913, quando se expandiu o emprego da MLC na construção de estruturas de coberturas de fábricas e escolas, bem como na montagem de pontes. 

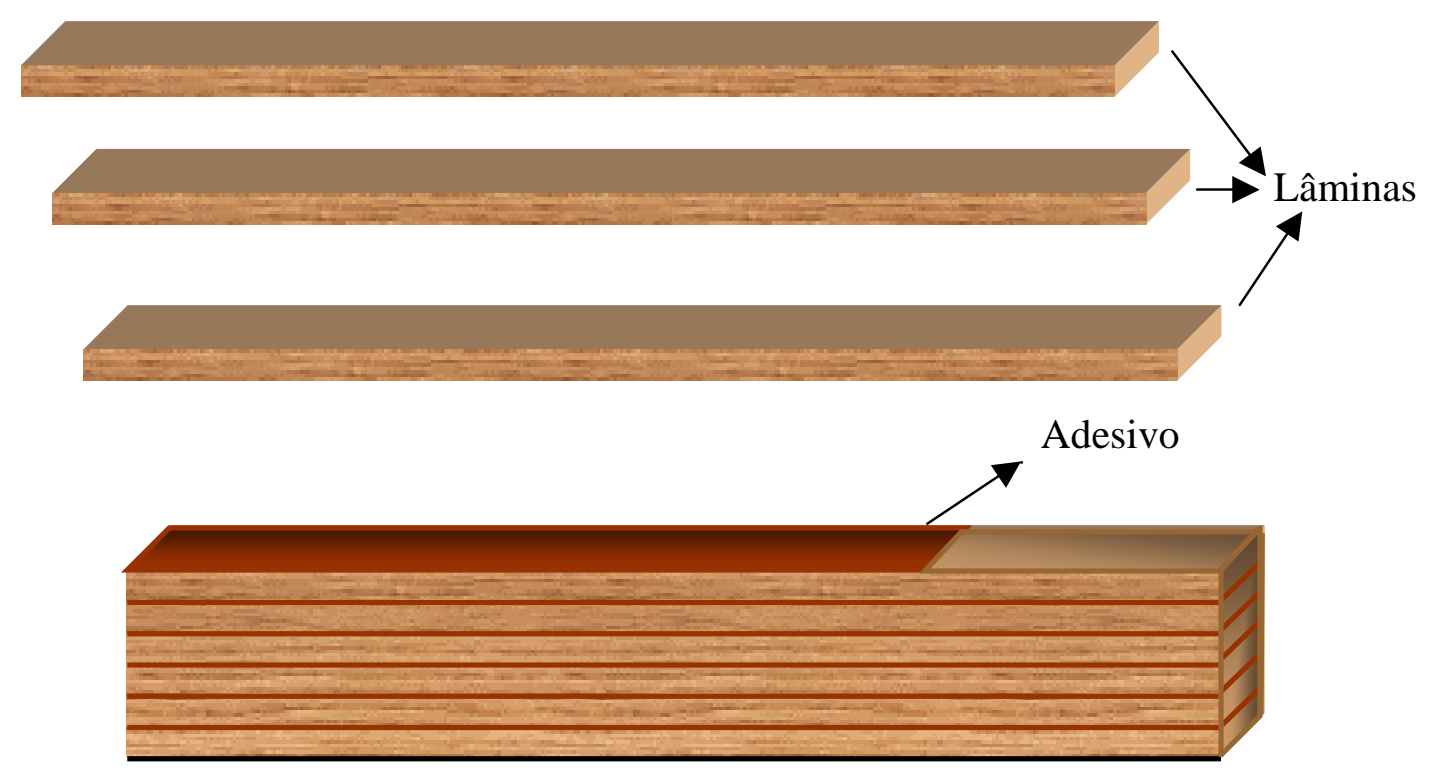

Figura 1 - Esquema de uma viga de MLC

Ganha impulso, então, o processo de aceitação dessa técnica por parte de outros países da Europa, como Dinamarca, Noruega, Suécia, Áustria, e, principalmente, Suíça, onde ocorreu grande disseminação de seu emprego.

Coube a Max Hanish, arquiteto e engenheiro alemão, trazer a tecnologia da MLC para a América. Após ensaios realizados nos Estados Unidos da América (EUA), para verificação da confiabilidade da MLC, foram instaladas algumas indústrias no Canadá e EUA.

Informações mais detalhadas sobre construções pioneiras em MLC, bem como relacionadas às bases teóricas para o dimensionamento de elementos estruturais, podem ser encontradas em publicações consideradas clássicas no assunto, mencionando-se, entre outras, as de SELBO \& FREAS (1954), CHUGG (1964) e MOODY (1970).

No Brasil, a primeira indústria de MLC, a ESMARA Estruturas de Madeira Ltda, foi fundada em 1934, em Curitiba-PR, com tecnologia trazida por alemães. Mais tarde, outra empresa de mesmo nome foi fundada em Viamão-RS. Têm-se obras marcantes destas duas empresas na Região Sul, com vastos arquivos de projetos.

Merecem citações outras indústrias também da Região Sul, como a PRÉ-MONTAL Estruturas de Madeira Ltda (PREMON), fundada em Curitiba-PR, em 1977, 
executando a maioria de seus projetos nas décadas de 70/80; a EMADEL Estruturas de Madeira Ltda, fundada em Araucária-PR, em 1981; e a BATTISTELLA Indústria e Comércio Ltda, situada em Lages-SC, atuando no setor madeireiro há mais de 40 anos e que, atualmente, possui uma linha de produção de casas e estruturas préfabricadas, com largo uso de elementos estruturais de MLC.

A LAMINARCO Madeira Industrial Ltda, fundada na década de 60 e localizada em São Paulo-SP, segundo BONO (1996), foi a primeira empresa produtora de MLC na Região Sudeste. Foi montada e gerenciada pelo engenheiro Vinício Walter Callia, pesquisador do Instituto de Pesquisas Tecnológicas do Estado de São Paulo (IPT), pioneiro nos estudos e publicações sobre o assunto.

Já estão instaladas algumas produtoras de peças estruturais de MLC na região metropolitana de Belo Horizonte, as quais têm empregado madeira de Eucalipto Grandis (Eucalyptus grandis). Na região norte do país, as primeiras tentativas para a produção de MLC a partir de espécies tropicais esbarraram na ausência de informações a respeito das variáveis envolvidas na produção, entre elas a compatibilidade da espécie com os adesivos, a pressão e o tempo de colagem e as propriedades de resistência a considerar no dimensionamento. Observa-se o paradoxo: diante da disponibilidade do material, o respectivo uso fica restrito (ou inviabilizado) pela ausência de informações tecnológicas que permitam sua correta aplicação.

As figuras 2 e 3 ilustram exemplos de aplicações estruturais de MLC. 


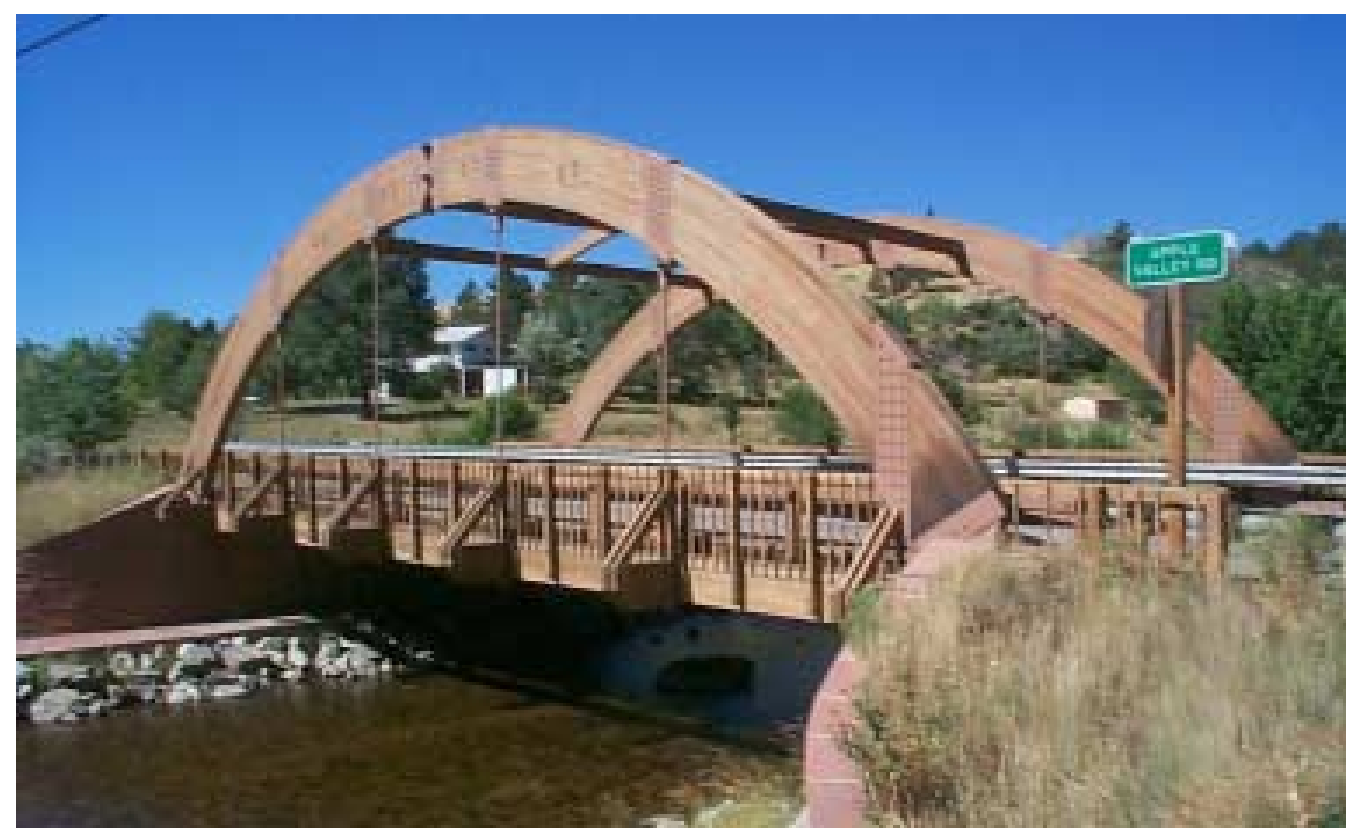

Figura 2 - Ponte em arco construída com madeira laminada colada Apple Valley - Colorado - EUA

Fonte: www.eng.auburn.edu

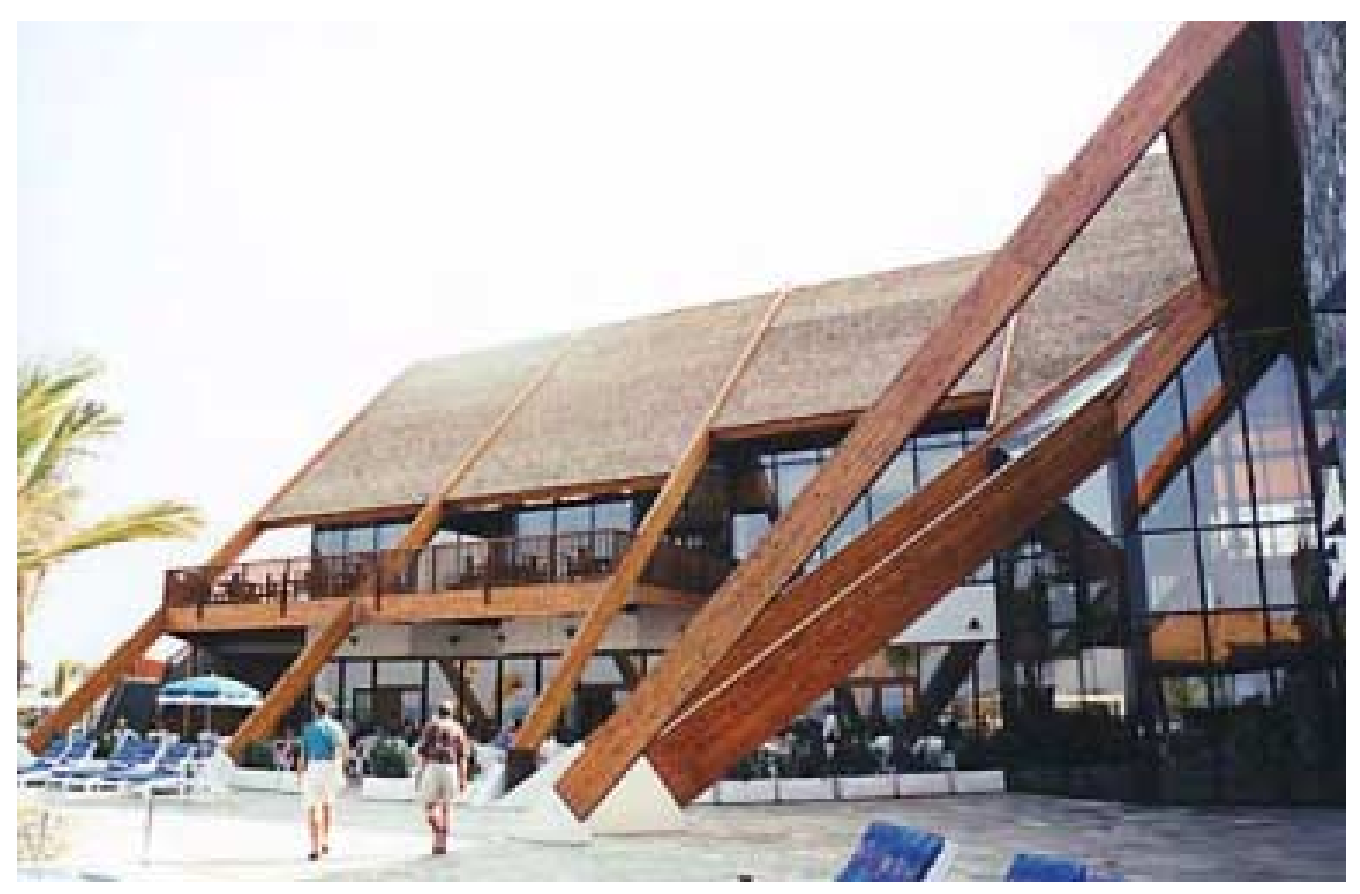

Figura 3 - Estrutura de cobertura em madeira laminada colada

Fonte: www.mcintosh.co.nz 


\subsection{Algumas pesquisas a respeito da MLC no Brasil}

A aceitação da MLC, como material estrutural, por projetistas e construtores vem incrementando pesquisas a respeito do assunto, gerando textos voltados à normalização, elaborados e publicados periodicamente por países da Europa e Estados Unidos da América, desde 1954.

Nesta resenha bibliográfica são destacados os principais trabalhos desenvolvidos no Brasil sobre o tema. O primeiro destes trabalhos foi publicado por CALLIA (1958), a partir de pesquisas realizadas no Instituto de Pesquisas Tecnológicas do Estado de São Paulo, sobre o uso do Pinho do Paraná (Araucaria Angustifolia) na produção de elementos estruturais de MLC.

No Laboratório de Madeiras e de Estruturas de Madeira (LaMEM), do Departamento de Engenharia de Estruturas (SET), Escola de Engenharia de São Carlos (EESC), Universidade de São Paulo (USP), o estudo da MLC ganhou impulso com o trabalho de ZANDER \& HELLMEISTER (1979), que abordou aspectos genéricos voltados à produção de MLC.

Citam-se, na continuação, os trabalhos de SIMIONI (1978), na Universidade Federal do Paraná, versando sobre a utilização de madeira do gênero Pinus na produção de vigas retas de MLC; de CHAHUD \& ROCCO LAHR (1983) avaliando a viabilidade do emprego de arcos de MLC como estruturas principais de pontes; de DIAS \& ROCCO LAHR (1983), sobre o ensaio de modelo reduzido de uma ponte pênsil com vigas de rigidez de MLC; e de ROCCO LAHR (1992), sobre a viabilidade do uso de peças de diferentes espécies na produção de um mesmo elemento estrutural de MLC. Outros pesquisadores, entre eles SZÜCS, da Universidade Federal de Santa Catarina, e MOURA, da Universidade Estadual de Londrina, desenvolveram estudos exploratórios da capacidade de peças de MLC, propriedades de resistência e de elasticidade, busca de adesivos nacionais, processos de colagem, e vigas de MLC fabricadas com espécies de reflorestamento.

Entretanto, nenhuma publicação brasileira fornece informações conclusivas a respeito da viabilidade do emprego de espécies nativas na produção de elementos estruturais de MLC, em particular com o uso do adesivo à base de resina fenólica ou do adesivo à base de resina poliuretânica obtida do processamento da mamona. 


\subsection{Vantagens da MLC}

Uma das características da MLC é a versatilidade na obtenção das mais variadas formas geométricas para elementos estruturais. As possibilidades arquitetônicas daí resultantes são inúmeras e dependem principalmente da indispensável colaboração entre arquitetos e engenheiros (NATTERER, 1991). Têm-se como principais vantagens:

- Facilidade na construção de grandes estruturas a partir de peças de dimensões comerciais;

- Redução de rachaduras e outros defeitos típicos de peças maciças de madeira, com grandes dimensões;

- Possibilidade de emprego de peças de qualidade inferior em zonas menos solicitadas, e de peças de melhor qualidade em zonas mais solicitadas, podendo-se combinar, assim, espécies distintas;

- Possibilidade de aplicação de contra-flechas durante o processo de fabricação;

- Baixa relação peso/ resistência, não exigindo equipamentos possantes para içamento, bem como conduzindo a fundações com ações de menores intensidades;

- Bom desempenho sob a ação do fogo, em razão de seções transversais avantajadas, e elevada resistência aos agentes corrosivos.

Como aspecto restritivo, pode ser citado que a MLC tem custo superior ao da madeira maciça, e requer técnicas especiais, equipamentos e mão-de-obra especializada no processo de fabricação.

\subsection{Madeiras da Floresta Amazônica}

A Floresta Amazônica, no Brasil, ocupa uma área de aproximadamente 2.800.000 $\mathrm{km}^{2}$ nas regiões Norte e Centro-Oeste, representando mais de um terço da área do país. Segundo SANTOS (1987), entre outros, há mais de quatro mil espécies de madeira na Floresta Amazônica, mas apenas uma fração é considerada de interesse comercial. Isto é explicado por algumas razões: 
- Excelente desempenho das espécies de uso consagrado;

- Grande disponibilidade destas espécies nas regiões da floresta que foram inicialmente exploradas;

- Poucas informações disponíveis sobre o potencial da utilização das chamadas espécies alternativas, substituindo as espécies tradicionais.

A partir da década de 80, algumas iniciativas oficiais incentivaram a caracterização de espécies nativas. Diversos trabalhos nesta direção vêm sendo conduzidos, desde então, no Laboratório de Produtos Florestais (LPF-IBAMA-Brasília), nos laboratórios do Instituto Nacional de Pesquisas da Amazônia - INPA (Manaus) e no LaMEM-SET (USP-São Carlos), entre outros, segundo registro de DIAS \& ROCCO LAHR (1999). Com isto, verifica-se gradual redução da utilização de espécies consagradas, provocando gradativa diminuição das áreas desmatadas.

Alguns trabalhos mostram que muitas espécies alternativas apresentam propriedades físicas, de resistência e de elasticidade, compatíveis para emprego na produção de elementos estruturais de MLC, embora não mencionem a necessidade de se compatibilizar a respectiva permeabilidade com os adesivos disponíveis. Esta necessidade, como será vista adiante, foi confirmada nos resultados preliminares obtidos no presente trabalho. Entretanto, não foram encontrados registros, senão o de ROCCO LAHR (1992), sobre estudos experimentais conduzidos sobre tais espécies, visando sua utilização em elementos estruturais de MLC. Mesmo assim, o trabalho desse autor se restringe à determinação de algumas propriedades de rigidez, sem possibilidade de se chegar a uma generalização dos resultados.

\subsection{Ensaios Não Destrutivos}

Os Ensaios Não Destrutivos (END) são realizados em diversos tipos de materiais para a verificação de defeitos e/ou descontinuidades, através de princípios físicos definidos, sem alterar suas propriedades físicas, químicas e mecânicas, e sem interferir em seu uso posterior. Na madeira, os END são empregados na sua caracterização, contribuindo para melhorar a competitividade deste material. Dentre as técnicas utilizadas nas avaliações não destrutivas, podem-se destacar a de ultrasom e a de vibração transversal. Segundo Oliveira (2001), a técnica de ultra-som tem 
se mostrado um método viável para a caracterização da madeira, apresentando algumas vantagens em relação aos métodos convencionais, como maior rapidez e versatilidade a um custo menor, podendo ser empregada em indústrias e distribuidores de madeira e derivados, e também na avaliação in loco de estruturas. A determinação das propriedades mecânicas da madeira usando propagação de ondas ultra-sônicas é baseada na relação entre a velocidade do som, a densidade e o módulo de elasticidade. Outra técnica de ensaios não destrutivos para determinação de propriedades de rigidez da madeira é a de vibração transversal. Consiste na determinação do módulo de elasticidade da peça estudada por meio da análise das suas frequiências de vibrações. Alguns aparelhos utilizam um microfone para captar os sinais de vibração da madeira, que são posteriormente digitalizados e, por meio de programas computacionais, determina-se então o valor do módulo de elasticidade. Nesta pesquisa, utilizou-se o equipamento Metriguard modelo 340-E, que possui uma célula de carga para captação das vibrações da peça. Assim como o equipamento de ultra-som, o aparelho de vibração transversal é de fácil manuseio e pode ser utilizado em indústrias e em outros setores madeireiros.

\subsection{Conclusões da Revisão Bibliográfica}

Pela revisão bibliográfica efetuada, é possível concluir que não foi desenvolvido, no país, qualquer trabalho de pesquisa objetivando gerar subsídios que contribuam para o emprego de espécies tropicais na produção de elementos estruturais de madeira laminada colada. Este fato justifica plenamente a presente dissertação, cujos resultados podem se constituir em interessante contribuição para que se estabeleça uma nova linha de investigação na área de madeiras e de estruturas de madeira no Brasil. 
$\mathrm{C}_{\text {aṕ́tulo } 3}$

"Um túmulo basta agora àquele para quem não bastava o mundo inteiro.”

Epitáfio de Alexandre Magno

\section{ENSAIOS PRELIMINARES}

A realização dos ensaios preliminares teve como objetivo avaliar o desempenho de algumas espécies nativas, por meio de ensaios com corpos-de-prova, seguindo as diretrizes previstas na NBR 7190:1997, Anexo B. A espécie que apresentou os melhores resultados foi então a escolhida para dar seqüência à próxima fase da pesquisa.

\subsection{Materiais}

\subsubsection{Espécies}

Para o desenvolvimento dos ensaios preliminares foram utilizadas espécies nativas de madeira, com densidades de até $0,75 \mathrm{~g} / \mathrm{cm}^{3}$, a $12 \%$ de umidade, valor de referência de acordo com as prescrições da NBR 7190:1997 - Projeto de Estruturas de Madeira, da Associação Brasileira de Normas Técnicas (ABNT). Foi feita uma pesquisa bibliográfica com o objetivo de listar as espécies cujas densidades fossem inferiores ou, no máximo, iguais ao valor citado acima, sendo estas apresentadas no Apêndice, tabela A1. Deste levantamento, foram escolhidas aquelas que estavam 
disponíveis no mercado madeireiro da região de São Carlos, num total de quatro espécies, a saber:

Envira Branca (Xylopia sp) - densidade $0,72 \mathrm{~g} / \mathrm{cm}^{3}$;

Cambará (Moquinia polymorpha) - densidade $0,63 \mathrm{~g} / \mathrm{cm}^{3}$;

Castanheira (Bertholetia excelsa) - densidade $0,70 \mathrm{~g} / \mathrm{cm}^{3}$;

Cedrinho (Erisma $s p$ ) - densidade $0,62 \mathrm{~g} / \mathrm{cm}^{3}$.

Foram adquiridas no mercado madeireiro da região seis vigas para cada espécie, com dimensões $6 \mathrm{~cm}$ x $12 \mathrm{~cm}$ x $300 \mathrm{~cm}$, das quais foram extraídos os corpos-de-prova para a realização dos ensaios.

\subsubsection{Adesivos}

Foram utilizados dois tipos de adesivos na colagem dos corpos-de-prova. O primeiro, à base de resina resorcinol, conhecido pelo nome comercial de Cascophen, usual na produção de elementos estruturais de MLC pela indústria brasileira. O segundo, à base de resina extraída da mamona, é um adesivo poliuretânico bicomponente, desenvolvido e produzido por pesquisadores do Instituto de Química de São Carlos da Universidade de São Paulo (IQSC - USP).

\subsubsection{Equipamentos}

Para a confecção dos corpos-de-prova foram utilizados os equipamentos elétricos da oficina do LaMEM, tais como serra circular (figura 4), furadeira (figura 6) e cortador tipo "asa" para emendas dentadas (figura 5). Para a obtenção das dimensões dos corpos-de-prova foi empregado um paquímetro digital com sensibilidade de 0,01 mm. Um dispositivo de reação, com anel dinamométrico, foi montado para fornecer a intensidade de pressão desejada (figura 11). Para o preparo dos adesivos foram utilizados pequenos recipientes, com capacidade de aproximadamente 1 litro, onde as partes foram misturadas. Na determinação das massas das partes foi utilizada uma balança digital, e pincéis foram empregados para a distribuição dos adesivos nos corpos-de-prova. Na condução dos ensaios foram utilizadas duas máquinas 
universais de ensaio: uma AMSLER, com capacidade de carregamento de $250 \mathrm{kN}$ (figura 7), e uma DARTEC M1000/RC, com capacidade de $100 \mathrm{kN}$ (figura 8).

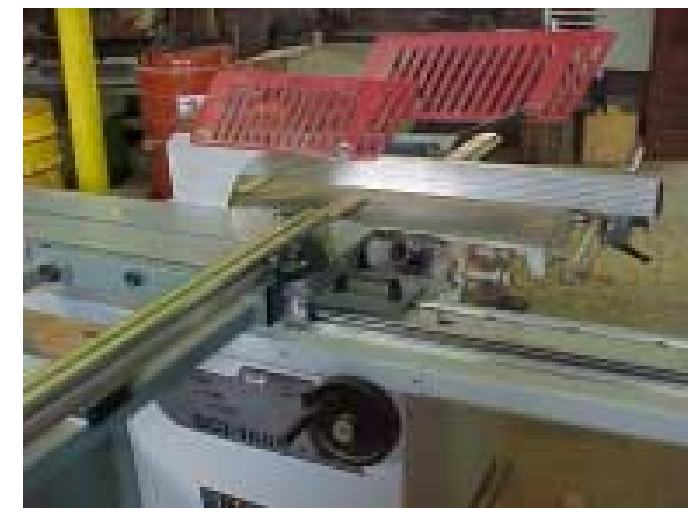

Figura 4 - Serra utilizada no corte das peças

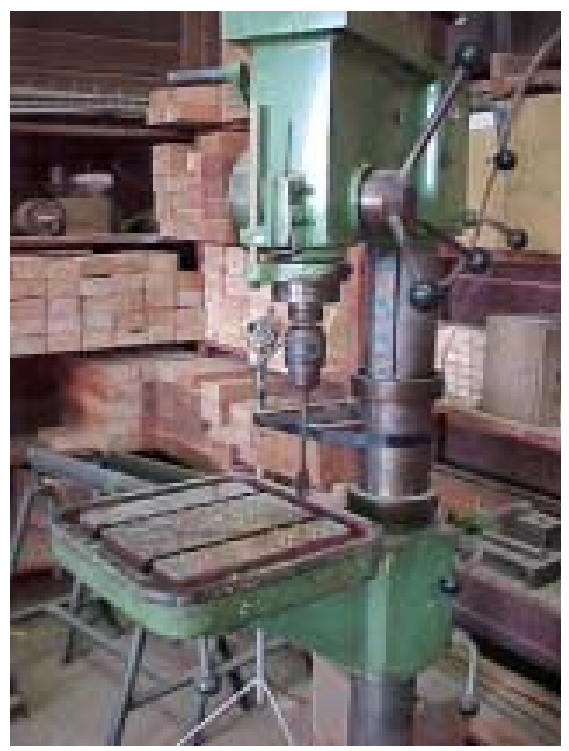

Figura 6 - Furadeira

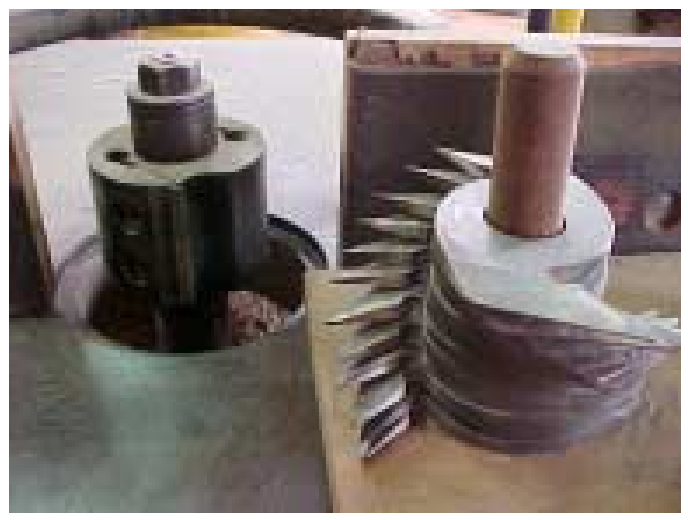

Figura 5 - Cortador tipo asa para emendas dentadas

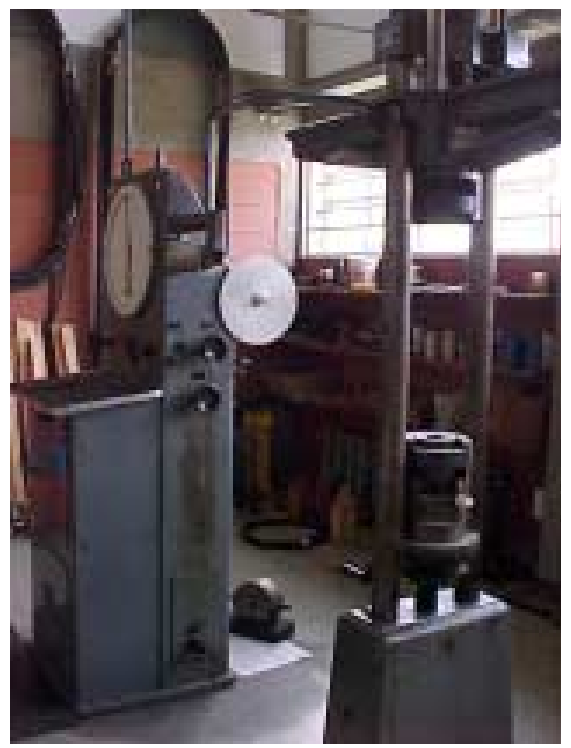

Figura 7 - Máquina Universal de ensaios AMSLER 


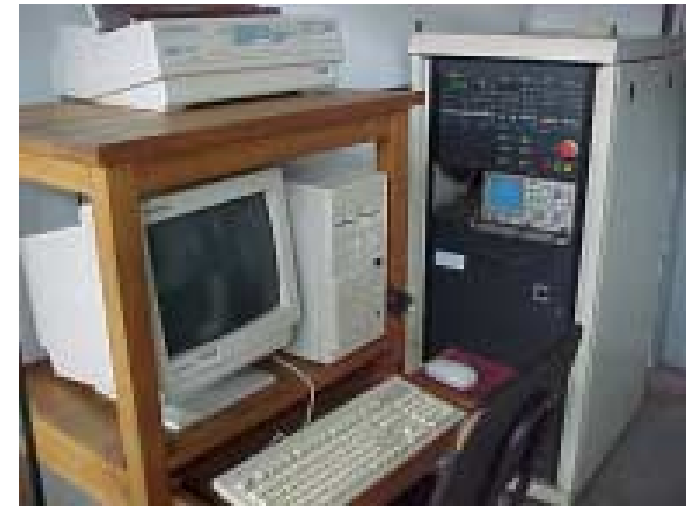

Figura 8.a)

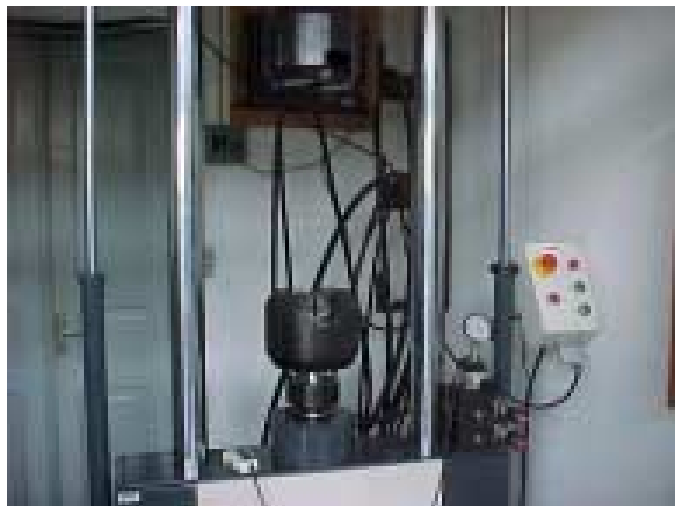

Figura 8.b)

Figura 8 - Máquina Universal de ensaios Dartec

\subsection{Métodos}

\subsubsection{Ensaios}

Nesta etapa do trabalho foram realizados ensaios de resistência à tração paralela às fibras, resistência à tração normal às fibras e resistência ao cisalhamento em corposde-prova de madeira maciça. Esses foram adotados como controle para a comparação com os corpos-de-prova colados, nos quais foram realizados ensaios para a determinação da resistência das emendas dentadas, resistência da lâmina de cola à tração normal e resistência ao cisalhamento na lâmina de cola.

\subsubsection{Obtenção dos corpos-de-prova}

Para a confecção dos corpos-de-prova a serem ensaiados, foram adquiridas seis peças de madeira (vigas) de cada espécie, com dimensões nominais de $6 \mathrm{~cm}$ x $12 \mathrm{~cm}$ x 300 $\mathrm{cm}$, escolhidas aleatoriamente no estabelecimento comercial que efetuou a venda do material.

Deve ser registrado que as peças de madeira foram recebidas, no SET-LaMEM, com elevada porcentagem de umidade. Este fato obrigou a adoção de um programa de secagem para as peças, utilizando as estufas e climatizadoras disponíveis para reduzir a umidade até valores próximos a 12\%, referência da NBR 7190:1997. Os tempos de secagem e climatização das espécies ficaram numa faixa entre 20 e 30 dias. 
Para a espécie Envira Branca, foram extraídos nove corpos-de-prova de cada viga: três para ensaios de tração paralela às fibras (um para madeira maciça e dois para os adesivos Cascophen e resina de mamona), três para ensaios de tração normal às fibras e três para ensaios de resistência ao cisalhamento. Após a realização dos ensaios com essa espécie, os resultados apontaram a necessidade de que mais corposde-prova fossem confeccionados para se obter intensidades diferentes de pressão de colagem. Assim, para as outras três espécies foram extraídos onze corpos-de-prova de cada viga: cinco para ensaios de tração paralela às fibras (um para madeira maciça e quatro para os ensaios com os adesivos), três para ensaios de tração normal às fibras e três para ensaios de resistência ao cisalhamento.

Sendo previstas seis vigas por espécies, chegou-se, portanto, a um total de cinqüenta e quatro corpos-de-prova preparados para a espécie Envira Branca e de sessenta e seis para as demais, totalizando duzentos e cinqüenta e dois ensaios realizados.

A figura a seguir mostra uma etapa da confecção de um corpo-de-prova para ensaio de resistência à tração normal às fibras

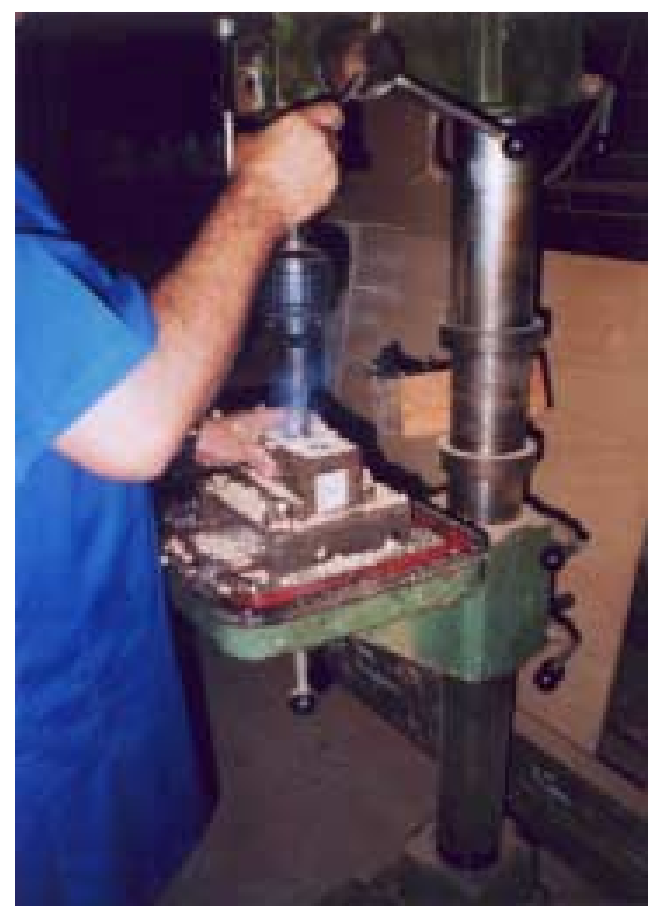

Figura 9 - Confecção de corpo-de-prova para ensaio de tração normal 


\subsubsection{Preparo dos adesivos e processo de colagem}

O adesivo à base fenólica (Cascophen) foi preparado de acordo com as instruções do fabricante, ou seja, uma parte em massa de catalisador para cada cinco partes em massa de adesivo. $\mathrm{O}$ adesivo poliuretânico obtido do processamento da mamona foi preparado de acordo com instruções dos pesquisadores do IQSC - USP, isto é, uma parte em massa de catalisador para cada parte em massa de adesivo.

O consumo de adesivo foi de $350 \mathrm{~g} / \mathrm{cm}^{3}$ e o tempo de aplicação de pressão foi de 10 horas para ambos os adesivos. O tempo de cura das peças coladas foi de, no mínimo, dez horas para o Cascophen e de noventa e seis horas (4 dias) para o adesivo de mamona.

A pressão de colagem foi de $0,8 \mathrm{MPa}$ para todos os ensaios, com base nos trabalhos de JESUS et al. (2000). Em virtude dos primeiros resultados obtidos com a espécie Envira Branca, optou-se por adotar mais um valor de pressão de colagem para os ensaios de resistência das emendas dentadas à tração paralela às fibras para as demais espécies. Esse novo valor adotado corresponde ao dobro do valor adotado até então, ou seja, 1,6 MPa.

A figura 10 ilustra o processo de aplicação do adesivo Cascophen em um corpo-deprova para ensaio de tração das emendas dentadas. A figura 11 mostra um dispositivo contendo corpos-de-prova submetidos à pressão para a colagem 


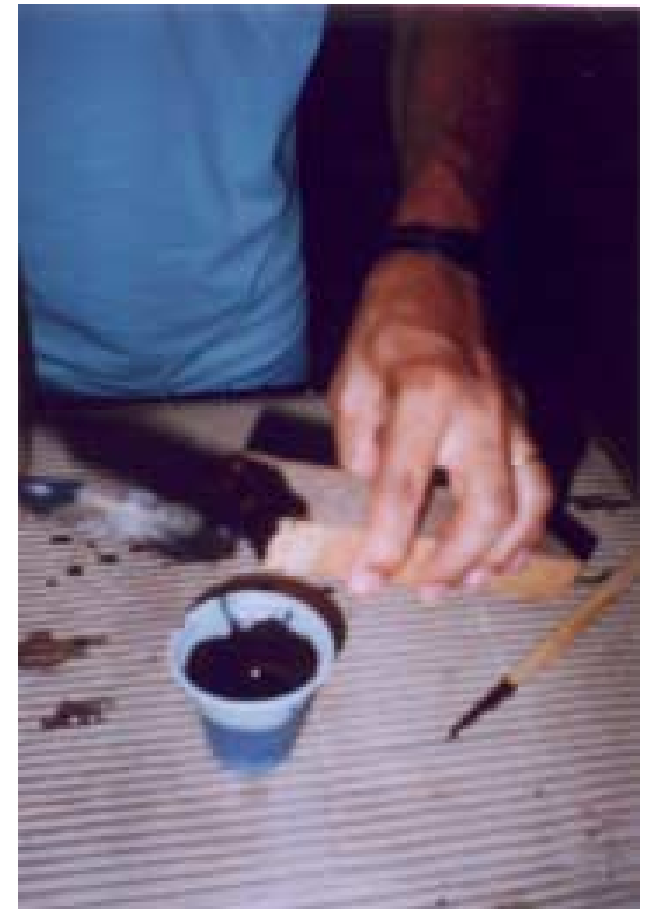

Figura 10 - Aplicação de adesivo

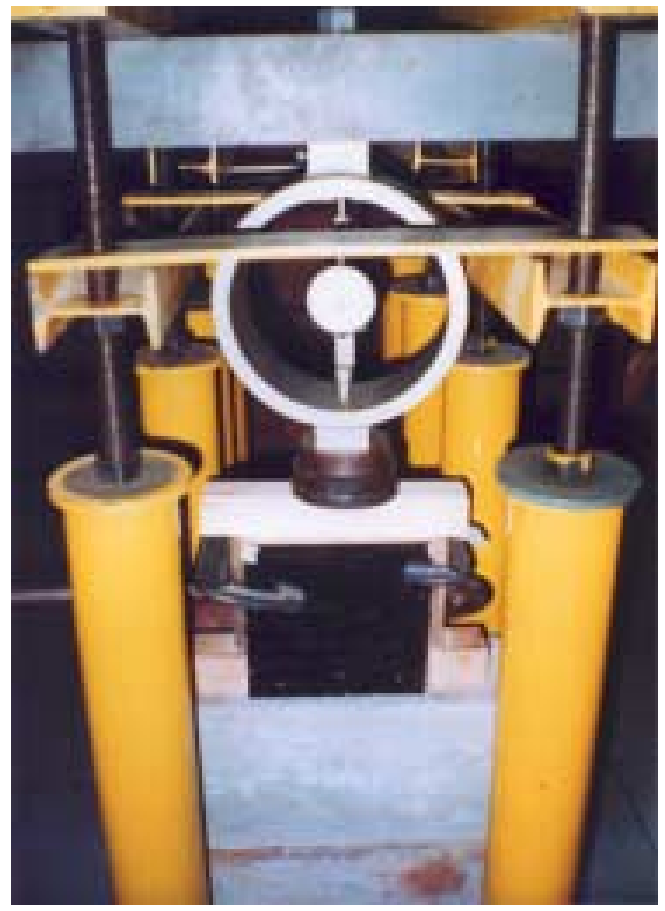

Figura 11 - Processo de colagem

\subsection{Planejamento estatístico}

Os ensaios em madeira maciça foram realizados de modo a servirem de controle para uma análise estatística. Os resultados obtidos nos corpos-de-prova colados com os adesivos Cascophen e à base de mamona foram comparados com os resultados obtidos nos corpos-de-prova em madeira natural. Para esta comparação, foi utilizado o programa estatístico MINITAB, por meio de análise de variância das médias, sendo feitas as seguintes hipóteses:

$H_{o}: \mu_{1}=\mu_{2}$

$H_{1}: \mu_{1} \neq \mu_{2}$

Chama-se, assim, $\mu_{1}$ de média dos resultados dos corpos-de-prova em madeira maciça, ou seja, de controle, e $\mu_{2}$ de média dos resultados dos corpos-de-prova colados. Para a verificação das hipóteses, utilizou-se o programa MINITAB, subrotina ANOVA - Dunnett's, com um nível de significância igual a 0,05, ou seja, a possibilidade de se considerar a hipótese $\mathrm{H}_{0}$ como sendo verdadeira e esta ser falsa é de $5 \%$. 


\subsection{Resultados}

As tabelas seguintes apresentam as tensões obtidas para as espécies Envira Branca (Xylopia sp), Cambará (Moquinia polymorpha), Castanheira (Bertholetia excelsa) e Cedrinho (Erisma sp). Os resultados apresentados em MPa, são referentes a madeira maciça, ao adesivo Cascophen e ao adesivo à base de resina de mamona. A coluna onde lê-se "Pressão" corresponde aos valores adotados na colagem dos corpos-deprova, também em MPa.

Tabela 1 - Tensões médias obtidas para a Envira branca (em MPa)

\begin{tabular}{|c|c|c|c|c|}
\cline { 2 - 5 } \multicolumn{1}{c|}{} & Pressão & Maciça & Cascophen & Mamona \\
\hline Tração paralela & 0,8 & 63,12 & 54,04 & 40,09 \\
\hline Cisalhamento & 0,8 & 12,53 & 12,00 & 11,45 \\
\hline Tração normal & 0,8 & 2,78 & 1,76 & 1,66 \\
\hline
\end{tabular}

Tabela 2 - Tensões médias obtidas para o Cambará (em MPa)

\begin{tabular}{|c|c|c|c|c|}
\cline { 2 - 5 } \multicolumn{1}{c|}{} & Pressão & Maciça & Cascophen & Mamona \\
\hline \multirow{2}{*}{ Tração paralela } & 0,8 & \multirow{2}{*}{52,17} & 45,18 & 25,66 \\
\cline { 2 - 3 } \cline { 4 - 5 } & 1,6 & & 47,31 & 43,61 \\
\hline Cisalhamento & 0,8 & 14,02 & 13,37 & 10,05 \\
\hline Tração normal & 0,8 & 2,48 & 2,47 & 1,15 \\
\hline
\end{tabular}

Tabela 3 - Tensões médias obtidas para a Castanheira (em MPa)

\begin{tabular}{|c|c|c|c|c|}
\cline { 2 - 5 } \multicolumn{1}{c|}{} & Pressão & Maciça & Cascophen & Mamona \\
\hline \multirow{2}{*}{ Tração paralela } & 0,8 & \multirow{2}{*}{64,35} & 38,41 & 28,05 \\
\cline { 2 - 3 } \cline { 4 - 5 } & 1,6 & & 36,50 & 19,38 \\
\hline Cisalhamento & 0,8 & 10,44 & 7,76 & 6,37 \\
\hline Tração normal & 0,8 & 4,84 & 2,86 & 2,84 \\
\hline
\end{tabular}


Tabela 4 - Tensões médias obtidas para o Cedrinho (em MPa)

\begin{tabular}{|c|c|c|c|c|}
\cline { 2 - 5 } \multicolumn{1}{c|}{} & Pressão & Maciça & Cascophen & Mamona \\
\hline \multirow{2}{*}{ Tração paralela } & 0,8 & \multirow{2}{*}{40,60} & 33,47 & 37,48 \\
\cline { 2 - 3 } \cline { 4 - 5 } & 1,6 & & 34,28 & 40,44 \\
\hline Cisalhamento & 0,8 & 8,37 & 8,13 & 8,13 \\
\hline Tração normal & 0,8 & 2,57 & 2,21 & 2,15 \\
\hline
\end{tabular}

As figuras seguintes mostram as ruínas de alguns corpos-de-prova.

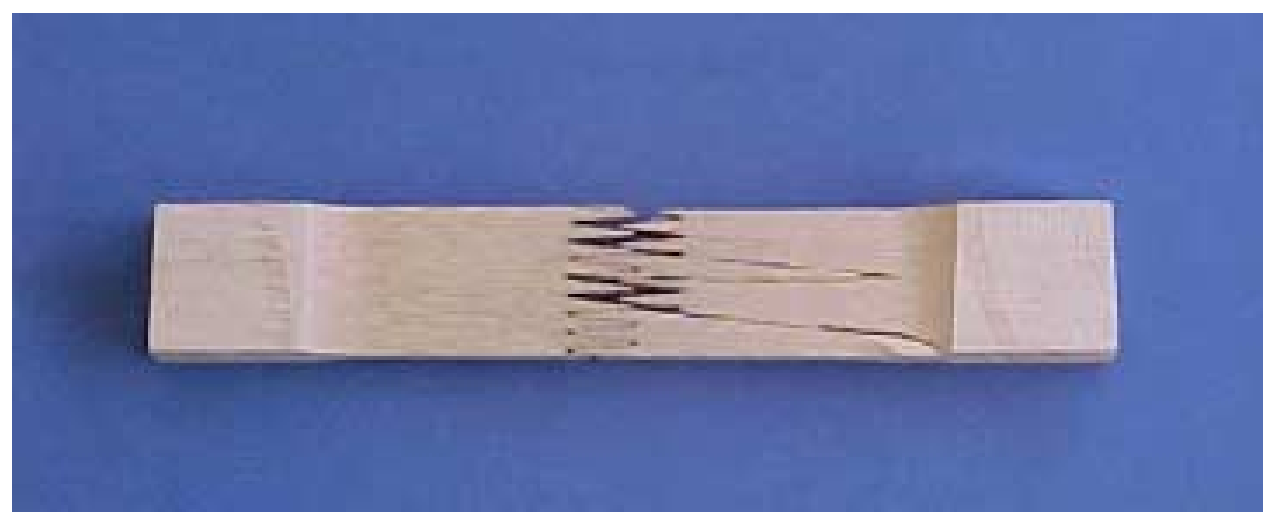

Figura 12 - Corpo-de-prova submetido a ensaio de tração paralela

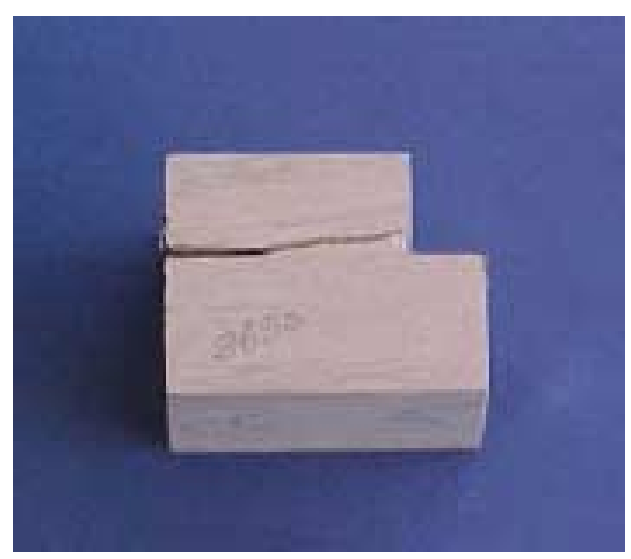

Figura 13 - Corpo-de-prova submetido a ensaio de cisalhamento 


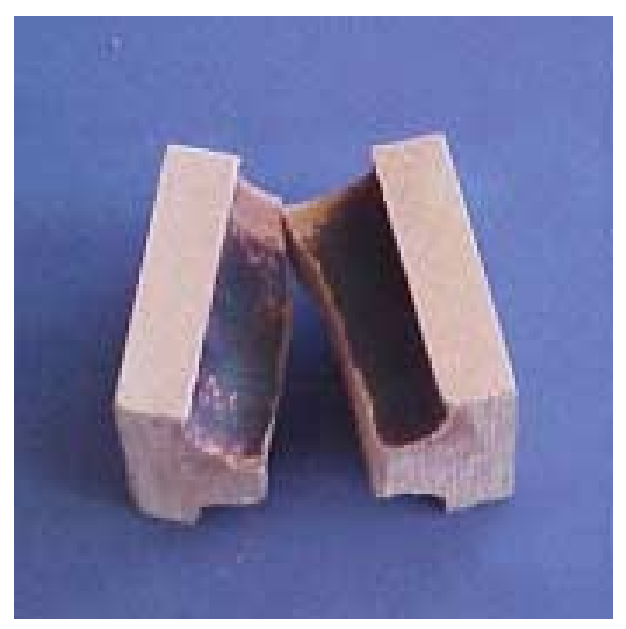

Figura 14 - Corpo-de-prova submetido a ensaio de tração normal

\subsection{Análise dos resultados}

Para a discussão dos resultados das quatro espécies pesquisadas foram utilizados os valores calculados na análise de variância do programa MINITAB. As tabelas seguintes apresentam esses valores para cada ensaio, de cada espécie, bem como as respectivas pressões de colagem. Foram analisadas as médias dos resultados dos corpos-de-prova de madeira maciça, adotadas como controle, versus as médias dos resultados dos corpos-de-prova colados com o adesivo Cascophen e com o adesivo de mamona.

O programa estatístico fornece os valores $F_{\text {observado, }}$, relações entre soma de quadrados médios das amostras, $p$, que é chamado de p-valor, e outros. Os valores críticos contidos na coluna $\mathrm{f}_{\mathrm{c}}$ foram obtidos da tabela de distribuição de Fischer-Snedecor (Apêndice - tabela A.2), considerando um nível de significância de 5\%.

Quando $F_{\text {observado }}$ é menor que $\mathrm{f}_{\mathrm{c}}$, diz-se então que as médias comparadas podem ser consideradas estatisticamente equivalentes. A quantificação dessa equivalência é representada pelo p-valor: quanto mais semelhantes forem, mais o p-valor se aproxima de 1, e quanto menos semelhantes, mais se aproxima de zero. Assim, pôdese escolher a espécie que melhor comportamento apresentou nos ensaios realizados. 


\section{a. Envira Branca}

A tabela seguinte apresenta os valores obtidos na análise de variância da espécie Envira Branca.

Tabela 5 - Análise de variância da Envira Branca

\begin{tabular}{|c|c|c|c|c|c|c|c|}
\cline { 3 - 8 } \multicolumn{1}{c|}{} & \multicolumn{3}{c|}{ Maciça x Cascophen } & \multicolumn{3}{c|}{ Maciça x Mamona } \\
\cline { 2 - 9 } \multicolumn{1}{c|}{} & Pressão & $\mathrm{F}_{\text {observado }}$ & $\mathrm{f}_{\mathcal{c}}$ & $\mathrm{p}$ & $\mathrm{F}_{\text {observado }}$ & $\mathrm{f}_{\mathrm{c}}$ & $\mathrm{p}$ \\
\hline Tração paralela & 0,8 & 0,95 & 5,117 & 0,356 & 12,50 & 4,965 & 0,005 \\
\hline Cisalhamento & 0,8 & 0,41 & 5,117 & 0,540 & 2,67 & 5,318 & 0,141 \\
\hline Tração normal & 0,8 & 7,27 & 4,965 & 0,022 & 12,72 & 4,965 & 0,005 \\
\hline
\end{tabular}

No que se refere à resistência ao cisalhamento, é possível observar que as resistências médias estão próximas, ou seja, 12,53 MPa para a madeira natural; 12,00 $\mathrm{MPa}$ para o adesivo Cascophen e 11,45 $\mathrm{MPa}$ para o adesivo à base de resina de mamona. A análise de variância das médias vem comprovar essa observação, com $F_{\text {observado }}$ igual a 0,41 , valor esse menor que $f_{c}(5,117)$, com p-valor igual 0,540 , na

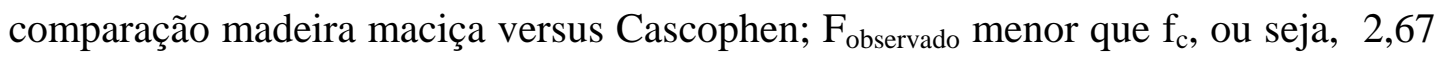
menor que 5,318, p-valor igual 0,141, em se tratando de madeira maciça versus mamona. Para os dois adesivos estudados, fica demonstrado seu bom desempenho para esta solicitação.

No que se refere à tração paralela em emendas dentadas, a resistência da madeira natural foi a maior das três determinadas, atingindo $63,12 \mathrm{MPa}$. Tal intensidade não foi atingido nem pelo adesivo Cascophen nem pelo adesivo à base de mamona, cujas resistências foram, respectivamente, 54,04 $\mathrm{MPa}$ e 40,09 $\mathrm{MPa}$. O documento normativo DIN 68140:1971 prevê redução de 16\% da resistência neste tipo de ensaio por causa da geometria do corpo-de-prova com dentes. Assim, levando-se em conta apenas este aspecto, o corpo-de-prova colado apresentaria $84 \%$ da resistência do corpo-de-prova não-colado. Para o adesivo Cascophen essa redução ficou em 85\% e para a mamona esse valor foi de $63 \%$. Na análise estatística foram apontados, para madeira maciça versus Cascophen, os valores 0,95 para $F_{\text {observado }}, 5,117$ para $f_{c} e$ 0,356 para p-valor, indicando um bom comportamento para esse adesivo. Já o mesmo não ocorreu para madeira maciça versus mamona, com 12,50 para $\mathrm{F}_{\text {observado, }}$ 
4,695 para $f_{c}$ e 0,005 para $p$, mostrando um mau desempenho nos ensaios com resina poliuretânica. Provavelmente isto se deve à pressão aplicada na confecção dos corpos-de-prova $(0,8 \mathrm{MPa})$, que pode não ter sido suficiente para promover a adequada penetração do adesivo na madeira.

Também no caso da tração normal na lâmina de cola, a resistência da madeira natural foi a maior das três determinadas, atingindo 2,78 $\mathrm{MPa}$, enquanto o adesivo Cascophen chegou a 1,76 MPa e o adesivo à base de resina de mamona a 1,66 MPa. Estatisticamente ficou comprovado o desempenho indesejável de ambos os adesivos, com $F_{\text {observado }}$ igual a 7,27, $\mathrm{f}_{\mathrm{c}}$ igual a 4,965 e p-valor de 0,022 na comparação madeira maciça versus Cascophen. Para a madeira maciça versus mamona, os valores calculados foram 12,72 para $F_{\text {observado, }}$ 4,965 para $f_{c}$ e 0,005 para p-valor. Também neste caso, provavelmente isto ocorreu em razão da pressão aplicada na confecção dos corpos-de-prova $(0,8 \mathrm{MPa})$ que pode não ter sido suficiente para promover a adequada penetração dos adesivos na madeira.

Esta constatação conduziu à adoção de pressão superior a 0,8 MPa na confecção dos corpos-de-prova para ensaio de tração paralela das demais espécies.

\section{b. Cambará}

A tabela 6 apresenta os resultados obtidos na análise de variância da espécie Cambará.

Tabela 6 - Análise de variância do Cambará

\begin{tabular}{|c|c|c|c|c|c|c|c|}
\cline { 2 - 9 } \multicolumn{1}{c|}{} & \multicolumn{3}{c|}{ Maciça x Cascophen } & \multicolumn{3}{c|}{ Maciça x Mamona } \\
\cline { 2 - 9 } \multicolumn{1}{c|}{} & Pressão & $\mathrm{F}_{\text {observado }}$ & $\mathrm{f}_{\mathcal{c}}$ & $\mathrm{p}$ & $\mathrm{F}_{\text {observado }}$ & $\mathrm{f}_{\mathrm{c}}$ & $\mathrm{p}$ \\
\hline \multirow{2}{*}{ Tração paralela } & 0,8 & 1,43 & 5,117 & 0,262 & 21,72 & 5,117 & 0,001 \\
\cline { 2 - 9 } & 1,6 & 0,56 & 5,117 & 0,473 & 1,63 & 5,117 & 0,233 \\
\hline Cisalhamento & 0,8 & 0,18 & 4,965 & 0,678 & 13,76 & 4,965 & 0,004 \\
\hline Tração normal & 0,8 & 0,00 & 4,965 & 0,979 & 8,99 & 4,965 & 0,013 \\
\hline
\end{tabular}

Relativamente aos resultados desta espécie, pode-se concluir, de início, pela conveniência de se utilizar pressão de colagem 1,6 MPa na confecção dos corposde-prova para determinação da resistência das emendas à tração. Para esta pressão 
foram obtidos os melhores resultados. Na madeira maciça se chegou ao valor de 52,17 MPa, enquanto para o Cascophen e para o adesivo à base de mamona os resultados foram bastante próximos, ou seja, 47,31 MPa e 43,61 MPa (91\% e 84\% do valor da madeira maciça). Quando analisadas suas variâncias, madeira maciça versus

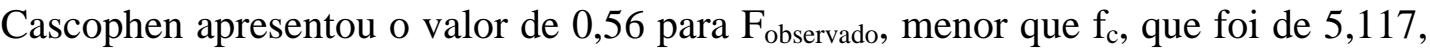
e p-valor de 0,473 . No caso da madeira maciça versus mamona, o comportamento um pouco menos favorável, com p-valor de 0,233 e $F_{\text {observado }}$ menor que $f_{c}$, ou seja, 1,63 e 5,117. Quando adotada a pressão de 0,8 MPa, os resultados foram bem inferiores para o adesivo à base de mamona $(25,64 \mathrm{MPa}$, representando $49 \%$ do valor de controle) e ligeiramente menores para o Cascophen (45,18 MPa, 87\% do valor de controle). Para madeira versus mamona, $\mathrm{F}_{\text {observado }}$ foi de 21,72 , valor muito maior que $\mathrm{f}_{\mathrm{c}}$, que foi de 5,117 , com p-valor muito baixo, tendendo a zero $(0,001)$, evidenciando o mau desempenho desse adesivo para essa intensidade de pressão. O contrário acontece na análise da madeira maciça versus Cascophen, onde $f_{c}$ foi o mesmo $(5,117)$, mas $F_{\text {observado }}$ foi muito menor $(1,43)$, conferindo um p-valor de 0,262 , sugerindo um bom desempenho do Cascophen mesmo com uma pressão de colagem de $0,8 \mathrm{MPa}$.

No caso de resistência ao cisalhamento, o Cascophen proporcionou resultado de 13,37 $\mathrm{MPa}$, muito próximo ao obtido para a madeira maciça, que atingiu 14,02 $\mathrm{MPa}$. Valor inferior foi alcançado com o adesivo à base de mamona, com 10,05 $\mathrm{MPa}$. Na comparação madeira maciça versus Cascophen, a situação foi favorável com $\mathrm{F}_{\text {observado }}$ de $0,18, f_{c}$ de 4,965 e p-valor de 0,678 , o mesmo não ocorrendo para a madeira maciça versus mamona, que apresentou valores de 13,76, 4,965 e 0,004 para $\mathrm{F}_{\text {observado }}, \mathrm{f}_{\mathrm{c}}$ e p-valor, respectivamente. Situação idêntica ocorreu para a resistência à tração normal, com 2,48 MPa para a madeira maciça, 2,47 MPa para o Cascophen e 1,15 MPa para o adesivo à base de mamona. Obtiveram-se $\mathrm{F}_{\text {observado }}$ de $0,00, \mathrm{f}_{\mathrm{c}}$ de 4,965 e p-valor de 0,979 para madeira maciça versus Cascophen, enquanto que para a madeira maciça versus mamona os valores foram de 8,99, 4,965 e 0,013 para $\mathrm{F}_{\text {observado }}, \mathrm{f}_{\mathrm{c}}$ e p-valor.

Começa a se evidenciar um aspecto de relevante significado na definição das espécies nativas e dos adesivos a empregar na confecção de elementos estruturais de madeira laminada colada. Não é suficiente, conforme registrava MACÊDO (1997), 
que a densidade da espécie esteja contida no intervalo de 0,5 a $0,75 \mathrm{~g} / \mathrm{cm}^{3}$. É preciso considerar a compatibilização entre a madeira e o adesivo, condicionada pela permeabilidade da espécie aos adesivos. E, por sua vez, a permeabilidade está associada não somente às particularidades anatômicas da espécie como também às características de viscosidade do adesivo. Observa-se que, para o Cambará, bons resultados foram obtidos com o Cascophen, enquanto que os apresentados pelo adesivo a base de mamona não foram satisfatórios. Assim, a compatibilização da espécie com o Cascophen se mostrou mais favorável. Deve ser registrado que, segundo MAINIERI et al. (1983), o Cambará apresenta "poros visíveis somente sob lente, muito pequenos, múltiplos e solitários, obstruídos por óleo resina e tilas." Estas peculiaridades influem na permeabilidade da espécie, tornando-a menos compatível ao adesivo à base de mamona em comparação com o Cascophen.

Por outro lado, conclui-se pela conveniência de descartar a pressão de 0,8 $\mathrm{MPa}$ na produção de corpos-de-prova para a avaliação da resistência à tração das emendas. Com isto, é possível reduzir o trabalho experimental sem perda da qualidade das informações.

\section{c. Castanheira}

A seguir são apresentados na tabela 7 os números obtidos na análise de variância da espécie Castanheira.

\section{Tabela 7 - Análise de variância da Castanheira}

\begin{tabular}{|c|c|c|c|c|c|c|c|}
\cline { 2 - 9 } \multicolumn{1}{c|}{} & \multicolumn{3}{c|}{ Maciça x Cascophen } & \multicolumn{3}{c|}{ Maciça x Mamona } \\
\cline { 2 - 9 } \multicolumn{1}{c|}{} & Pressão & $\mathrm{F}_{\text {observado }}$ & $\mathrm{f}_{\mathcal{c}}$ & $\mathrm{p}$ & $\mathrm{F}_{\text {observado }}$ & $\mathrm{f}_{\mathcal{c}}$ & $\mathrm{p}$ \\
\hline \multirow{2}{*}{ Tração paralela a } & 0,8 & 22,90 & 4,965 & 0,001 & 29,33 & 4,965 & 0,000 \\
\cline { 2 - 9 } & 1,6 & 21,04 & 4,965 & 0,001 & 85,82 & 4,965 & 0,000 \\
\hline Cisalhamento & 0,8 & 8,22 & 4,965 & 0,017 & 14,54 & 4,965 & 0,003 \\
\hline Tração normal & 0,8 & 8,41 & 4,965 & 0,016 & 6,89 & 5,117 & 0,028 \\
\hline
\end{tabular}

Com relação a esta espécie, comentários diferentes dos apresentados para a Envira Branca e para o Cambará são pertinentes. 
Percebe-se que, para todas as resistências e para as duas pressões de colagem utilizadas, não foi possível alcançar, com os dois adesivos considerados, valores próximos aos da madeira maciça. No caso da resistência das emendas à tração, os melhores valores para os adesivos foram alcançados com 0,8 $\mathrm{MPa}$ de pressão de colagem: 38,41 MPa para o Cascophen e 28,05 MPa para o adesivo à base de mamona, contra 64,35 MPa para a madeira maciça. Desta maneira, a média das resistências obtidas com Cascophen foi $60 \%$ menor que a média de controle, com a mamona apresentando uma redução de $44 \%$. Tais médias conduziram aos seguintes resultados: para a madeira maciça versus Cascophen, 22,90 para $\mathrm{F}_{\text {observado }}$, 4,965 para $\mathrm{f}_{\mathrm{c}}$ e 0,001 para p-valor; e para a madeira maciça versus mamona, os números para $\mathrm{F}_{\text {observado }} \mathrm{f}_{\mathrm{c}}$ e p-valor são, respectivamente, 29,33, 4,965 e 0,000.

Resultados análogos foram obtidos no caso da resistência ao cisalhamento (7,76 MPa para o Cascophen e 6,37 MPa para o adesivo à base de mamona, contra 10,44 $\mathrm{MPa}$ para a madeira maciça), com madeira maciça contra Cascophen apresentando

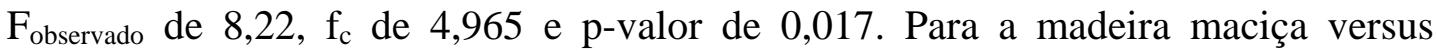
mamona obteve-se $\mathrm{F}_{\text {observado }}$ igual $14,54, \mathrm{f}_{\mathrm{c}}$ igual ao adesivo resorcinol e p-valor de 0,003. A mesma situação se repete no caso da tração normal $(2,86 \mathrm{MPa}$ para o Cascophen e 2,84 MPa para o adesivo à base de mamona, contra 4,84 MPa para a madeira maciça), levando aos valores de $\mathrm{F}_{\text {observado }}$ igual 8,41, $\mathrm{f}_{\mathrm{c}}$ igual 4,965 e p-valor igual 0,016 (maciça versus Cascophen) e $\mathrm{F}_{\text {observado }}$ igual 6,89, $\mathrm{f}_{\mathrm{c}}$ igual 5,117 e p-valor igual 0,028 (maciça versus mamona).

Mais uma vez fica evidenciada a necessidade de ser buscada a compatibilização entre espécies e adesivos (e não apenas o intervalo de densidade) para a definição das espécies mais convenientes com vistas à produção de madeira laminada colada. Destaca-se que esta espécie apresenta, segundo MAINIEIRI et al. (1983), "poros médios a grandes, poucos, solitários e múltiplos, quase sempre obstruídos por tilas”. O número pequeno de poros e a obstrução praticamente sistemática provocada pelas tilas prejudicam a permeabilidade da espécie e, em linhas gerais, limitam grandemente seu emprego para a confecção de elementos estruturais de madeira laminada colada, com os adesivos estudados. 


\section{d. Cedrinho}

A tabela 8 mostra os resultados obtidos na análise de variância da espécie Cedrinho.

\section{Tabela 8 - Análise de variância do Cedrinho}

\begin{tabular}{|c|c|c|c|c|c|c|c|}
\cline { 3 - 8 } \multicolumn{1}{c|}{} & \multicolumn{3}{c|}{ Maciça x Cascophen } & \multicolumn{3}{c|}{ Maciça x Mamona } \\
\cline { 2 - 8 } \multicolumn{1}{c|}{} & Pressão & $\mathrm{F}_{\text {observado }}$ & $\mathrm{f}_{\mathrm{c}}$ & $\mathrm{p}$ & $\mathrm{F}_{\text {observado }}$ & $\mathrm{f}_{\mathrm{c}}$ & $\mathrm{p}$ \\
\hline \multirow{2}{*}{ Tração paralela } & 0,8 & 1,17 & 4,965 & 0,305 & 0,31 & 4,965 & 0,592 \\
\cline { 2 - 9 } & 1,6 & 1,24 & 4,965 & 0,292 & 0,00 & 4,965 & 0,984 \\
\hline Cisalhamento & 0,8 & 0,07 & 4,965 & 0,798 & 0,06 & 4,965 & 0,809 \\
\hline Tração normal & 0,8 & 0,99 & 4,965 & 0,343 & 1,62 & 4,965 & 0,232 \\
\hline
\end{tabular}

Relativamente aos resultados desta espécie, pode-se concluir pela conveniência de se utilizar pressão de colagem 1,6 $\mathrm{MPa}$ na confecção dos corpos-de-prova para determinação da resistência das emendas à tração. Para esta pressão foram obtidos os melhores resultados. Na madeira maciça se chegou ao valor de 40,60 MPa, enquanto para o Cascophen a 34,28 MPa (84\% da média da maciça) e para o adesivo à base de mamona a média dos resultados foi 40,44 $\mathrm{MPa}$, (99\% da média do controle) bastante próxima à da madeira maciça. $O \mathrm{~F}_{\text {observado }}$ foi de 1,24 para a madeira maciça contra 0 Cascophen, menor que $f_{c}$, que foi de 4,965, com p-valor igual a 0,292. Para a madeira maciça versus mamona, os resultados foram muito satisfatórios, com $\mathrm{F}_{\text {observado }}$ de $0,00, \mathrm{f}_{\mathrm{c}}$ de 4,965 e p-valor igual 0,984, muito próximo de 1 , indicando serem as médias praticamente idênticas. Observa-se que os dois adesivos conduziram a resultados de resistência bastante próximos ao da madeira maciça, com vantagem para o adesivo à base de mamona. Quando adotada a pressão de 0,8 $\mathrm{MPa}$ os resultados foram inferiores.

No caso de resistência ao cisalhamento, o Cascophen e o adesivo à base de mamona levaram ao resultado de $8,13 \mathrm{MPa}$, muito próximo ao obtido para a madeira maciça, que atingiu 8,37 $\mathrm{MPa}$. $\mathrm{Na}$ análise estatística, madeira versus Cascophen e madeira versus mamona apresentaram resultados bastante próximos, compartilhando o mesmo $\mathrm{f}_{\mathrm{c}}$, que foi de 4,965 (o mesmo para todos os ensaios com Cedrinho). Para a primeira relação, os valores foram de 0,07 para $F_{\text {observado }}$ e 0,798 para o p-valor, 
enquanto que, para a segunda análise, os números são de 0,06 e 0,809 para $\mathrm{F}_{\text {observado }} \mathrm{e}$ p-valor, respectivamente.

Para a resistência à tração normal, foram obtidos 2,57 MPa para a madeira maciça, 2,21 MPa para o Cascophen e 2,15 MPa para o adesivo à base de mamona. Madeira

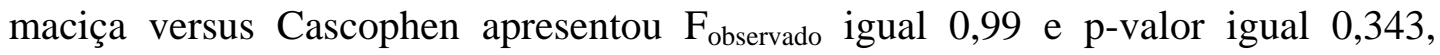
enquanto que madeira maciça versus mamona teve como resultados $F_{\text {observado }}$ igual 1,62 e p-valor igual 0,232 .

Mais uma vez fica evidenciada a necessidade de ser buscada a compatibilização entre espécies e adesivos (e não apenas o intervalo de densidade) para a definição das madeiras mais convenientes com vistas à produção de madeira laminada colada. Destaca-se que esta espécie apresenta, segundo MAINIEIRI et al. (1983), "poros grandes, visíveis a olho nu, poucos, solitários e múltiplos, tilas de paredes finas”. O número pequeno de poros é compensado pela pequena obstrução provocada pelas tilas de paredes finas. Isto confere, à espécie, permeabilidade suficiente para viabilizar seu emprego na confecção de elementos estruturais de madeira laminada colada, com os adesivos estudados.

\subsection{Conclusões preliminares}

A partir da discussão dos resultados apresentados anteriormente, pode-se concluir que:

- Para a produção de elementos estruturais de madeira laminada colada não basta que a espécie apresente densidade entre 0,5 a $0,75 \mathrm{~g} / \mathrm{cm}^{3}$, como preconizava MACÊDO (1997). Tão importante quanto a densidade é a permeabilidade da espécie em relação aos adesivos disponíveis para a produção de MLC.

- Para se verificar a compatibilidade das espécies com densidade entre 0,5 a $0,75 \mathrm{~g} / \mathrm{cm}^{3}$ para a produção de MLC é indispensável a realização da série de ensaios recomendada pela NBR 7190:1997, os quais demonstrarão o efetivo desempenho da espécie. 
- A indicação de uma determinada espécie para a produção de elementos estruturais de MLC com base apenas na sua densidade (entre 0,5 e 0,75 $\mathrm{g} / \mathrm{cm}^{3}$ ) poderá levar a resultados extremamente negativos.

- Existem espécies tropicais, com densidade entre 0,5 e $0,75 \mathrm{~g} / \mathrm{cm}^{3} \mathrm{com}$ permeabilidade adequada para a produção de elementos estruturais de madeira laminada colada. Neste trabalho merece destaque o potencial da espécie Cedrinho, entre as quatro estudadas.

- É conveniente utilizar pressão de colagem 1,6 MPa na confecção dos corposde-prova para determinação da resistência das emendas à tração.

- A espécie escolhida para a continuação dessa pesquisa é o Cedrinho, pois apresentou resultados estatisticamente satisfatórios nos ensaios realizados. $\mathrm{O}$ mesmo não se pode afirmar da espécie Envira Branca (com valores inferiores aos desejados nos ensaios de tração normal para ambos os adesivos e no ensaio de tração paralela com o adesivo à base de mamona), do Cambará (apesar do bom desempenho com o adesivo Cascophen, o mesmo não acontecendo para a resina de mamona) e da Castanheira (com resultados insatisfatórios em todos os ensaios). 
"É verdade que minha forma é estranha, mas culpar a mim seria o mesmo que culpar a Deus. Se eu pudesse me recriar, não falharia em cada detalhe para agradar a todos".

Joseph Carey Merrick - o Homem-Elefante, portador da Síndrome de Proteus

\section{ENSAIOS PRINCIPAIS}

Neste capítulo são descritos os materiais e os métodos empregados na experimentação principal deste trabalho. São apresentados a espécie de madeira, os tipos de adesivos, os equipamentos, a metodologia experimental e o planejamento estatístico utilizado na realização desta pesquisa.

\subsection{Materiais}

\subsubsection{Espécie}

A partir dos ensaios preliminares (capítulo 3) foi escolhida a espécie Cedrinho (figuras 15 e 16) para o desenvolvimento dessa fase da pesquisa. Além de apresentar densidade de $0,62 \mathrm{~g} / \mathrm{cm}^{3}$, situada numa faixa indicada para a produção de elementos estruturais de MLC, apresentou compatibilidade para os dois tipos de adesivos utilizados nos ensaios prescritos pela NBR 7190:1997 - Projeto de Estruturas de 
Madeira, em seu Anexo B, confirmada pelo seu desempenho às solicitações mecânicas apresentado no capítulo anterior.

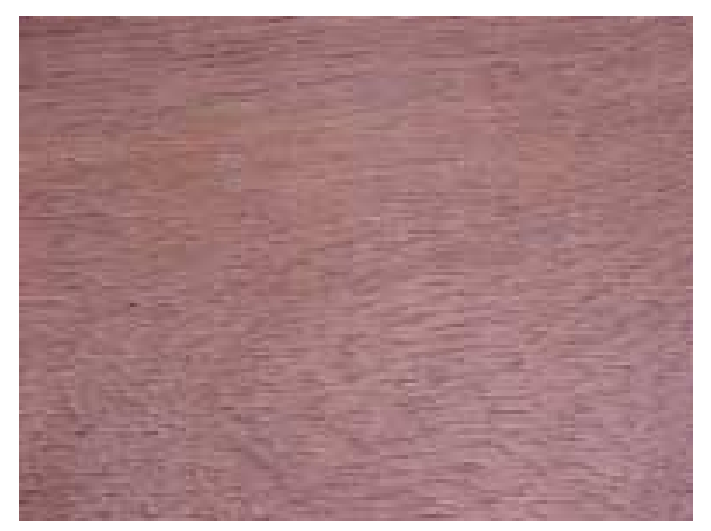

Figura 15- Aspecto da madeira Cedrinho

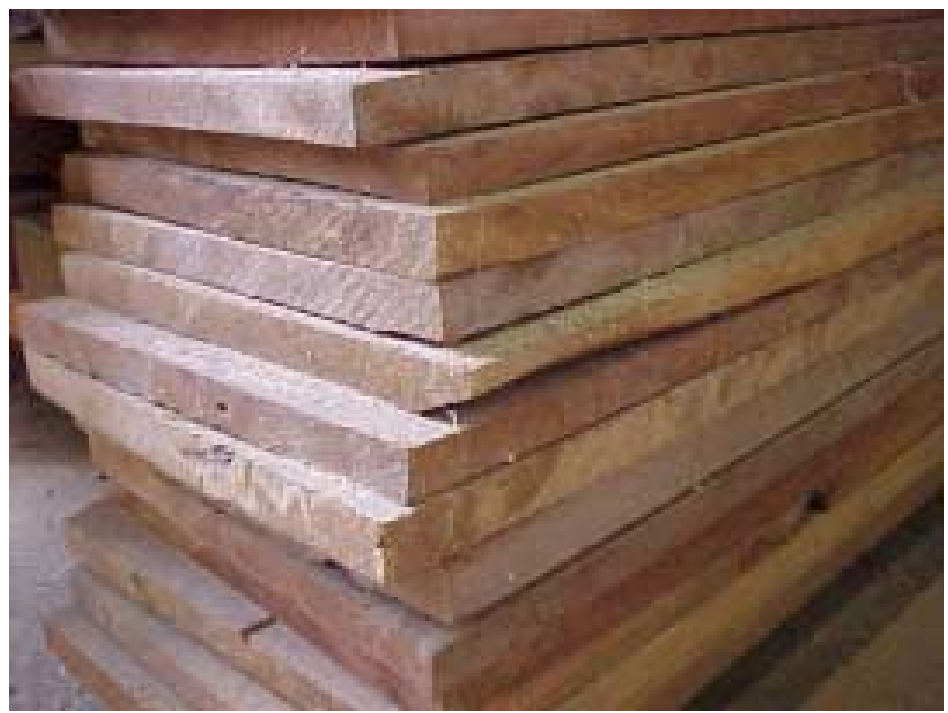

Figura 16 - Tábuas de Cedrinho

\subsubsection{Adesivos}

Os adesivos utilizados na colagem dos elementos estruturais foram dois. O primeiro, à base de resorcinol, é conhecido pelo nome comercial de Cascophen, muito utilizado na produção de elementos estruturais de MLC pela indústria brasileira. É misturado com o preparado endurecedor em pó FM. O segundo é uma resina poliuretana à base de mamona, desenvolvido e produzido por pesquisadores do 
Instituto de Química de São Carlos, da Universidade de São Paulo (IQSC - USP). Derivado do óleo da mamona, esse adesivo é do tipo bicomponente e de cura a frio, composto do prepolímero A249 e do poliol B16030. Uma vez misturados, o tempo de utilização é em torno de 20 minutos, com sua viscosidade aumentando após esse período. A figura 17 mostra os adesivos empregados nas colagens.

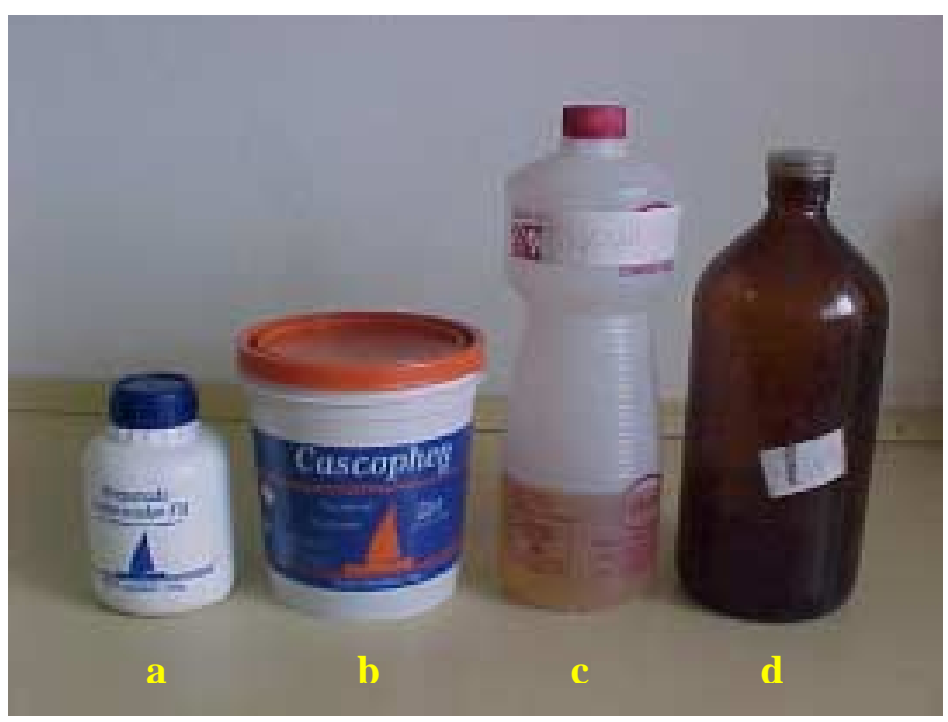

Figura 17 - Adesivos utilizados nas colagens:

a - Preparado endurecedor em pó FM

b - Cascophen RS

c - Poliol B16030

d - Prepolímero A249

\subsubsection{Equipamentos}

Para a obtenção das lâminas componentes das vigas, foi utilizada a serra circular da oficina do LaMEM. Suas dimensões nominais foram medidas com o auxílio de uma trena de 5 metros. Para os ensaios de flexão estática das lâminas, foram utilizados massas padronizados de $1 \mathrm{~kg}$ e relógio comparador com sensibilidade de $0,01 \mathrm{~mm}$. Para a mistura dos adesivos, foram empregados recipientes com capacidades de aproximadamente 1 litro, balança digital para mensurar as partes a serem misturadas e pincel para distribuição nas lâminas. Um dispositivo para prensagem constituído de 
guias com roscas foi montado para fornecer a pressão às vigas (figura 28). A pressão foi feita por porcas, giradas com torquímetro, este calibrado numa célula de carga. Para o ensaio de flexão estática de quatro pontos, usou-se um dispositivo montado com pistão acionado hidraulicamente, com anel dinamométrico de capacidade $20 \mathrm{kN}$. Nos métodos não-destrutivos foi utilizado o aparelho Sylvatest, ensaios de ultra-som, e o Metriguard 340-E, ensaios de vibração transversal, tanto para as vigas como também para as lâminas.

\subsection{Métodos}

\subsubsection{Obtenção das lâminas}

Foram adquiridas tábuas de dimensões nominais $2 \mathrm{~cm}$ x $30 \mathrm{~cm}$, comprimentos que variaram entre 400 e $600 \mathrm{~cm}$, no comércio madeireiro da região, e estas foram serradas de modo a se obterem lâminas de dimensões nominais $2 \mathrm{~cm}$ x $6 \mathrm{~cm}$ x 300 $\mathrm{cm}$, totalizando assim 116 lâminas. O esquema a seguir mostra como foram obtidas as lâminas a partir de uma tábua cujo comprimento era de 600 centímetros.
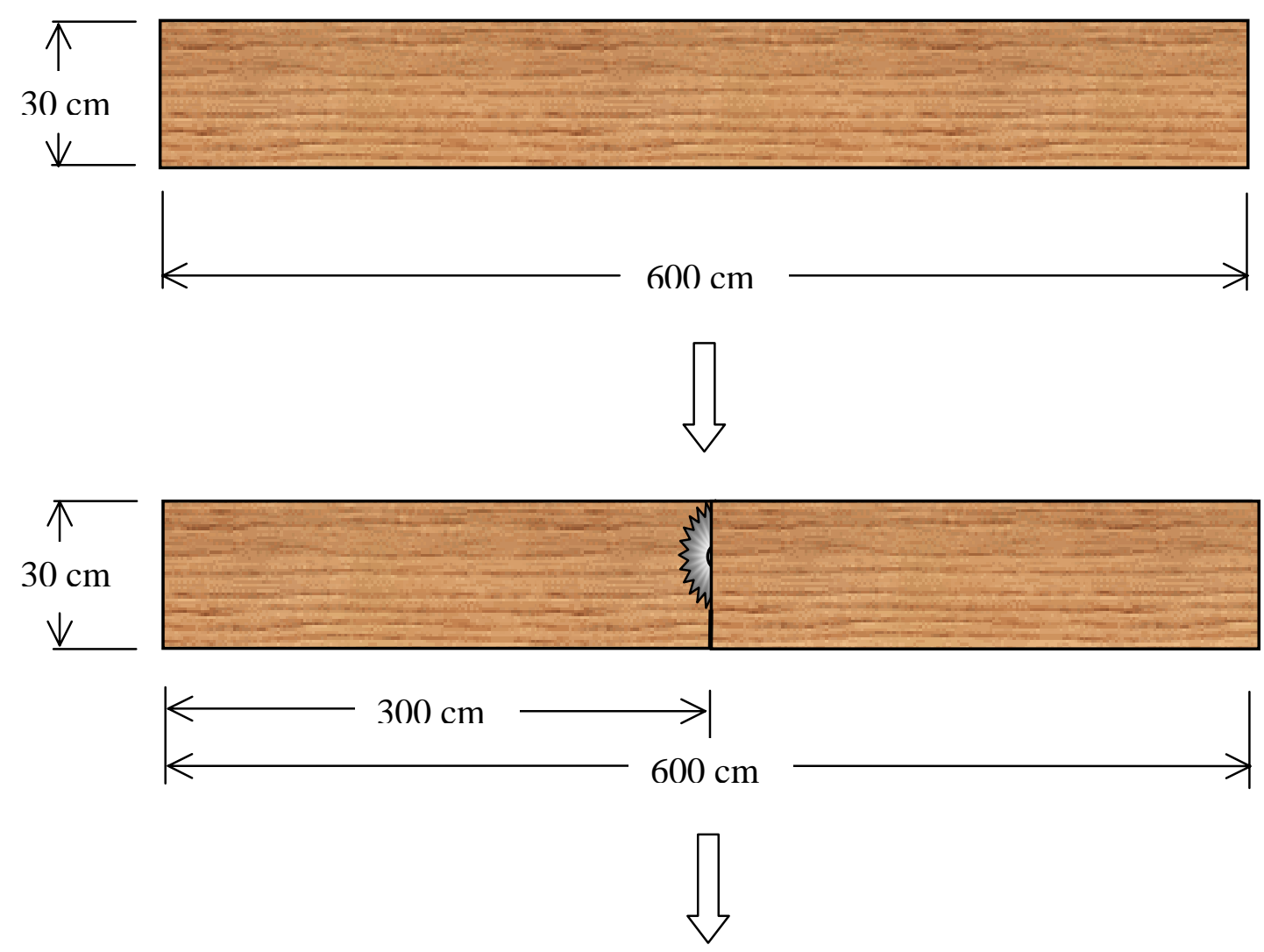

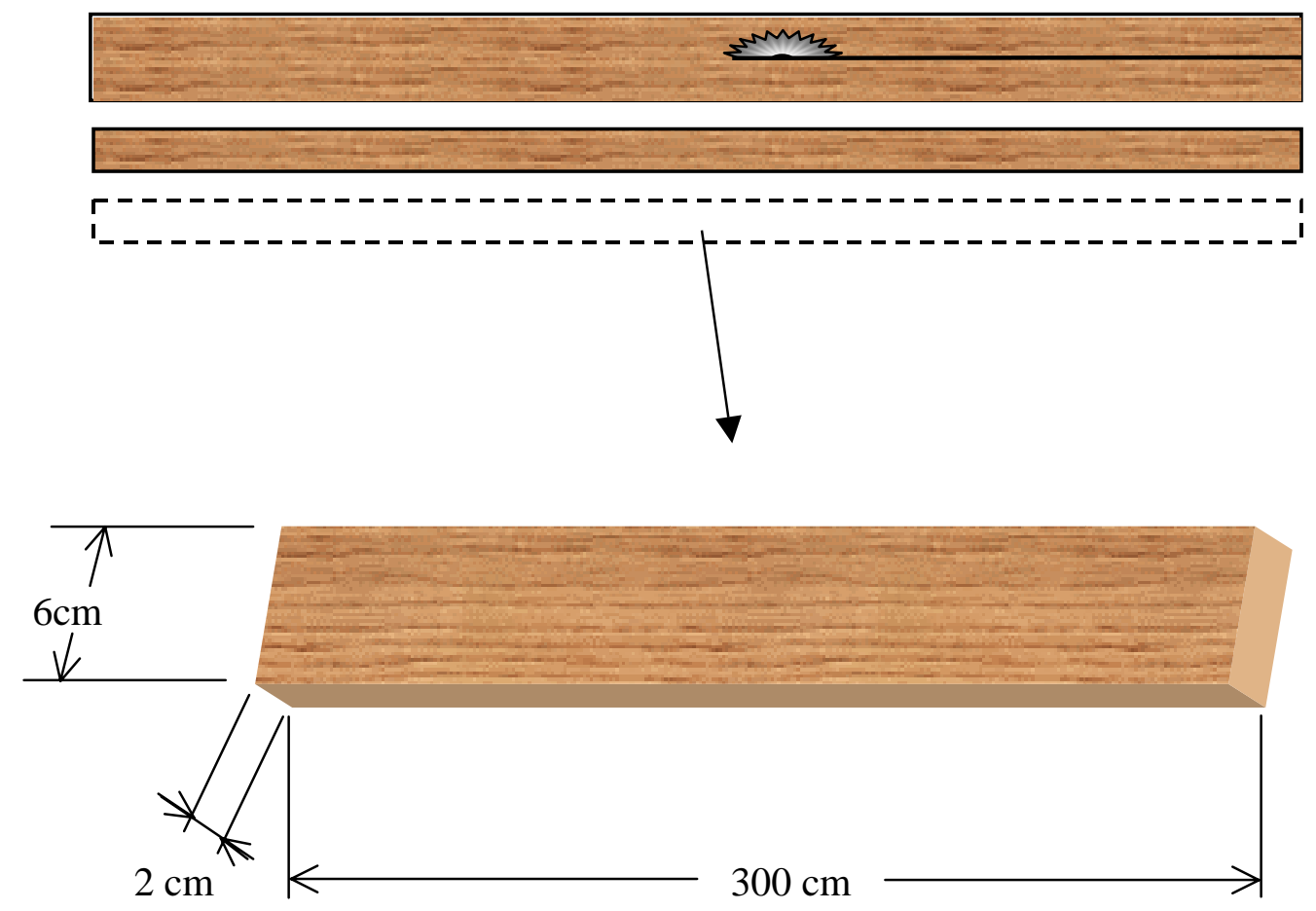

Figura 18 - Esquema de corte das tábuas para obtenção das lâminas

\subsubsection{Ensaios das lâminas}

Foram realizados ensaios de flexão estática nas lâminas, seguindo-se as diretrizes da NBR 7190:1997, com o objetivo de se obter seus módulos de elasticidade. Cada vez mais difundidos, os ensaios não destrutivos foram inseridos nessa pesquisa com o intuito de serem, os resultados, comparados com aqueles obtidos nos tradicionais ensaios de flexão estática normatizados. Assim, foram feitos ensaios para a determinação do módulo de elasticidade por vibração transversal e também ensaios de ultra-som para a determinação da constante dinâmica $\mathrm{C}_{\mathrm{LL}}$, e os resultados foram correlacionados com os ensaios de flexão estática. 


\subsubsection{Flexão estática nas lâminas}

No ensaio para a determinação do módulo de elasticidade, por flexão estática das lâminas, foram utilizados dois apoios que permitiam rotação, massas padronizadas e um relógio comparador. O carregamento foi aplicado no meio do vão, e o deslocamento foi medido no relógio comparador na face oposta à superfície de aplicação da força. A figura a seguir apresenta o esquema do ensaio.

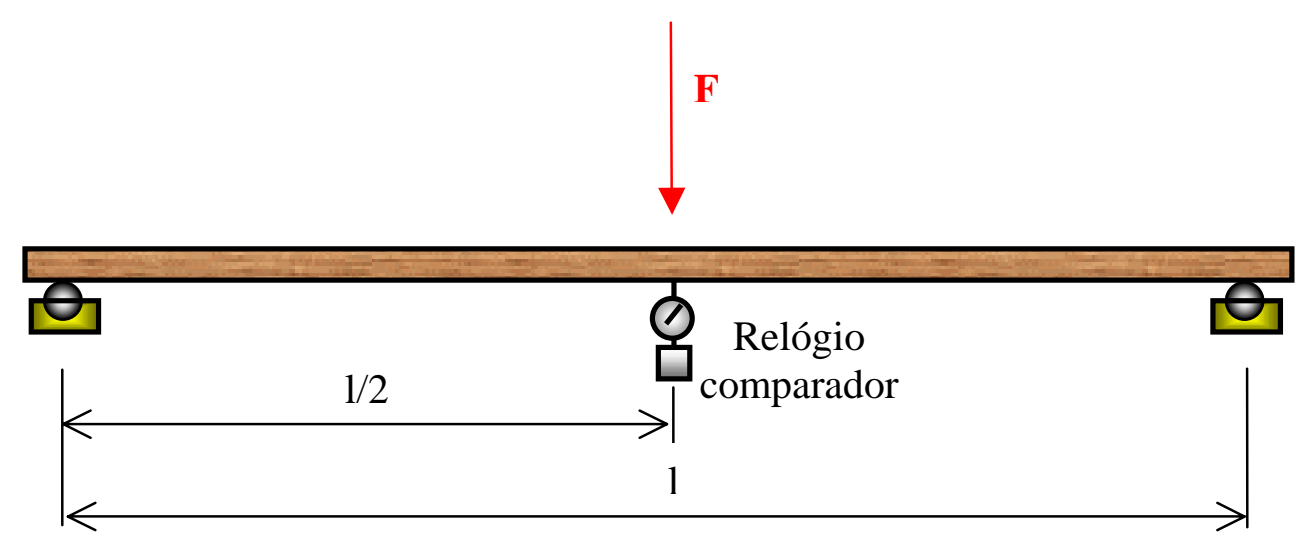

Figura 19 - Esquema de ensaio de flexão estática para as lâminas

O deslocamento é dado pela expressão:

$$
a=\frac{F l^{3}}{48 E I}
$$

Onde:

$\mathrm{a}=$ deslocamento medido em $1 / 2$;

$\mathrm{F}=$ força aplicada;

1 = distância entre os apoios;

$\mathrm{E}=$ módulo de elasticidade da lâmina;

I = momento de inércia da lâmina. 


\subsubsection{Vibração transversal}

Nos ensaios para determinação dos módulos de elasticidade por vibração transversal, foi utilizado o aparelho Metriguard Modelo 340-E. O equipamento é composto por dois tripés metálicos, uma unidade de interface, uma célula de carga, uma unidade de controle manual e cabos, sendo o sistema completado por um programa computacional. A unidade de interface recebe os sinais provenientes da célula de carga localizada sobre um dos tripés e o transmite para o computador, onde um programa calcula e transmite dados como o módulo de elasticidade, a densidade, a freqüência de vibração, e outros. Como procedimento inicial, logo após a montagem do aparelho, faz-se a calibração do sistema utilizando para isso uma barra de alumínio com as dimensões, massa e módulo de elasticidade conhecidos. Após os ajustes iniciais, a peça a ser ensaiada é apoiada sobre os tripés metálicos e uma liberação é feita no programa, indicando que uma vibração pode ser produzida. Essa pode ser provocada tanto por um simples golpe manual como também por uma ferramenta manual, como um martelo, por exemplo. Durante a vibração, é feita uma leitura (ou quantas se desejarem), e o programa realiza os cálculos, com os valores expressos diretamente na tela do computador, não sendo necessárias considerações posteriores.

Na seqüência estão apresentadas algumas figuras que ilustram o ensaio. 


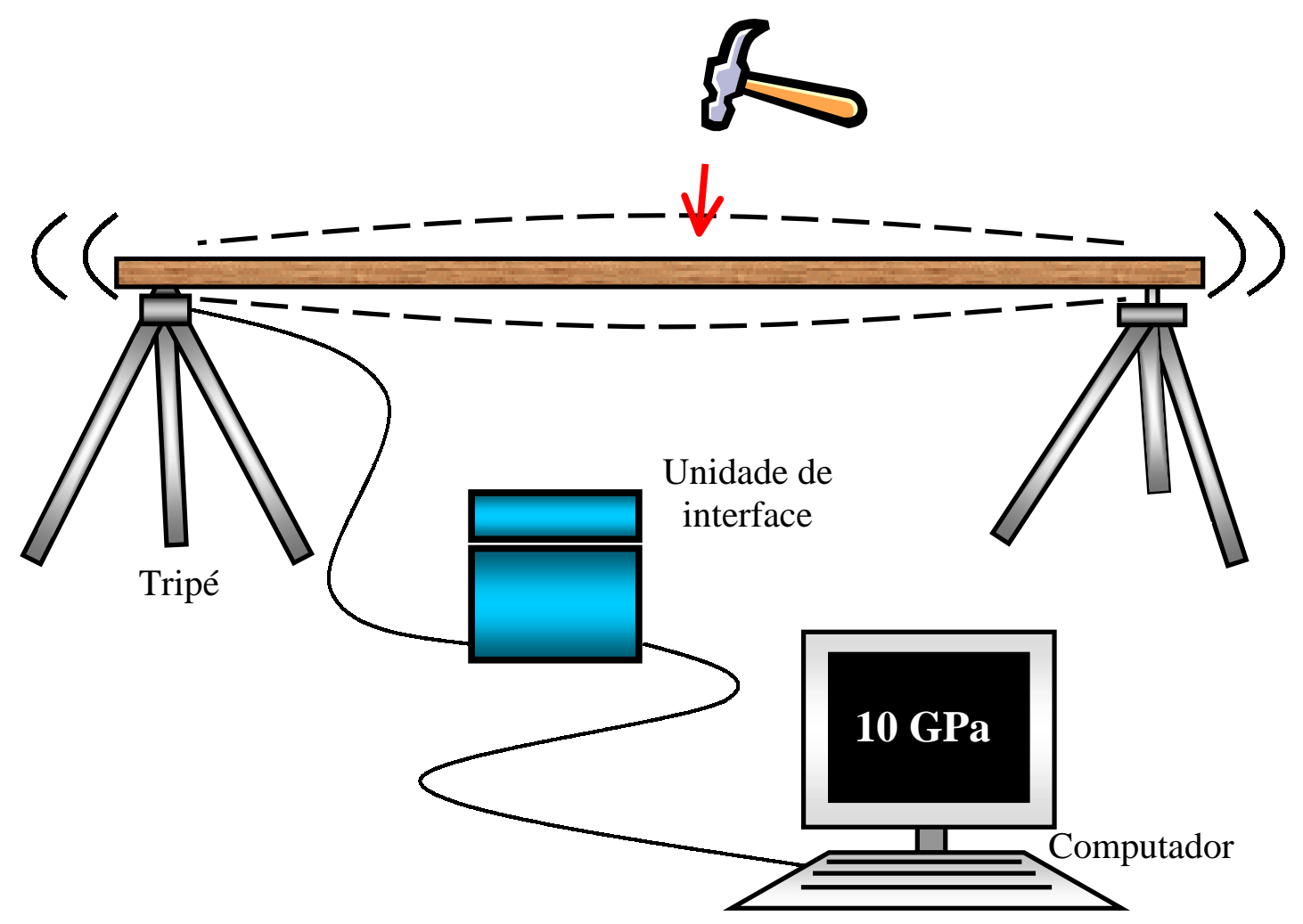

Figura 20 - Esquema do ensaio de determinação do módulo de elasticidade por meio de vibração transversal

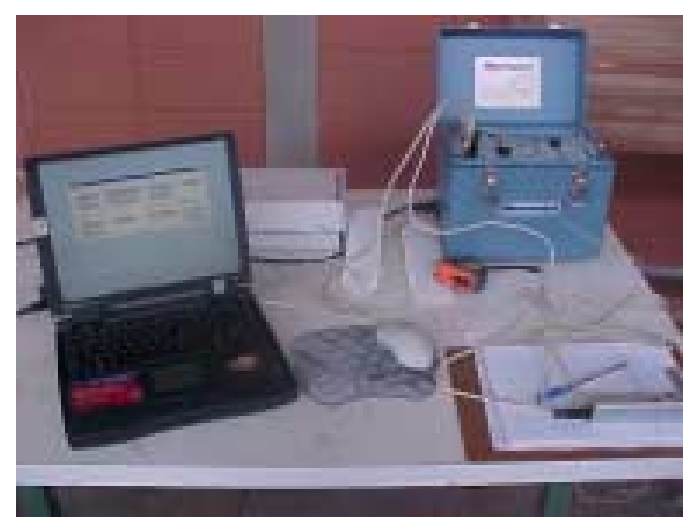

Figura 21 - Detalhe do equipamento de vibração transversal

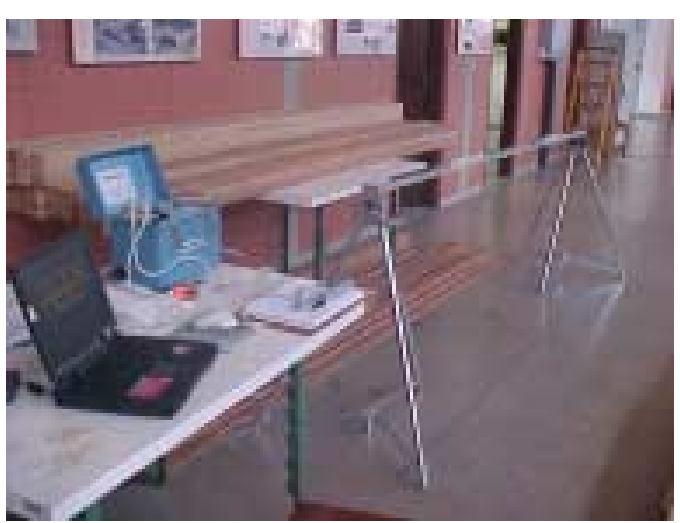

Figura 22 - Equipamento de vibração transversal 


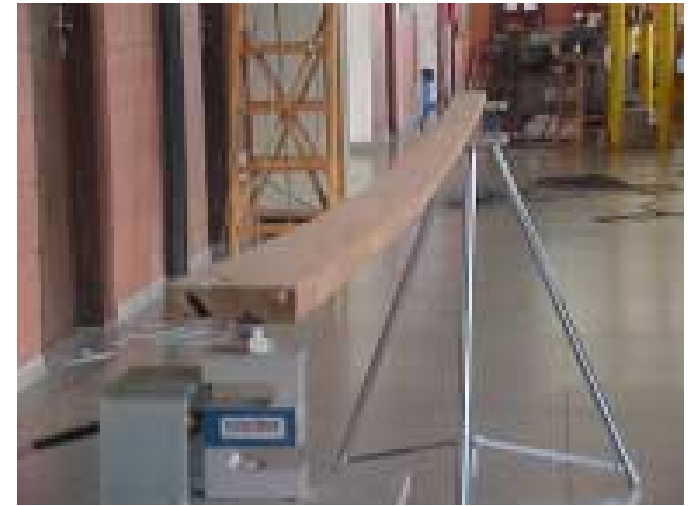

Figura 23 - Lâmina em ensaio

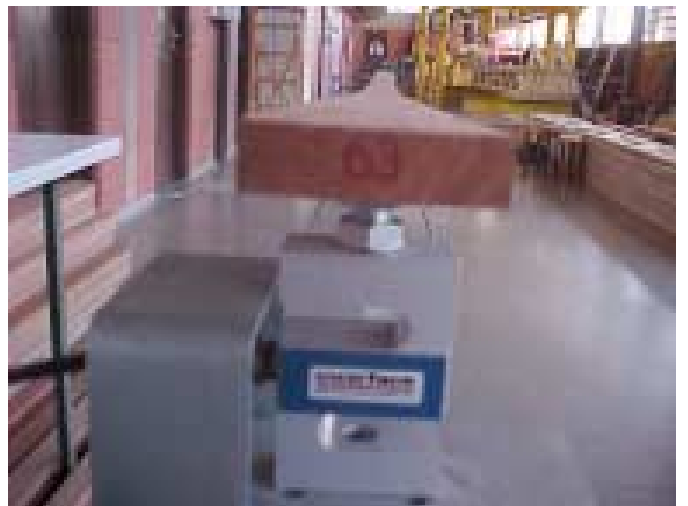

Figura 24 - Detalhe da célula de carga

\subsubsection{Ultra-som}

A madeira é considerada um material ortotrópico, possuindo três eixos de simetria elástica. Para estes materiais, os módulos de elasticidade de Young são proporcionais às constantes dinâmicas corrigidas dos coeficientes de Poisson. De acordo com Oliveira (2001), os termos da matriz de rigidez [C] podem ser determinados pelas medições com ultra-som. Assim, foi utilizado o aparelho Sylvatest para a determinação do termo $\mathrm{C}_{\mathrm{LL}}$ da matriz de rigidez. $\mathrm{O}$ equipamento é composto por dois transdutores de $22 \mathrm{kHz}$ e o aparelho propriamente dito. Os transdutores são posicionados nas extremidades da peça a ser ensaiada e, então, um deles emite ondas ultra-sônicas que percorrem o elemento, sendo recebidas pelo outro transdutor na extremidade oposta. É medida a velocidade com que a onda se propaga e então é feito o cálculo para determinação da constante dinâmica $C_{L L}$. Fatores como defeitos na peça, presença de nós, teor de umidade, e outros que possam influenciar a propagação da onda contribuem para que possam ocorrer problemas de leitura ou uma leitura com alguns desvios.

O cálculo da constante dinâmica é feito a partir da expressão:

$$
C_{L L}=\rho \cdot v^{2} \cdot 10^{-6}
$$

Onde: 
$\mathrm{C}_{\mathrm{LL}}=$ constante dinâmica, em MPa;

$\rho=$ densidade aparente, $\mathrm{em} \mathrm{kg} / \mathrm{m}^{3}$;

$\mathrm{v}=$ velocidade de propagação da onda, em $\mathrm{m} / \mathrm{s}$.

As figuras seguintes ilustram este tipo de ensaio e o aparelho utilizado.

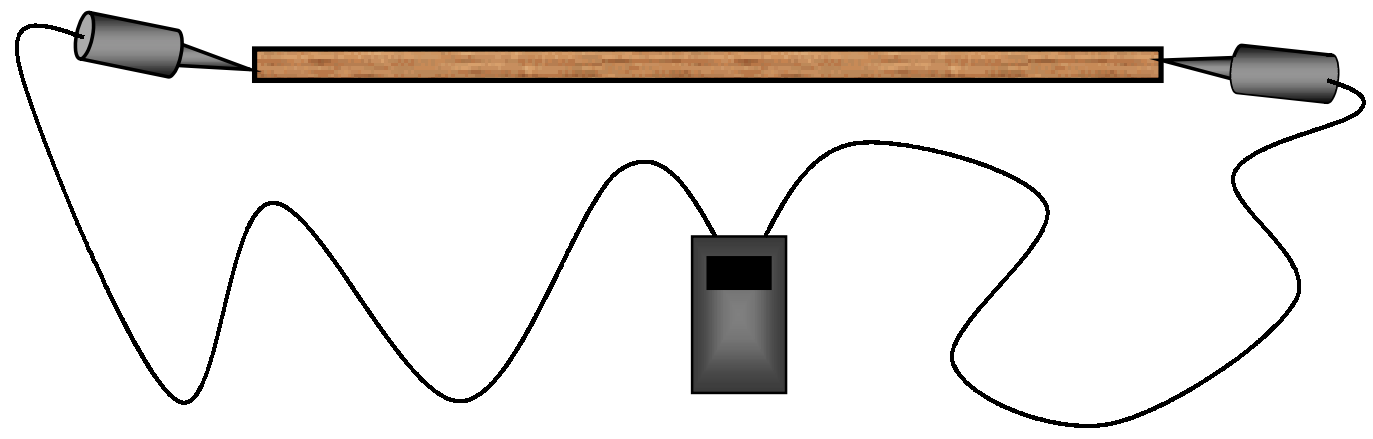

Figura 25 - Esquema de ensaio para determinação da constante dinâmica por meio de ultra-som

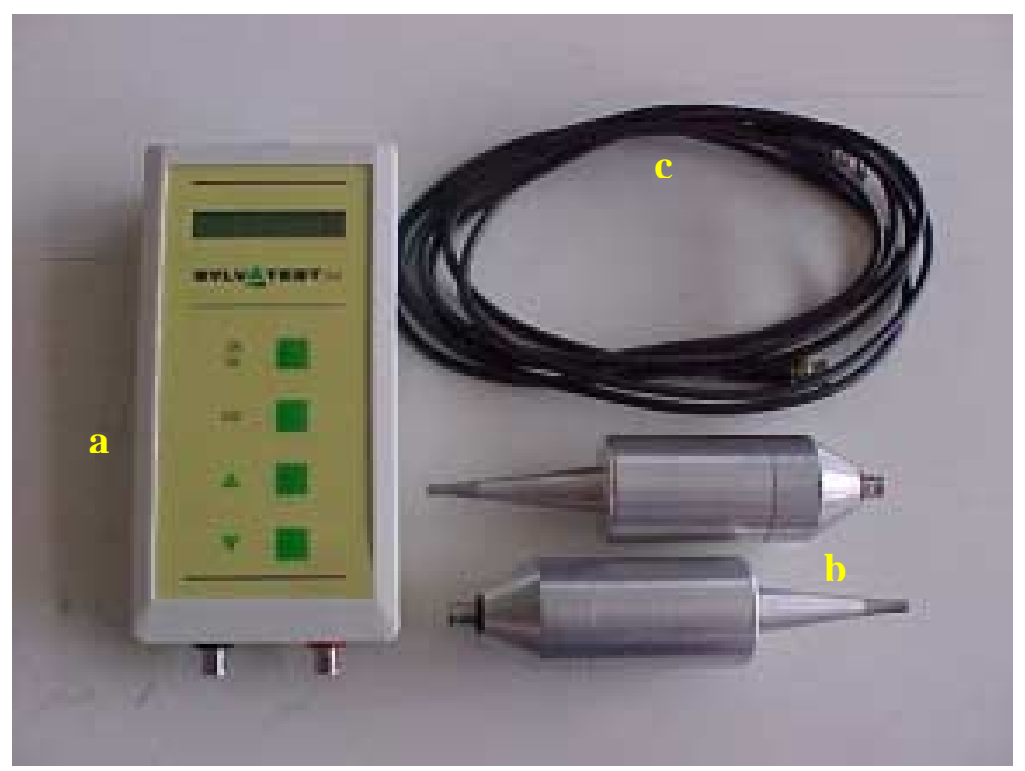

Figura 26 - Aparelho de ultra-som Sylvatest

a - aparelho de aquisição dos dados

b - transdutores

c - cabos 


\subsubsection{Critérios para a montagem dos elementos estruturais}

Após a determinação dos módulos de elasticidade das lâminas, por ensaios de flexão estática, estas foram classificadas em ordem decrescente e separadas em dois lotes: um para montagem de vigas com distribuição não-aleatória de lâminas, e outro com distribuição aleatória, sendo cada elemento estrutural formado por um conjunto de seis lâminas (figura 27) sobrepostas. No total, foram formados dezesseis conjuntos (que deram origem a dezesseis vigas): oito a partir do lote de lâminas não aleatórias e oito a partir do lote de lâminas aleatórias.

$\mathrm{Na}$ montagem das vigas com distribuições não-aleatórias (NA), as lâminas com módulos de elasticidade mais elevados foram dispostas nas regiões mais solicitadas da peça, enquanto que as de módulos mais baixos foram colocadas nas regiões de menor solicitação. O mesmo já não ocorre na montagem dos elementos estruturais com distribuições aleatórias (A). Nestas, as lâminas de cada conjunto foram dispostas sem que critério algum de distribuição fosse seguido, garantindo assim a aleatoriedade desejada.

Para uma estimativa dos valores dos módulos de intensidade das vigas, antes que estas fossem ensaiadas foram realizados cálculos a partir da média aritmética dos valores dos módulos das lâminas que compõem a peça, de acordo com a equação:

$$
E_{\text {médio }}=\frac{\sum_{i=1}^{n} E_{i}}{n}
$$

Onde $E_{\text {médio }}$ é o módulo médio aritmético estimado para a peça estrutural, $E_{i}$ é o módulo da lâmina i (com i variando de 1 até $n$ ), e $n$ é o número de lâminas que formam a viga, ou seja, igual a 6 .

Com o intuito de se levar em consideração a contribuição dos módulos de elasticidade das lâminas em função de suas posições na seção da viga, calculou-se também um módulo de elasticidade médio ponderado, $E_{p}$, a partir da seguinte equação: 


$$
E_{p}=\frac{\sum_{i=1}^{n} E_{i} \cdot I_{i}}{\sum_{i=1}^{n} I_{i}}
$$

Onde $E_{i}$ e $I_{i}$ são, respectivamente, o módulo de elasticidade e momento de inércia da lâmina i na seção $(i=1,2, \ldots, n), \operatorname{com} n=6$.

Para este último cálculo, foi feita a homogeneização da seção em função do módulo de elasticidade da primeira lâmina posicionada no elemento estrutural no sentido de baixo para cima (apenas como critério) e, a partir disso, foi determinada a posição do novo centro de gravidade para a seção. Em seguida, foram calculados os momentos de inércia das seções de cada lâmina que constituem a viga e procedeu-se, então, ao cálculo da estimativa do módulo de elasticidade médio ponderado.

\subsubsection{Colagem das vigas}

O preparo dos adesivos seguiu as recomendações dos fabricantes, ou seja, uma parte em massa de catalisador para cada cinco partes em massa de adesivo para o Cascophen, e uma parte em massa de catalisador para cada parte em massa de adesivo para a mamona. Uma vez preparados, os adesivos foram distribuídos nas superfícies das lâminas com a utilização de pincéis (figuras 29 e 30). O consumo de adesivo foi de quatrocentos gramas de Cascophen para cada viga colada, e de trezentos e cinquienta gramas para o adesivo à base de mamona. Em seguida, as peças foram colocadas num dispositivo (figura 28) montado com eixos contendo roscas e porcas para transmitirem pressão ao elemento estrutural (figuras 32 e 33). Para a aplicação da força necessária em cada eixo, foi empregado um torquímetro (figura 31), previamente calibrado em uma célula de carga. Na união das lâminas, oito vigas foram coladas com Cascophen: quatro com intensidade de pressão 0,8 MPa e quatro com intensidade de pressão 1,2 $\mathrm{MPa}$, e outras oito coladas com adesivo à base de mamona, com as mesmas intensidades de pressão. O tempo de aplicação de pressão foi de 10 horas para ambos os adesivos. O tempo de cura das peças coladas foi de, no mínimo, dez horas para o Cascophen e de noventa e seis horas (4 dias) para o adesivo 
de mamona. Após a cura as vigas foram aparelhadas e então estavam prontas para serem ensaiadas (figura 34 ).

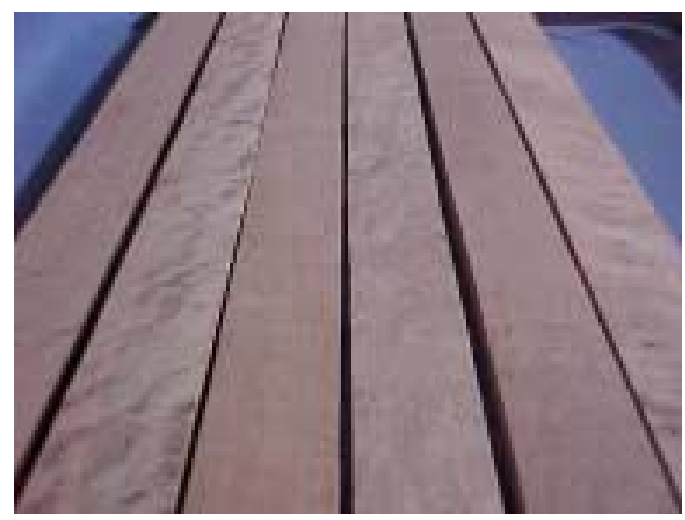

Figura 27 - Lâminas para montagem da peça estrutural

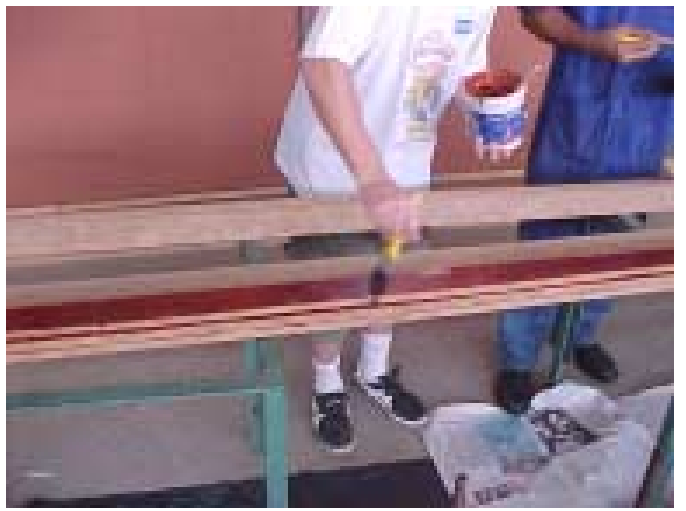

Figura 29 - Distribuição do adesivo nas lâminas

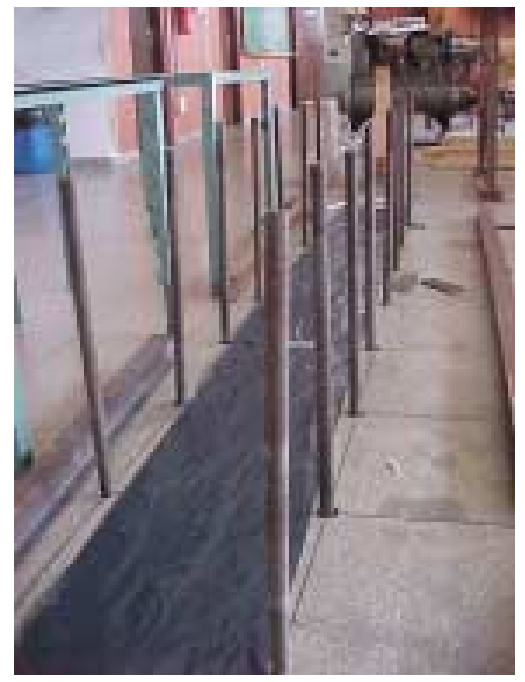

Figura 28 - Dispositivo para prensagem das vigas

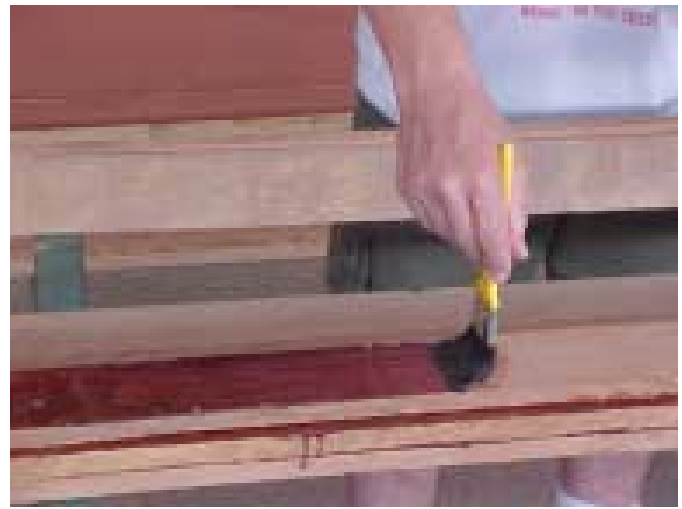

Figura 30 - Detalhe da distribuição 


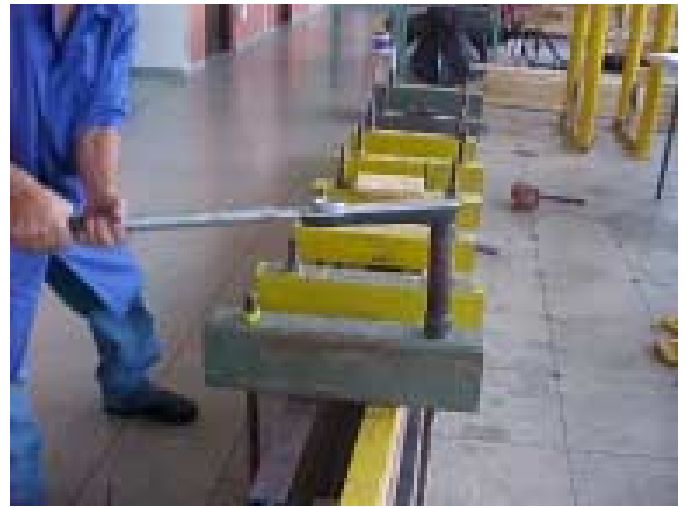

Figura 31 - Aplicação da pressão com uso de torquímetro

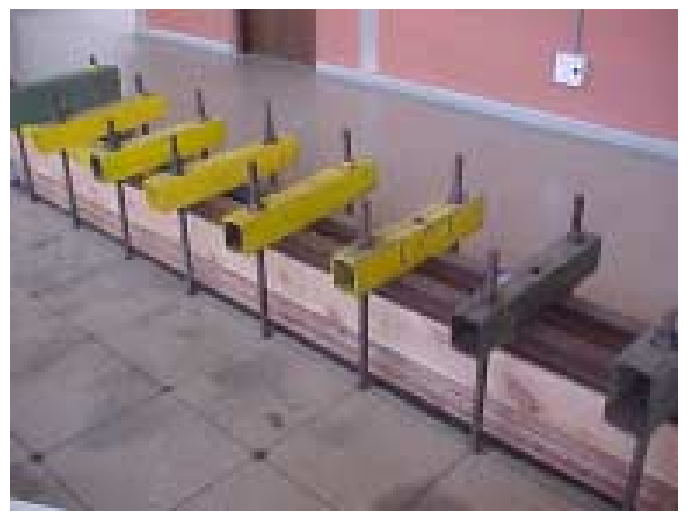

Figura 33 - Vigas sob pressão

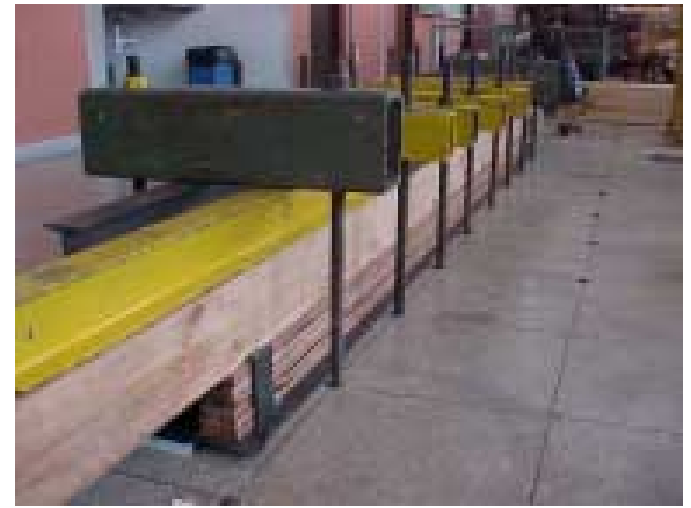

Figura 32 - Vigas sob pressão

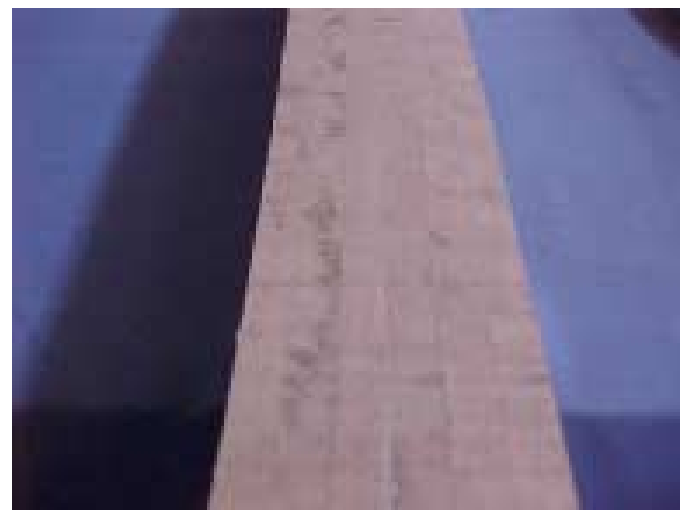

Figura 34 - Vista lateral de uma viga colada.

\subsubsection{Ensaios das vigas}

Os ensaios realizados nas peças estruturais foram análogos aos realizados nas lâminas que as compõem. Foram determinados os módulos de elasticidade a partir da flexão estática dos elementos e por meio de vibração transversal, e também foi determinada a constante dinâmica por meio de ultra-som.

\subsubsection{Flexão estática}

Para o ensaio de flexão estática das vigas foram utilizados dois apoios que permitem rotação, um relógio comparador e, neste caso, um dispositivo montado para aplicação de forças nos terços do vão do elemento estrutural. O carregamento foi 
feito por um pistão hidráulico, e a força medida por um anel dinamométrico com capacidade de $20 \mathrm{kN}$, com constante $\mathrm{K}=1,828$ daN/divisão.

Foram aplicados três ciclos de força, com registro de medidas no último ciclo. Foram feitas seis leituras, correspondentes a 10\%, 20\%, 30\%, 40\%, 50\% e 100\% de uma força que promoveria um deslocamento de aproximadamente 1/200, e o módulo de elasticidade foi calculado a partir da média aritmética das leituras.

O deslocamento na metade do vão (1/2) é dado pela expressão:

$$
a=\frac{F l^{3}}{24 E I}\left(3 \frac{l_{1}}{l}-4 \frac{l_{1}^{3}}{l^{3}}\right)
$$

Onde:

$\mathrm{a}=$ deslocamento no ponto médio da viga;

$\mathrm{F}=$ força aplicada num dos terços da viga;

1 = distância entre os apoios da viga;

$\mathrm{E}=$ módulo de elasticidade da viga;

I = momento de inércia;

$1_{1}=$ distância entre o apoio e o ponto de aplicação da força.

As figuras a seguir ilustram a condução deste ensaio. 


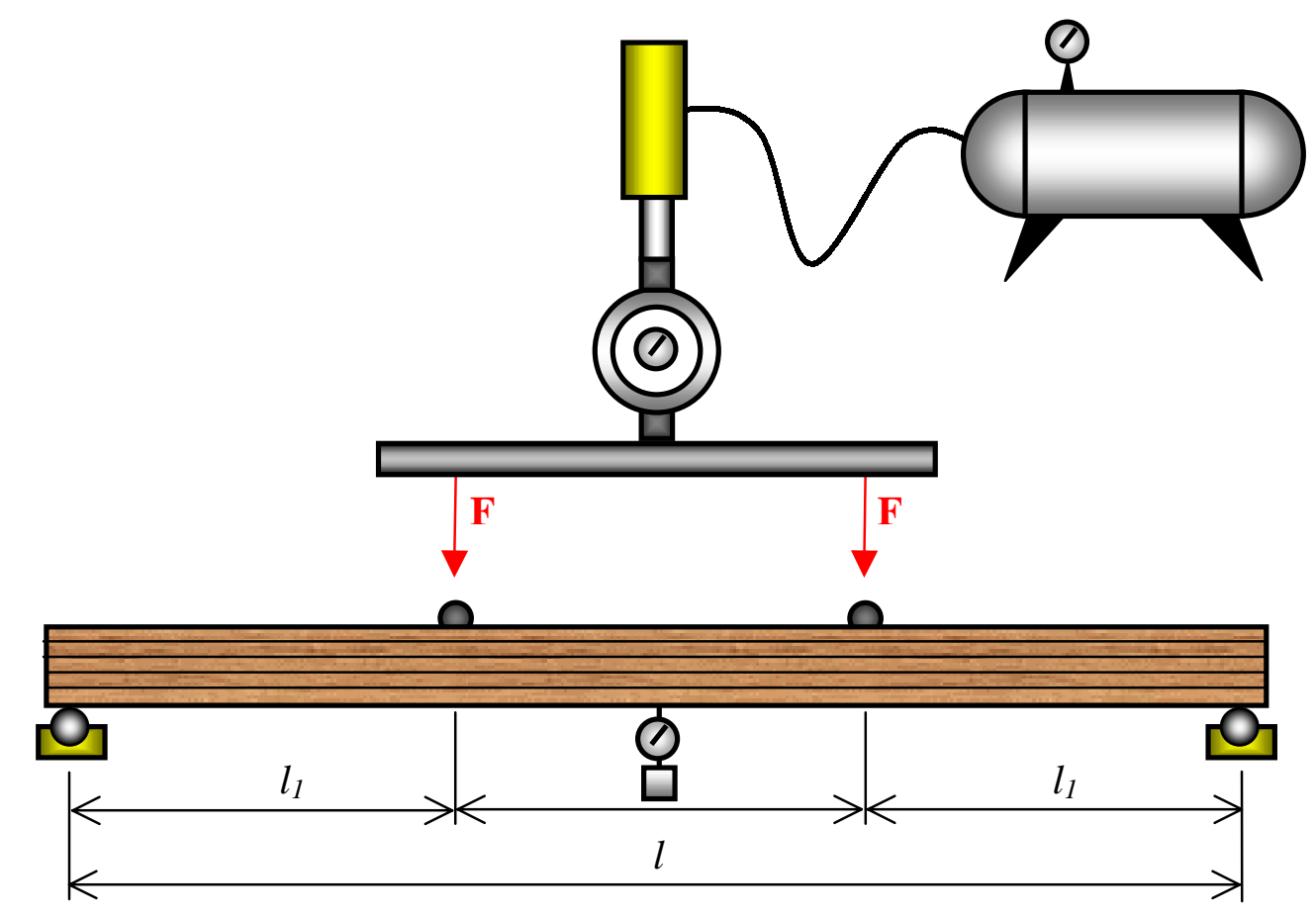

Figura 35 - Esquema de ensaio de flexão estática de 4 pontos

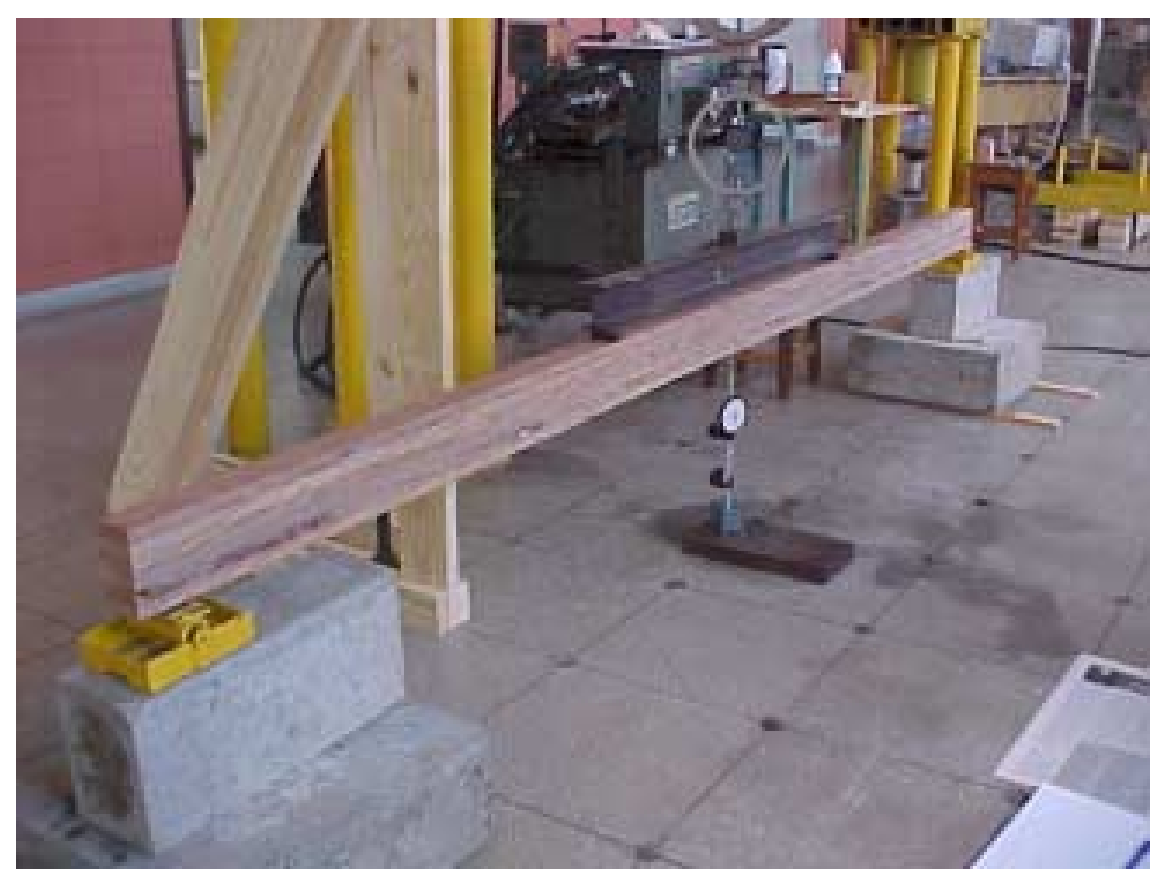

Figura 36 - Ensaio de flexão estática de 4 pontos em uma viga 


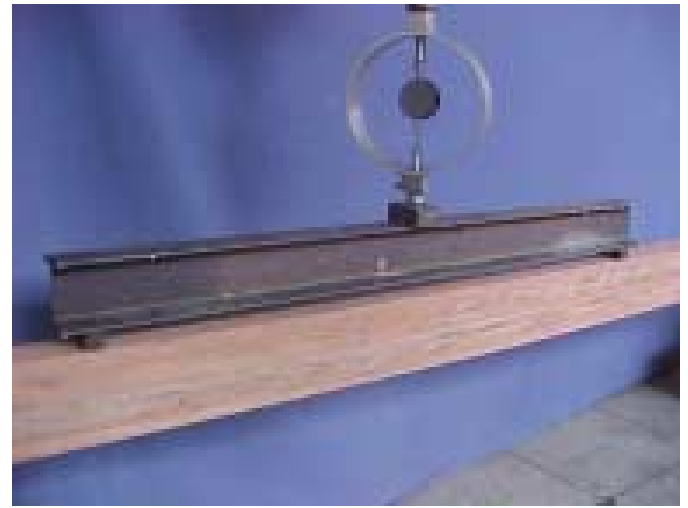

Figura 37 - Detalhe de aplicação de força no ensaio.

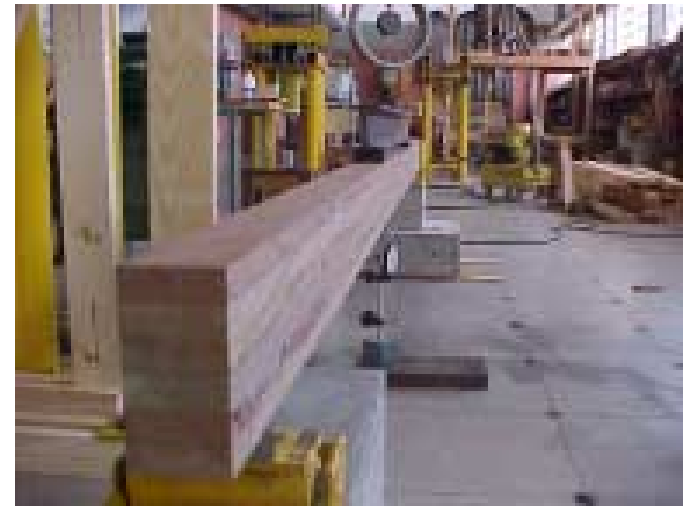

Figura 38 - Vista lateral do ensaio de flexão estática.

\subsubsection{Vibração transversal}

O procedimento adotado neste ensaio foi análogo ao do ensaio das lâminas. As vigas foram dispostas sobre os cavaletes e golpes de martelo foram aplicados para produzirem vibrações. O programa forneceu, então, os resultados solicitados.

As figuras seguintes mostram algumas etapas deste ensaio.

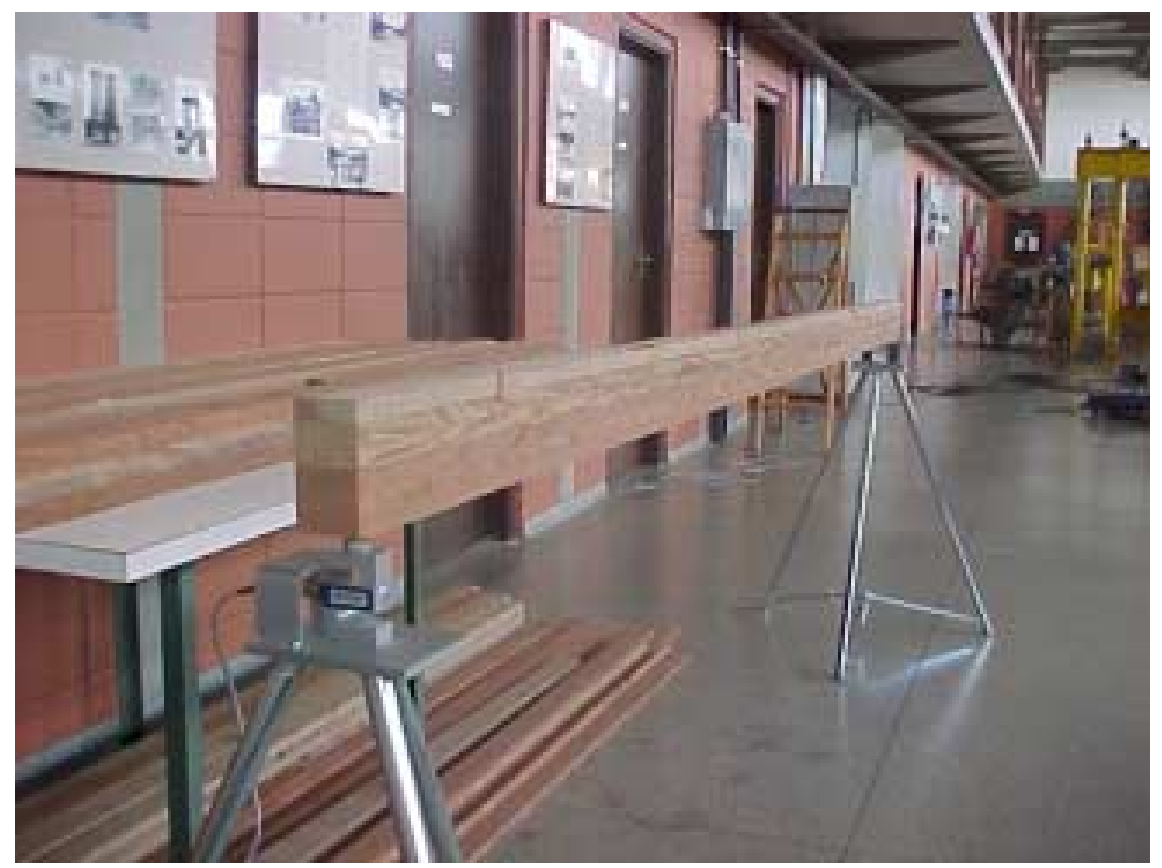

Figura 39 - Elemento estrutural preparado para ensaio de vibração transversal 


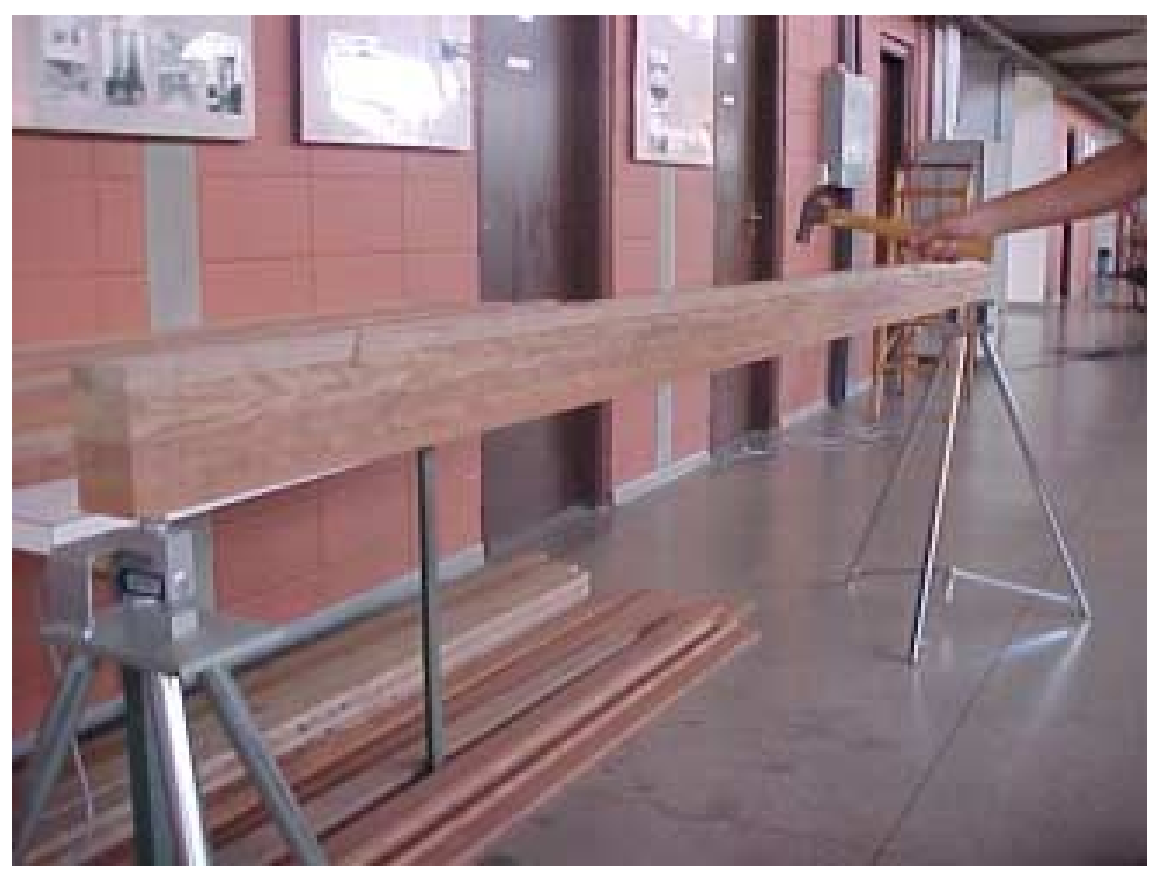

Figura 40 - Viga sofrendo impacto em ensaio de vibração transversal

\subsubsection{Ultra-som}

No ensaio de ultra-som, os transdutores foram posicionados nas extremidades das vigas e, então, foram efetuadas três leituras dos valores do tempo que as ondas demoraram pra percorrer toda a extensão das peças. Considerando a expressão (2) foram calculadas as constantes dinâmicas das vigas, utilizando uma média de três leituras de tempo de propagação. A figura seguinte ilustra o ensaio. 


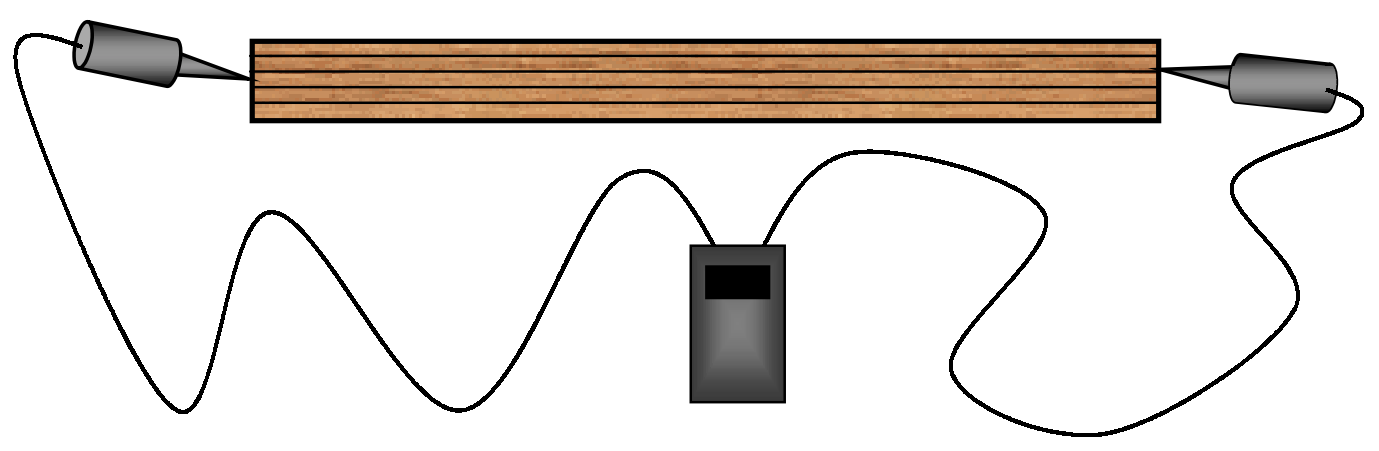

Figura 41 - Esquema de ensaio de ultra-som em viga de MLC

\subsubsection{Planejamento estatístico}

Neste trabalho desejou-se determinar a influência das variáveis (adesivo, pressão de colagem e distribuição das lâminas) no comportamento da peça. Para isso, foi feito um planejamento fatorial $2^{3}$, com dois adesivos (Cascophen e à base de mamona), duas intensidades de pressão de colagem (0,8 e 1,2 MPa) e dois tipos de distribuições de lâminas (aleatória e não aleatória).

Adotou-se representar os fatores por letras maiúsculas (D, A e P para distribuição, adesivo e pressão, respectivamente) e seus níveis por números (-1 e 1), como normalmente são representados. Para uma viga com distribuição não aleatória, colada com adesivo de mamona sob uma pressão de $0,8 \mathrm{MPa}$, tem-se, por exemplo, as seguintes representações: $\mathrm{D}=-1 \quad \mathrm{~A}=1 \quad \mathrm{P}=-1$.

A tabela 9 mostra a matriz modelo de planejamento para o caso em questão. 
Tabela 9 - Matriz planejamento para análise estatística

\begin{tabular}{|c|c|c|c|c|}
\hline \multirow{2}{*}{ Ensaios } & \multicolumn{3}{|c|}{ Variáveis } & Resposta \\
\hline & D & A & P & $\mathbf{y}_{1}$ \\
\hline 1 & -1 & -1 & -1 & \\
\hline 2 & -1 & -1 & -1 & \\
\hline 3 & 1 & -1 & -1 & \\
\hline 4 & 1 & -1 & -1 & \\
\hline 5 & -1 & 1 & -1 & \\
\hline 6 & -1 & 1 & -1 & \\
\hline 7 & 1 & 1 & -1 & \\
\hline 8 & 1 & 1 & -1 & \\
\hline 9 & -1 & -1 & 1 & \\
\hline 10 & -1 & -1 & 1 & \\
\hline 11 & 1 & -1 & 1 & \\
\hline 12 & 1 & -1 & 1 & \\
\hline 13 & -1 & 1 & 1 & \\
\hline 14 & -1 & 1 & 1 & \\
\hline 15 & 1 & 1 & 1 & \\
\hline 16 & 1 & 1 & 1 & \\
\hline
\end{tabular}

A análise da influência dos efeitos, isolados e também interagindo entre si, sobre a variável resposta (módulo de elasticidade) da peça foi feita com o emprego do programa estatístico MINITAB, e a sub-rotina DOE/fatorial. Com a finalidade de comparar os valores obtidos nos ensaios com os valores calculados, também foi feita uma análise de variância das médias, usando o programa citado e a sub-rotina ANOVA. 


\section{Curruons}

"O que caracteriza as pessoas que exibem exageradamente a sua virtude é que, quanto menos ameaçada está a fortaleza, mais guardas lhe põem".

Victor Hugo

\section{APRESENTAÇÃO E ANÁLISE DOS RESULTADOS}

Neste capítulo são apresentados os valores obtidos nos ensaios conduzidos nas lâminas de Cedrinho e também nas peças estruturais. São mostrados os valores de módulos de elasticidade obtidos por ensaios de flexão estática e vibração transversal, e das constantes dinâmicas obtidas por ultra-som. São estudados os resultados dos ensaios por intermédio de correlações para as lâminas, e pela análise do planejamento fatorial, correlações e análises de variância das médias para as vigas. $\mathrm{Na}$ análise de variância, o valor calculado pelo programa MINITAB ( $\left.\mathrm{F}_{\text {observado}}\right)$ tem que ser inferior ao valor crítico tabelado $\left(f_{\text {crítico }}\right)$, determinado em função dos graus de liberdade. Atendida essa condição, analisa-se então o p-valor, que quanto mais se aproximar de 1, mais semelhantes são as médias avaliadas. Para a análise fatorial, observa-se diretamente o p-valor. Se este for menor que o nível de significância 0,05 $(\alpha=0,05)$, afirma-se que a variável estudada influencia significativamente no resultado final, com uma intensidade mostrada pelo valor apresentado na coluna “efeito". Para a correlação, estuda-se o valor encontrado para $\mathrm{R}^{2}$, sendo que quanto mais próximo de 1 estiver esse valor, mais os números envolvidos estão relacionados. É importante ressaltar que o ensaio de flexão estática foi realizado em 
todas as lâminas (cento e treze lâminas no total, pois três se quebraram), o mesmo não acontecendo para os ensaios não destrutivos, nos quais oitenta e uma lâminas foram submetidas aos procedimentos técnicos. A justificativa para este fato é que quando foram sugeridos os dois últimos métodos de ensaios pela Comissão Examinadora do Exame de Qualificação, quatro vigas já haviam sido construídas, estando então suas lâminas coladas, impossibilitando assim os ensaios individuais.

\subsection{Valores obtidos nos ensaios com as lâminas}

\subsubsection{Flexão estática}

A tabela 10 apresenta o números de identificação (L) das lâminas e seus respectivos módulos de elasticidade (em daN/ $\mathrm{cm}^{2}$ ), calculados pela expressão (1). Apresenta também a média (M) dos valores, o desvio padrão (DP) e o coeficiente de variação $(\mathrm{CV})$. 
Tabela 10 - Módulos de elasticidade das lâminas obtidos por flexão estática

\begin{tabular}{|c|c|c|c|c|c|c|c|}
\hline $\mathrm{L}$ & E & $\mathrm{L}$ & $\mathrm{E}$ & $\mathrm{L}$ & E & $\mathrm{L}$ & E \\
\hline 1 & 118062 & 30 & 108885 & 59 & 139692 & 88 & 160616 \\
\hline 2 & 125161 & 31 & 93656 & 60 & 140909 & 89 & 93366 \\
\hline 3 & 99876 & 32 & 102758 & 61 & 97737 & 90 & 83825 \\
\hline 4 & 129251 & 33 & 139201 & 62 & 81737 & 91 & 108340 \\
\hline 5 & 96465 & 34 & 94132 & 63 & 80874 & 92 & 113704 \\
\hline 6 & 130531 & 35 & 98154 & 64 & 102536 & 93 & 100298 \\
\hline 7 & 153298 & 36 & 114841 & 65 & 88001 & 94 & 100298 \\
\hline 8 & 111548 & 37 & 106334 & 66 & 91143 & 95 & 91873 \\
\hline 9 & 90928 & 38 & 96912 & 67 & 106334 & 96 & 92988 \\
\hline 10 & 153298 & 39 & 108340 & 68 & 76560 & 97 & 104877 \\
\hline 11 & 129608 & 40 & 92242 & 69 & 98154 & 98 & 117785 \\
\hline 12 & 126348 & 41 & 102996 & 70 & 96912 & 99 & 86023 \\
\hline 13 & 96315 & 42 & 96912 & 71 & 96505 & 100 & 78928 \\
\hline 14 & 113002 & 43 & 93748 & 72 & 97737 & 101 & 93748 \\
\hline 15 & 111298 & 44 & 85067 & 73 & 146294 & 102 & 113144 \\
\hline 16 & 87155 & 45 & 100298 & 74 & 126896 & 103 & 82619 \\
\hline 17 & 116798 & 46 & 82619 & 75 & 114841 & 104 & 82323 \\
\hline 18 & 95934 & 47 & 107832 & 76 & 92988 & 105 & 91143 \\
\hline 19 & 115456 & 48 & 84753 & 77 & 105358 & 106 & 105844 \\
\hline 20 & 111298 & 49 & 82619 & 78 & 91507 & 107 & 80590 \\
\hline 21 & 122076 & 50 & 82029 & 79 & 103928 & 108 & 83825 \\
\hline 22 & 84353 & 51 & 106334 & 80 & 80874 & 109 & 89719 \\
\hline 23 & 105535 & 52 & 106334 & 81 & 119626 & 110 & 140909 \\
\hline 24 & 120789 & 53 & 92242 & 82 & 118392 & 111 & 69812 \\
\hline 25 & 101828 & 54 & 90783 & 83 & 100737 & 112 & 91873 \\
\hline 26 & 148810 & 55 & 98154 & 84 & 121525 & 113 & 76053 \\
\hline 27 & 156327 & 56 & 85633 & 85 & 90783 & & \\
\hline 28 & 125952 & 57 & 96212 & 86 & 83521 & M & 103966 \\
\hline 29 & 111548 & 58 & 104817 & 87 & 77858 & DP & 19346 \\
\hline & & & & & & $\mathrm{CV}$ & 0,19 \\
\hline
\end{tabular}

\subsubsection{Vibração transversal}

A tabela 11 apresenta o número de identificação (L) das lâminas e seus respectivos módulos de elasticidade (em daN/ $\mathrm{cm}^{2}$ ), obtidos nos ensaios de vibração transversal, 
pela leitura direta da saída dos dados. Apresenta, também, a média (M) dos valores, o desvio padrão (DP) e o coeficiente de variação $(\mathrm{CV})$.

Tabela 11 - Módulos de elasticidade das lâminas, obtidos por vibração transversal

\begin{tabular}{|c|c|}
\hline $\mathrm{L}$ & $\mathrm{E}_{\mathrm{vt}}$ \\
\hline 33 & 132700 \\
\hline 34 & 94300 \\
\hline 35 & 94200 \\
\hline 36 & 106300 \\
\hline 37 & 99900 \\
\hline 38 & 96900 \\
\hline 39 & 96500 \\
\hline 40 & 89500 \\
\hline 41 & 93900 \\
\hline 42 & 95300 \\
\hline 43 & 78200 \\
\hline 44 & 80000 \\
\hline 45 & 95400 \\
\hline 46 & 83200 \\
\hline 47 & 105900 \\
\hline 48 & 77600 \\
\hline 49 & 81900 \\
\hline 50 & 83600 \\
\hline 51 & 103300 \\
\hline 52 & 95300 \\
\hline 53 & 86000 \\
\hline 54 & 84600 \\
\hline
\end{tabular}

\begin{tabular}{|c|c|}
\hline $\mathrm{L}$ & $\mathrm{E}_{\mathrm{vt}}$ \\
\hline 55 & 92000 \\
\hline 56 & 72900 \\
\hline 57 & 90300 \\
\hline 58 & 98700 \\
\hline 59 & 123400 \\
\hline 60 & 131400 \\
\hline 61 & 92400 \\
\hline 62 & 86200 \\
\hline 63 & 80200 \\
\hline 64 & 91500 \\
\hline 65 & 84700 \\
\hline 66 & 86400 \\
\hline 67 & 98100 \\
\hline 68 & 77600 \\
\hline 69 & 89000 \\
\hline 70 & 87700 \\
\hline 71 & 82900 \\
\hline 72 & 87700 \\
\hline 73 & 134400 \\
\hline 74 & 117700 \\
\hline 75 & 106400 \\
\hline 76 & 86500 \\
\hline & \\
\hline
\end{tabular}

\begin{tabular}{|c|c|}
\hline $\mathrm{L}$ & $\mathrm{E}_{\mathrm{vt}}$ \\
\hline 77 & 93000 \\
\hline 78 & 85000 \\
\hline 79 & 90600 \\
\hline 80 & 72400 \\
\hline 81 & 103300 \\
\hline 82 & 105800 \\
\hline 83 & 88800 \\
\hline 84 & 108000 \\
\hline 85 & 84800 \\
\hline 86 & 75000 \\
\hline 87 & 73100 \\
\hline 88 & 141200 \\
\hline 89 & 82600 \\
\hline 90 & 76700 \\
\hline 91 & 94500 \\
\hline 92 & 103700 \\
\hline 93 & 101700 \\
\hline 94 & 90000 \\
\hline 95 & 81700 \\
\hline 96 & 88400 \\
\hline 97 & 99700 \\
\hline 98 & 101300 \\
\hline & \\
\hline
\end{tabular}

\begin{tabular}{|c|c|}
\hline $\mathrm{L}$ & $E_{v t}$ \\
\hline 99 & 82000 \\
\hline 100 & 70900 \\
\hline 101 & 85000 \\
\hline 102 & 102000 \\
\hline 103 & 74700 \\
\hline 104 & 75800 \\
\hline 105 & 90900 \\
\hline 106 & 95500 \\
\hline 107 & 73600 \\
\hline 108 & 73700 \\
\hline 109 & 82000 \\
\hline 110 & 132600 \\
\hline 111 & 73900 \\
\hline 112 & 85000 \\
\hline 113 & 83700 \\
\hline $\mathrm{M}$ & 92286 \\
\hline DP & 15248 \\
\hline $\mathrm{CV}$ & 0,17 \\
\hline
\end{tabular}

\subsubsection{Ultra-som}

A tabela 12 apresenta o números de identificação (L) das lâminas e suas respectivas constantes dinâmicas $\mathrm{C}_{\mathrm{LL}}\left(\mathrm{em} \mathrm{daN} / \mathrm{cm}^{2}\right.$ ), calculadas através da expressão (2). Apresenta também a média (M) dos valores, o desvio padrão (DP) e o coeficiente de variação $(\mathrm{CV})$. 
Tabela 12 - Constantes dinâmicas das lâminas obtidas por ultra-som

\begin{tabular}{|c|c|}
\hline $\mathrm{L}$ & $\mathrm{C}_{\mathrm{LL}}$ \\
\hline 33 & 169094 \\
\hline 34 & 117506 \\
\hline 35 & 120517 \\
\hline 36 & 128890 \\
\hline 37 & 128447 \\
\hline 38 & 126202 \\
\hline 39 & 123440 \\
\hline 40 & 106062 \\
\hline 41 & 113927 \\
\hline 42 & 126853 \\
\hline 43 & 101707 \\
\hline 44 & 99262 \\
\hline 45 & 118597 \\
\hline 46 & 107053 \\
\hline 47 & 127935 \\
\hline 48 & 99942 \\
\hline 49 & 109843 \\
\hline 50 & 111676 \\
\hline 51 & 131993 \\
\hline 52 & 122362 \\
\hline 53 & 109760 \\
\hline 54 & 108826 \\
\hline & \\
\hline
\end{tabular}

\begin{tabular}{|c|c|}
\hline $\mathrm{L}$ & $\mathrm{C}_{\mathrm{LL}}$ \\
\hline 55 & 130570 \\
\hline 56 & 89865 \\
\hline 57 & 112053 \\
\hline 58 & 163183 \\
\hline 59 & 151936 \\
\hline 60 & 157963 \\
\hline 61 & 121611 \\
\hline 62 & 111979 \\
\hline 63 & 100062 \\
\hline 64 & 116138 \\
\hline 65 & 115318 \\
\hline 66 & 117222 \\
\hline 67 & 122557 \\
\hline 68 & 113617 \\
\hline 69 & 112265 \\
\hline 70 & 112463 \\
\hline 71 & 104988 \\
\hline 72 & 116834 \\
\hline 73 & 163133 \\
\hline 74 & 141944 \\
\hline 75 & 129812 \\
\hline 76 & 113041 \\
\hline & \\
\hline
\end{tabular}

\begin{tabular}{|c|c|}
\hline $\mathrm{L}$ & $\mathrm{C}_{\mathrm{LL}}$ \\
\hline 77 & 114342 \\
\hline 78 & 107384 \\
\hline 79 & 112619 \\
\hline 80 & 109181 \\
\hline 81 & 126439 \\
\hline 82 & 131872 \\
\hline 83 & 118256 \\
\hline 84 & 135739 \\
\hline 85 & 112299 \\
\hline 86 & 93588 \\
\hline 87 & 95216 \\
\hline 88 & 176934 \\
\hline 89 & 108556 \\
\hline 90 & 101037 \\
\hline 91 & 126136 \\
\hline 92 & 129582 \\
\hline 93 & 124370 \\
\hline 94 & 115326 \\
\hline 95 & 110377 \\
\hline 96 & 117518 \\
\hline 97 & 125232 \\
\hline 98 & 125938 \\
\hline & \\
\hline
\end{tabular}

\begin{tabular}{|c|c|}
\hline $\mathrm{L}$ & $\mathrm{C}_{\mathrm{LL}}$ \\
\hline 99 & 108456 \\
\hline 100 & 98354 \\
\hline 101 & 112858 \\
\hline 102 & 130329 \\
\hline 103 & 96204 \\
\hline 104 & 103293 \\
\hline 105 & 114951 \\
\hline 106 & 124396 \\
\hline 107 & 101224 \\
\hline 108 & 94573 \\
\hline 109 & 111131 \\
\hline 110 & 165191 \\
\hline 111 & 90283 \\
\hline 112 & 117184 \\
\hline 113 & 110400 \\
\hline
\end{tabular}

\begin{tabular}{|c|c|}
\hline $\mathrm{M}$ & 118830 \\
\hline $\mathrm{DP}$ & 17862 \\
\hline $\mathrm{CV}$ & 0,15 \\
\hline
\end{tabular}

\subsubsection{Análises dos resultados obtidos para as lâminas}

Neste subitem são feitas as correlações para os resultados encontrados nos ensaios. Os valores obtidos nos ensaios de flexão estática são correlacionados com os valores obtidos nos ensaios não-destrutivos. Para esta avaliação, foram estudadas 81 lâminas com identificação a partir do número 33, uma vez que as 32 primeiras lâminas não foram ensaiadas por vibração transversal e nem por ultra-som, conforme já mencionado. A média dos valores das 81 lâminas foi de $99432 \mathrm{daN} / \mathrm{cm}^{2}$, com desvio padrão de $17541 \mathrm{daN} / \mathrm{cm}^{2}$ e coeficiente de variação de 0,18 . 
Na seqüência, são apresentados o gráfico comparativo das médias (figura 42) e as correlações feitas para flexão estática versus vibração transversal, flexão estática versus ultra-som e vibração transversal versus ultra-som.

\section{Médias dos ensaios}

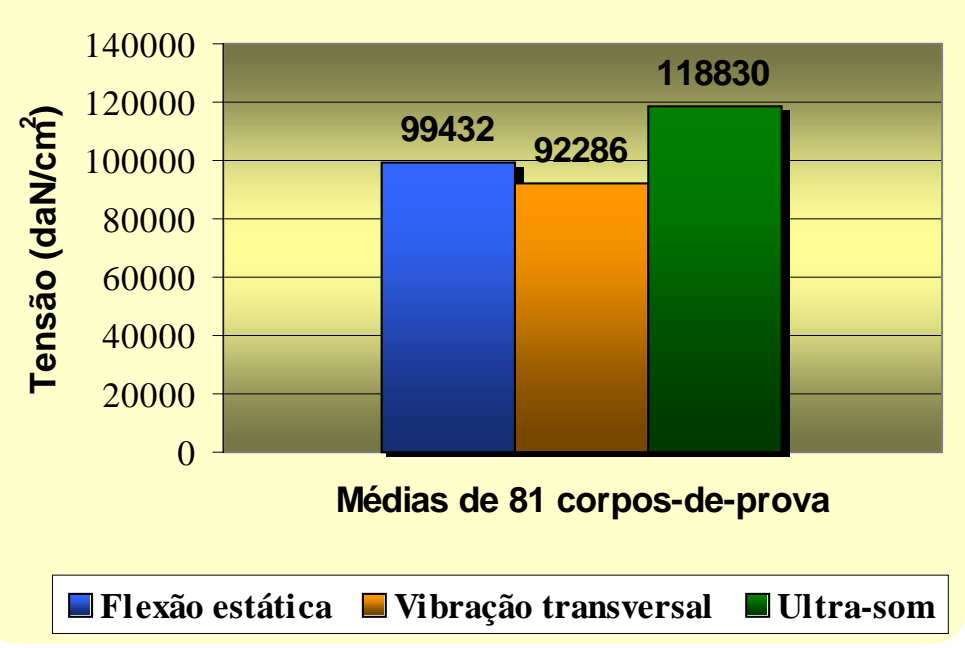

Figura 42 - Médias dos ensaios

\subsubsection{Flexão estática versus vibração transversal}

Neste estudo foi realizada a correlação dos valores encontrados nos ensaios de flexão estática e de vibração transversal. A figura 43 mostra os resultados obtidos. 


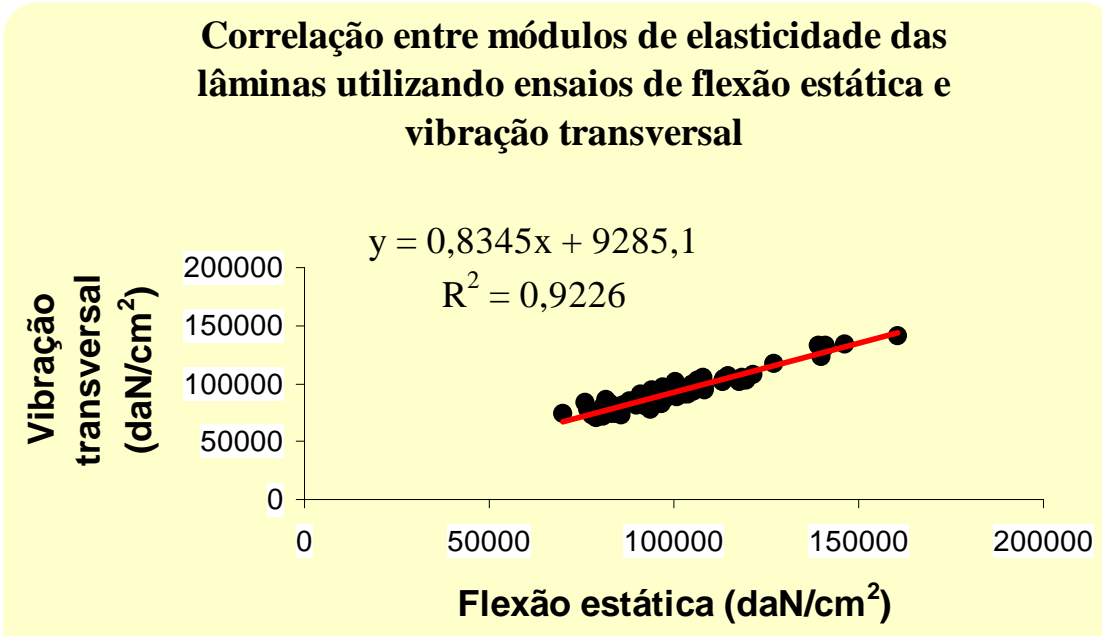

Figura 43 - Correlação para as lâminas: flexão x vibração

Nesta avaliação obteve-se o valor de 0,9226 para $\mathrm{R}^{2}$, muito próximo de 1 , indicando uma forte correlação entre os valores de módulos de elasticidade obtidos nos ensaios de flexão estática e de vibração transversal.

\subsubsection{Flexão estática versus ultra-som}

Aqui o mesmo procedimento é repetido para a correlação entre os resultados obtidos nos ensaios de flexão estática e de ultra-som. A seguir os dados são apresentados.

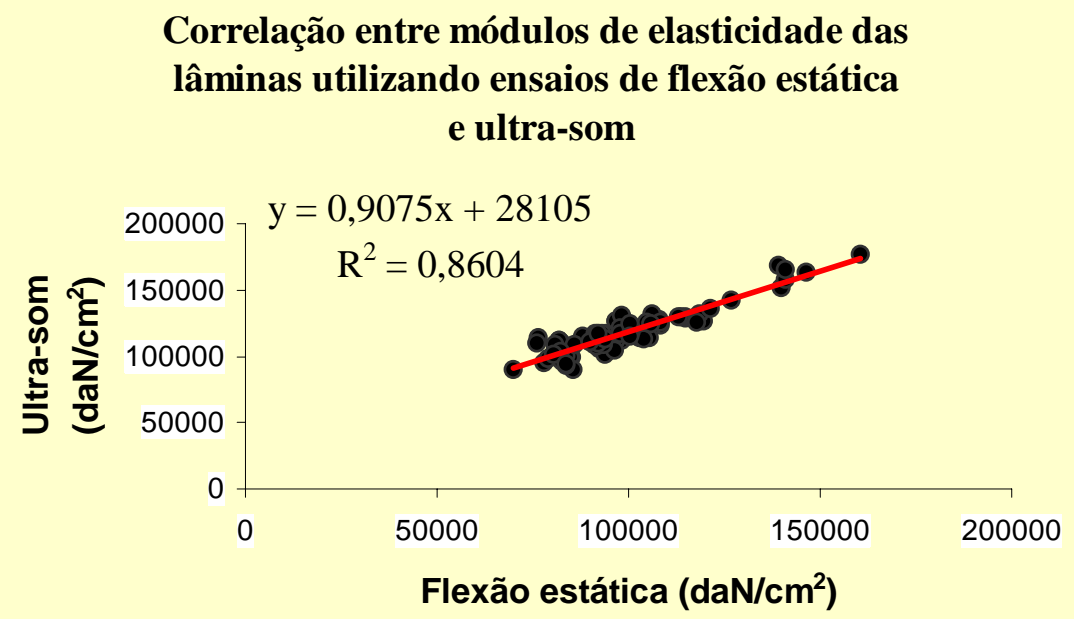

Figura 44 - Correlação para as lâminas: flexão x ultra-som 
Para esta correlação, o valor encontrado para $R^{2}$ foi de 0,8604 , indicando uma boa correlação para os valores obtidos nos ensaios de flexão estática das lâminas e de ultra-som.

\subsubsection{Vibração transversal versus ultra-som}

Aqui é feita a correlação para os valores obtidos nestes ensaios, com a figura seguinte mostrando os resultados.

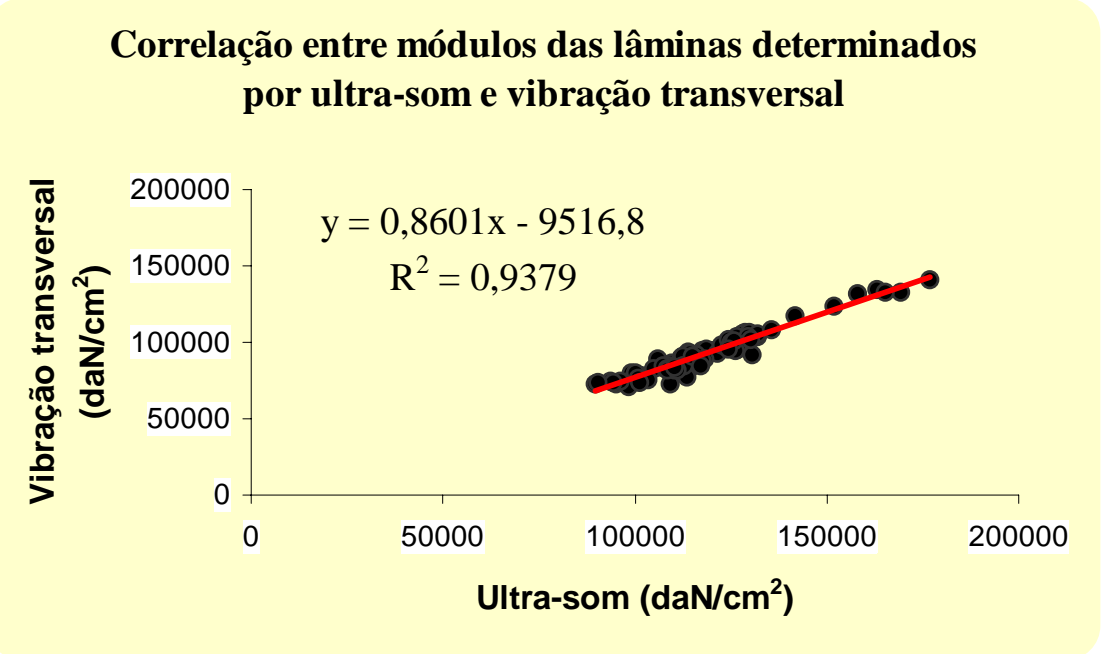

Figura 45 - Correlação para as lâminas: ultra-som x vibração

Neste caso obteve-se o maior valor para o parâmetro $\mathrm{R}^{2}$, ou seja, 0,9379. Tal resultado, muito próximo de 1 , indica uma forte correlação entre os valores obtidos nos ensaios de ultra-som e de vibração transversal.

\subsection{Resultados obtidos para as vigas}

A partir dos valores dos módulos de elasticidade das lâminas (tabela 10), procedeu-se à distribuição dessas para a construção das vigas. Como já citado anteriormente, as peças estruturais foram moldadas com dois tipos de distribuição de lâminas, dois tipos de adesivos e duas intensidades de pressão de colagem. Foi adotada uma simbologia para a identificação das vigas: 
NA - montadas com distribuição não-aleatória de lâminas;

A - montadas com distribuição aleatórias de lâminas;

1 - réplica número 1 ;

2 - réplica número 2;

$\mathrm{C}$ - coladas com adesivo Cascophen;

$\mathrm{M}$ - coladas com adesivo à base de mamona;

0,8 - viga colada com intensidade de pressão de $0,8 \mathrm{MPa}$

1,2 - viga colada com intensidade de pressão de 1,2 MPa.

Assim, por exemplo, uma peça montada com distribuição não-aleatória de lâminas, sendo a primeira de duas réplicas colada com Cascophen, e unida com pressão de 0,8 $\mathrm{MPa}$, tem a seguinte identificação: NA 1 C 0,8 .

As médias calculadas foram obtidas de acordo com as equações (3) para média aritmética simples e (4) para média ponderada. A seguir, são apresentados os cálculos para a viga A 1 C 0,8 .

\begin{tabular}{|l|}
\hline 76 \\
\hline 73 \\
\hline 37 \\
\hline 82 \\
\hline 45 \\
\hline 36 \\
\hline
\end{tabular}

92988

146294

106334

118392

100298

114841

\section{Figura 46 - Esquema da viga} sem colar
A figura ao lado ilustra o esquema de montagem da viga $\mathrm{A} 1 \mathrm{C} 0,8$. Os números no interior da seção correspondem aos números de identificação das lâminas que formam a peça estrutural, e os números laterais à seção são os valores dos módulos de elasticidade das lâminas. Assim, a lâmina número 76 possui módulo de elasticidade $92.988 \mathrm{daN} / \mathrm{cm}^{2}$.

Como resultado da média aritmética simples obteve-se:

$$
\begin{gathered}
E_{\text {médio }}=\frac{\sum_{i=1}^{n} E_{i}}{n} \\
E_{\text {médio }}=\frac{92988+146294+106334+118392+100298+114841}{6}=113191 \mathrm{daN} / \mathrm{cm}^{2}
\end{gathered}
$$


Para o cálculo da média ponderada foram feitas as seguintes etapas:

1) Determinação de uma nova posição do centro de gravidade:

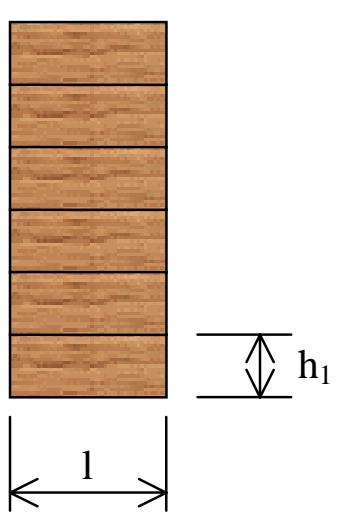

2) Cálculo das novas áreas das seções:

$$
\begin{array}{ll}
\mathrm{A}_{1}=1 * \mathrm{~h}_{1}=5,7 * 1,9=10,8 \mathrm{~cm}^{2} ; & \mathrm{A}_{4}=\mathrm{l}_{4} * \mathrm{~h}_{1}=6,2 * 1,9=11,8 \mathrm{~cm}^{2} ; \\
\mathrm{A}_{2}=1_{2} * \mathrm{~h}_{1}=6,5 * 1,9=12,4 \mathrm{~cm}^{2} ; & \mathrm{A}_{5}=1_{5} * \mathrm{~h}_{1}=4,5 * 1,9=8,5 \mathrm{~cm}^{2} ; \\
\mathrm{A}_{3}=1_{3} * \mathrm{~h}_{1}=5,5 * 1,9=10,5 \mathrm{~cm}^{2} ; & \mathrm{A}_{6}=1_{6} * \mathrm{~h}_{1}=7,0 * 1,9=13,3 \mathrm{~cm}^{2} .
\end{array}
$$

$$
\begin{aligned}
& 1=5,7 \mathrm{~cm} \quad \mathrm{~h}_{1}=1,9 \mathrm{~cm} \\
& 1_{2}=\mathrm{E}_{1} / \mathrm{E}_{2} * 1=114841 / 100298 * 5,7=6,5 \mathrm{~cm} \\
& 1_{3}=\mathrm{E}_{1} / \mathrm{E}_{3} * 1=114841 / 118392 * 5,7=5,5 \mathrm{~cm} \\
& 1_{4}=\mathrm{E}_{1} / \mathrm{E}_{4} * 1=114841 / 106334 * 5,7=6,2 \mathrm{~cm} \\
& 1_{5}=\mathrm{E}_{1} / \mathrm{E}_{5} * 1=114841 / 146294 * 5,7=4,5 \mathrm{~cm} \\
& 1_{6}=\mathrm{E}_{1} / \mathrm{E}_{6} * 1=114841 / 92988 * 5,7=7,0 \mathrm{~cm}
\end{aligned}
$$

3) Nova posição do centro de gravidade: 


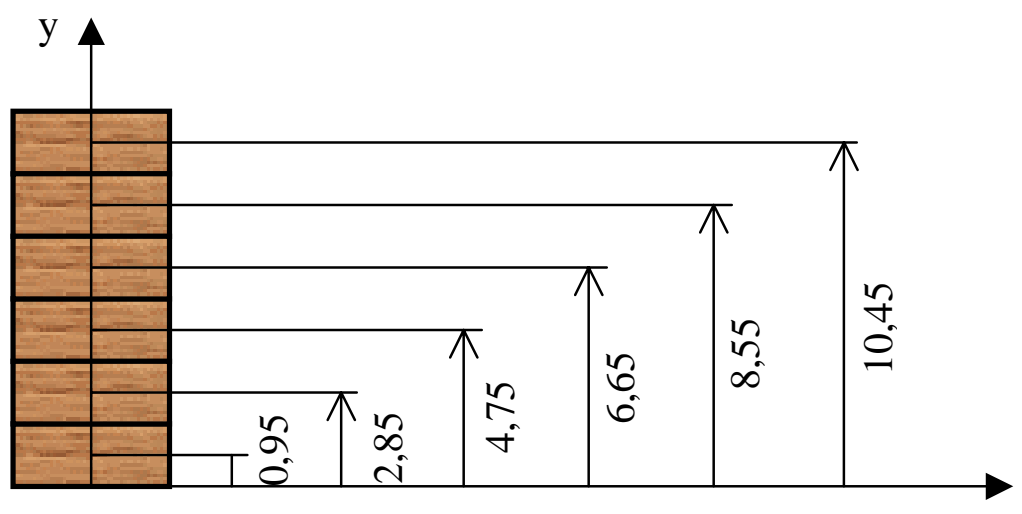

$$
y_{c g}=\frac{\sum_{i=1}^{n} y_{i} A_{i}}{A_{i}} \longrightarrow y_{c g}=5,73 \mathrm{~cm}
$$

$$
I_{i}=\frac{b \cdot h^{3}}{12}+b \cdot h \cdot\left(y_{c g}-y_{i}\right)^{2} \quad\left\{\begin{array}{l}
\mathrm{I}_{1}=251 \mathrm{~cm}^{4} \\
\mathrm{I}_{2}=93 \mathrm{~cm}^{4} \\
\mathrm{I}_{3}=14 \mathrm{~cm}^{4} \\
\mathrm{I}_{4}=12 \mathrm{~cm}^{4} \\
\mathrm{I}_{5}=89 \mathrm{~cm}^{4} \\
\mathrm{I}_{6}=245 \mathrm{~cm}^{4}
\end{array}\right.
$$


4) Determinação da média do módulo de elasticidade ponderada:

$$
\begin{gathered}
E_{p}=\frac{\sum_{i=1}^{n} E_{i} \cdot I_{i}}{\sum_{i=1}^{n} I_{i}} \\
E_{p}=\frac{114841 * 251+100298 * 93+118392 * 14+106334 * 12+146294 * 89+92988 * 245}{251+93+14+12+89+245} \\
E_{p}=109237 \mathrm{daN} / \mathrm{cm}^{2}
\end{gathered}
$$

Assim, para a viga A 1 C 0,8 foram determinados os valores de $113.191 \mathrm{daN} / \mathrm{cm}^{2}$ para a média aritmética simples e de $109.237 \mathrm{daN} / \mathrm{cm}^{2}$ para a média ponderada. Este procedimento foi feito para as 16 vigas.

\subsubsection{Disposição das lâminas nas vigas}

As distribuições das lâminas nas seções das vigas são mostradas nos esquemas seguintes. Destacado na cor laranja, tem-se o número da lâmina e, ao lado, o valor do módulo de elasticidade obtido por meio de ensaio de flexão estática da mesma, em $\mathrm{daN} / \mathrm{cm}^{2}$.

NA 1 C 0,8

\begin{tabular}{|c|c|}
\hline 28 & 125952 \\
\hline 15 & 111298 \\
\hline 31 & 93656 \\
\hline 25 & 101828 \\
\hline 1 & 118062 \\
\hline 27 & 156327 \\
\hline
\end{tabular}

47-a)

NA 1 C 1,2

\begin{tabular}{|c|c|}
\hline 106 & 105844 \\
\hline 57 & 96212 \\
\hline 65 & 88001 \\
\hline 112 & 91873 \\
\hline 55 & 98154 \\
\hline 33 & 139201 \\
\hline
\end{tabular}

47 e)
NA 2 C 0,8

\begin{tabular}{|c|c|}
\hline 4 & 129251 \\
\hline 8 & 111548 \\
\hline 13 & 96315 \\
\hline 23 & 105535 \\
\hline 21 & 122076 \\
\hline 10 & 153298 \\
\hline
\end{tabular}

47 b)

NA 2 C 1,2

\begin{tabular}{|c|c|}
\hline 41 & 102996 \\
\hline 96 & 92988 \\
\hline 44 & 85067 \\
\hline 9 & 90928 \\
\hline 38 & 96912 \\
\hline 20 & 111298 \\
\hline
\end{tabular}

$47 \mathrm{f})$
NA 1 M 0,8

\begin{tabular}{|c|c|}
\hline 12 & 126348 \\
\hline 29 & 111548 \\
\hline 18 & 95934 \\
\hline 32 & 102758 \\
\cline { 2 - 2 } 24 & 120789 \\
\hline 26 & 148810 \\
\hline
\end{tabular}

47 c)

NA 1 M 1,2

\begin{tabular}{|c|c|}
\hline 58 & 104817 \\
\hline 101 & 93748 \\
\hline 99 & 86023 \\
\hline 66 & 91143 \\
\hline 61 & 97737 \\
\hline 102 & 113144 \\
\hline
\end{tabular}

$47 \mathrm{~g})$
NA 2 M 0,8

\begin{tabular}{|c|c|}
\hline 11 & 129608 \\
\hline & 113002 \\
\hline 3 & 99876 \\
\hline & 108885 \\
\hline & 125161 \\
\hline & 153298 \\
\hline
\end{tabular}

47 d)

NA 2 M 1,2

\begin{tabular}{|c|c|}
\hline 93 & 100298 \\
\hline 53 & 92242 \\
\hline 22 & 84353 \\
\hline 85 & 90783 \\
\hline 70 & 96912 \\
\hline & 106334 \\
\hline
\end{tabular}

$47 \mathrm{~h})$ 
A 1 C 0,8

\begin{tabular}{|c|c|}
\hline 76 & 92988 \\
\hline 73 & 146294 \\
\hline 37 & 106334 \\
\hline 82 & 118392 \\
\hline 45 & 100298 \\
\hline 36 & 114841 \\
\hline
\end{tabular}

47 i)

A $1 \mathrm{C} 1,2$

\begin{tabular}{|c|c|}
\hline 78 & 91507 \\
\hline 69 & 98154 \\
\hline 56 & 85633 \\
\hline 77 & 105358 \\
\hline 5 & 96465 \\
\hline 59 & 139692 \\
\hline
\end{tabular}

$47 \mathrm{~m})$
A $2 \mathrm{C} 0,8$

\begin{tabular}{|c|c|}
\hline 97 & 104877 \\
\hline 88 & 160616 \\
\hline 84 & 121525 \\
\hline 91 & 108340 \\
\hline 34 & 94132 \\
\hline 17 & 116798 \\
\hline
\end{tabular}

47 j)

A 2 C 1,2

\begin{tabular}{|c|c|}
\hline 90 & 83825 \\
\hline 40 & 92242 \\
\hline 64 & 102536 \\
\hline 42 & 96912 \\
\hline 54 & 90783 \\
\hline 47 & 107832 \\
\hline
\end{tabular}

$47 \mathrm{n})$
A $1 \mathrm{M} 0,8$

\begin{tabular}{|c|c|}
\hline 83 & 100737 \\
\hline 43 & 93748 \\
\hline 60 & 140909 \\
\hline 108 & 83825 \\
\hline 39 & 108340 \\
\hline 81 & 119626 \\
\hline
\end{tabular}

$47 \mathrm{k})$

A 1 M 1,2

\begin{tabular}{|c|c|}
\hline 72 & 97737 \\
\hline 48 & 84753 \\
\hline 75 & 114841 \\
\hline 105 & 91143 \\
\hline 79 & 103928 \\
\hline 89 & 93366 \\
\hline
\end{tabular}

47 o)
A $2 \mathrm{M} 0,8$

\begin{tabular}{|c|c|}
\hline 92 & 113704 \\
\hline 49 & 82619 \\
\hline 110 & 140909 \\
\hline 74 & 126896 \\
\hline 51 & 106334 \\
\hline 35 & 98154 \\
\hline
\end{tabular}

47 l)

A 2 M 1,2

\begin{tabular}{|c|c|}
\hline 95 & 91873 \\
\hline 109 & 89719 \\
\hline 86 & 83521 \\
\hline 71 & 96505 \\
\hline 67 & 106334 \\
\hline 94 & 100298 \\
\hline \multicolumn{2}{|c}{$\mathbf{4 7} \mathbf{p})$}
\end{tabular}

Figura 47 - Distribuição das lâminas nas vigas

\subsubsection{Valores calculados}

A tabela 13 apresenta a identificação da viga, sua média aritmética simples para o módulo de elasticidade ( $\mathrm{E}_{\text {médio }}$, o desvio padrão da mesma (DP) e seu coeficiente de variação $(\mathrm{CV})$, mostrando também a média ponderada $\left(\mathrm{E}_{\mathrm{p}}\right)$ e a diferença, em porcentagem, da relação entre a média ponderada e a média simples. Vale ressaltar que $E_{\text {médio }}$ e $E_{p}$ (expressos em daN/ $\mathrm{cm}^{2}$ ) são valores calculados para estimação dos números a serem obtidos nos ensaios. 
Tabela 13 - Resultados calculados obtidos para as vigas

\begin{tabular}{|c|c|c|c|c|c|}
\hline Viga & $\mathrm{E}_{\text {médio }}$ & $\mathrm{DP}$ & $\mathrm{CV}$ & $\mathrm{E}_{\mathrm{p}}$ & Diferença* \\
\hline NA 1 C 0,8 & 117854 & 22051 & 0,19 & 133592 & $13,35 \%$ \\
\hline NA 2 C 0,8 & 119671 & 20197 & 0,17 & 134209 & $12,15 \%$ \\
\hline NA 1 C 1,2 & 103214 & 18637 & 0,18 & 115724 & $12,12 \%$ \\
\hline NA 2 C 1,2 & 96698 & 9330 & 0,10 & 103420 & $6,95 \%$ \\
\hline NA 1 M 0,8 & 117698 & 18905 & 0,16 & 131264 & $11,53 \%$ \\
\hline NA 2 M 0,8 & 121638 & 18916 & 0,16 & 135090 & $11,06 \%$ \\
\hline NA 1 M 1,2 & 97769 & 9840 & 0,10 & 104932 & $7,33 \%$ \\
\hline NA 2 M 1,2 & 95154 & 7730 & 0,08 & 100580 & $5,70 \%$ \\
\hline A 1 C 0,8 & 113191 & 18692 & 0,17 & 109237 & $-3,49 \%$ \\
\hline A 2 C 0,8 & 117715 & 23086 & 0,20 & 116037 & $-1,42 \%$ \\
\hline A 1 C 1,2 & 102802 & 19243 & 0,19 & 112452 & $9,39 \%$ \\
\hline A 2 C 1,2 & 95688 & 8632 & 0,09 & 95445 & $-0,25 \%$ \\
\hline A 1 M 0,8 & 107864 & 20290 & 0,19 & 108181 & $0,29 \%$ \\
\hline A 2 M 0,8 & 111436 & 20716 & 0,19 & 103992 & $-6,68 \%$ \\
\hline A 1 M 1,2 & 97628 & 10602 & 0,11 & 95523 & $-2,16 \%$ \\
\hline A 2 M 1,2 & 94708 & 8096 & 0,09 & 96880 & $2,29 \%$ \\
\hline
\end{tabular}

* Diferença, em porcentagem, de $\mathrm{E}_{\mathrm{p}} / \mathrm{E}_{\text {médio }}$

Estudando os dados calculados mostrados, percebe-se que todas as vigas montadas com distribuição não-aleatória de lâminas (NA) apresentam os valores da média ponderada maiores que os valores da média aritmética simples. A diferença variou de $5,70 \%$ a $13,35 \%$. Tal fato se explica pelas distribuições de lâminas com maiores módulos de elasticidade nas regiões mais solicitadas da peça, sendo que estas últimas têm maior contribuição no momento de inércia final do elemento estrutural. Para as vigas com distribuição aleatória pode-se dizer que não existe um padrão: três tiveram os valores dos módulos de elasticidade ponderados acima dos valores obtidos com a média simples, e as demais apresentaram valores de $\mathrm{E}_{\mathrm{p}}$ abaixo dos valores de $\mathrm{E}_{\text {médio. }}$. 


\subsubsection{Valores obtidos nos ensaios}

Assim como com as lâminas, as vigas tiveram seus módulos de elasticidade determinados por meio de ensaios de flexão estática e de vibração transversal, e suas constantes dinâmicas por meio de ultra-som.

\subsubsection{Flexão estática}

Foram realizados ensaios de quatro pontos nas peças estruturais, seguindo-se o esquema da figura 35 e os parâmetros genéricos da NBR 7190:1997 e ASTM D198:1984. As vigas montadas com suas lâminas distribuídas aleatoriamente foram ensaiadas duas vezes, ora com determinada lâmina voltada para baixo, ora com determinada lâmina voltada para cima. Isso foi feito com o objetivo de estudar o comportamento da peça em ambas as situações, pois poderia acontecer, pela aleatoriedade, dos módulos estarem “desbalanceados”, ou seja, um lado da viga ser mais resistente às ações do que outro lado. $\mathrm{O}$ mesmo procedimento foi repetido para a viga NA 1 C 1,2 (escolhida ao acaso para representar as não-aleatórias) para confirmar que esta tivesse um comportamento parecido em ambas as situações de solicitação Os valores dos módulos $\left(\mathrm{em} \mathrm{daN} / \mathrm{cm}^{2}\right.$ ) são apresentados na tabela 14 e foram calculados pela expressão (5). 
Tabela 14 - Valores obtidos por ensaios de flexão estática

\begin{tabular}{|c|c|c|}
\hline Viga & Particularidade & $\mathrm{E}$ \\
\hline NA $1 \mathrm{C} 0,8$ & lâmina 27 embaixo & 115435 \\
\hline NA 2 C 0,8 & lâmina 10 embaixo & 119658 \\
\hline \multirow{2}{*}{ NA 1 C 1,2} & lâmina 33 embaixo & 116615 \\
\hline & lâmina 33 em cima & 114759 \\
\hline NA 2 C 1,2 & lâmina 20 embaixo & 100174 \\
\hline NA $1 \mathrm{M} 0,8$ & lâmina 26 embaixo & 108349 \\
\hline NA 2 M 0,8 & lâmina 07 embaixo & 112474 \\
\hline NA 1 M 1,2 & lâmina 102 embaixo & 123071 \\
\hline NA 2 M 1,2 & lâmina 52 embaixo & 108364 \\
\hline \multirow{2}{*}{ A 1 C 0,8} & lâmina 36 embaixo & 106119 \\
\hline & lâmina 36 em cima & 105802 \\
\hline \multirow{2}{*}{ A 2 C 0,8} & lâmina 17 embaixo & 117518 \\
\hline & lâmina 17 em cima & 121393 \\
\hline \multirow{2}{*}{ A 1 C 1,2} & lâmina 59 embaixo & 113120 \\
\hline & lâmina 59 em cima & 114040 \\
\hline \multirow{2}{*}{ A 2 C 1,2} & lâmina 47 embaixo & 98689 \\
\hline & lâmina 47 em cima & 97463 \\
\hline \multirow{2}{*}{ A $1 \mathrm{M} 0,8$} & lâmina 81 embaixo & 102557 \\
\hline & lâmina 81 em cima & 104086 \\
\hline \multirow{2}{*}{ A 2 M 0,8} & lâmina 35 embaixo & 105055 \\
\hline & lâmina 35 em cima & 102149 \\
\hline \multirow{2}{*}{ A 1 M 1,2 } & lâmina 89 embaixo & 87134 \\
\hline & lâmina 89 em cima & 89277 \\
\hline \multirow{2}{*}{ A 2 M 1,2 } & lâmina 94 embaixo & 97574 \\
\hline & lâmina 94 em cima & 96560 \\
\hline
\end{tabular}

Sentido de aplicação da força

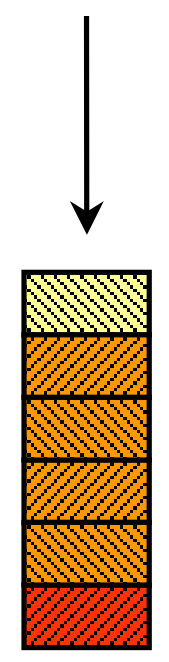

Lâmina em cima Lâmina embaixo

Os valores destacados em negrito foram os adotados para uso do programa estatístico para a análise dos dados, sendo o critério para a escolha desses números a posição da lâmina (embaixo) na seção da viga. Como diferença percentual entre o valor do módulo de elasticidade da lâmina posicionada embaixo em relação ao valor da lâmina posicionada em cima, tem-se para a viga NA 1 C 1,2 o valor de 1,6\%, e para as demais, que apresentam distribuição aleatória, os percentuais tiveram uma variação entre $-3,2 \%$ a 2,8\%. Em todos os casos, os valores percentuais foram muito 
baixos, e a diferença pode ser explicada pela baixa heterogeneidade do material de cada uma das lâminas ensaiadas.

\subsubsection{Vibração transversal}

No ensaio de vibração transversal, os valores dos módulos de elasticidade das peças foram obtidos diretamente, ou seja, o programa computacional que compõe o aparelho fornece os números já calculados. Na tabela seguinte são apresentados os valores de módulo de elasticidade para cada viga, obtidos na saída de dados.

Tabela 15 - Valores obtidos nos ensaios de vibração transversal

\begin{tabular}{|c|c|}
\hline Viga & $E_{\text {v.t. }}^{1}$ \\
\hline NA 1 C 0,8 & 109300 \\
\hline NA 2 C 0,8 & 108500 \\
\hline NA 1 C 1,2 & 110900 \\
\hline NA 2 C 1,2 & 104300 \\
\hline NA 1 M 0,8 & 100200 \\
\hline NA 2 M 0,8 & 98300 \\
\hline NA 1 M 1,2 & 114300 \\
\hline NA 2 M 1,2 & 98900 \\
\hline A 1 C 0,8 & 108700 \\
\hline A 2 C 0,8 & 117600 \\
\hline A 1 C 1,2 & 115800 \\
\hline A 2 C 1,2 & 99900 \\
\hline A 1 M 0,8 & 107900 \\
\hline A 2 M 0,8 & 102100 \\
\hline A 1 M 1,2 & 92300 \\
\hline A 2 M 1,2 & 105400 \\
\hline
\end{tabular}

1) Valores em daN/cm ${ }^{2}$

\subsubsection{Ultra-som}

As respostas apresentadas na tabela 16 foram calculadas pela equação (2). O aparelho forneceu o tempo utilizado pela onda para percorrer as dimensões longitudinais das peças, medido em micro-segundos. 
Tabela 16 - Valores obtidos em ensaios por ultra-som

\begin{tabular}{|c|c|c|c|}
\hline Viga & Densidade $^{(1)}$ & Leitura* $^{*}$ & $\mathrm{C}_{\mathrm{LL}}{ }^{(2)}$ \\
\hline NA 1 C 0,8 & 600 & 673 & 112950 \\
\hline NA 2 C 0,8 & 592 & 658 & 116583 \\
\hline NA 1 C 1,2 & 697 & 719 & 119731 \\
\hline NA 2 C 1,2 & 665 & 741 & 107552 \\
\hline NA 1 M 0,8 & 596 & 693 & 105815 \\
\hline NA 2 M 0,8 & 615 & 685 & 111753 \\
\hline NA 1 M 1,2 & 710 & 715 & 123333 \\
\hline NA 2 M 1,2 & 695 & 746 & 110902 \\
\hline A 1 C 0,8 & 710 & 705 & 126856 \\
\hline A 2 C 0,8 & 682 & 680 & 130978 \\
\hline A 1 C 1,2 & 683 & 731 & 113506 \\
\hline A 2 C 1,2 & 684 & 750 & 107986 \\
\hline A 1 M 0,8 & 703 & 729 & 117472 \\
\hline A 2 M 0,8 & 718 & 694 & 132385 \\
\hline A 1 M 1,2 & 690 & 746 & 110104 \\
\hline A 2 M 1,2 & 699 & 764 & 106346 \\
\hline
\end{tabular}

1) Valores em $\mathrm{kg} / \mathrm{m}^{3} \quad *$ Média de 3 leituras

2) Valores em daN/cm ${ }^{2}$

\subsubsection{Análise dos resultados}

Para verificação da influência das variáveis (distribuição, adesivo e pressão) nas respostas (módulos de elasticidade) das vigas, foi feita uma análise estatística fatorial. As respostas adotadas foram as obtidas nos ensaios de flexão estática de quatro pontos. Para comparação dos métodos de ensaios e também destes em relação aos valores calculados, foram feitas correlações dos valores e análises de variância das médias dos módulos das dezesseis vigas. Tanto a análise fatorial como a análise de variância foram feitas no programa MINITAB. 


\subsubsection{Análise fatorial}

Com uso da sub-rotina DOE/fatorial, fez-se a verificação das influências dos efeitos principais, avulsos e também relacionados, sobre as respostas. Mas para que estas análises sejam feitas, é preciso fazer uma verificação da adequabilidade do modelo, ou seja, verificar se as suposições de igualdade de variância e de normalidade se cumprem. Essa verificação pode ser feita por análises de gráficos. A tabela 17 traz, na coluna resposta, os resultados obtidos nos ensaios, as colunas distribuição, adesivo e pressão compõem a matriz planejamento fatorial, e nas três últimas colunas são mostrados os valores estimados, os resíduos e os escores normais.

Tabela 17 - Resultados obtidos nos ensaios, matriz planejamento, valores estimados, resíduos e escores normais.

\begin{tabular}{|c|c|c|c|c|c|c|}
\hline Resposta & Distribuição & Adesivo & Pressão & Estimados & Resíduos & E. normais \\
\hline 115435 & -1 & -1 & -1 & 117547 & $-2111,36$ & $-0,39573$ \\
\hline 119658 & -1 & -1 & -1 & 117547 & 2111,36 & 0,39573 \\
\hline 106119 & 1 & -1 & -1 & 111819 & $-5699,39$ & $-0,76184$ \\
\hline 117518 & 1 & -1 & -1 & 111819 & 5699,39 & 0,76184 \\
\hline 108349 & -1 & 1 & -1 & 110411 & $-2062,69$ & $-0,23349$ \\
\hline 112474 & -1 & 1 & -1 & 110411 & 2062,69 & 0,23349 \\
\hline 102557 & 1 & 1 & -1 & 103806 & $-1248,86$ & $-0,0772$ \\
\hline 105055 & 1 & 1 & -1 & 103806 & 1248,86 & 0,0772 \\
\hline 116615 & -1 & -1 & 1 & 108395 & 8220,12 & 1,76883 \\
\hline 100174 & -1 & -1 & 1 & 108395 & $-8220,12$ & $-1,76883$ \\
\hline 113120 & 1 & -1 & 1 & 105905 & 7215,17 & 0,98815 \\
\hline 98689 & 1 & -1 & 1 & 105905 & $-7215,17$ & $-0,98815$ \\
\hline 123071 & -1 & 1 & 1 & 115718 & 7353,84 & 1,28155 \\
\hline 108364 & -1 & 1 & 1 & 115718 & $-7353,84$ & $-1,28155$ \\
\hline 87134 & 1 & 1 & 1 & 92354 & $-5220,08$ & $-0,56918$ \\
\hline 97574 & 1 & 1 & 1 & 92354 & 5220,08 & 0,56918 \\
\hline
\end{tabular}

O gráfico seguinte tem em seu eixo das ordenadas os resíduos e em seu eixo das abscissas os valores estimados. Esse tipo de gráfico, segundo Martinez (2001), é utilizado para avaliar a suposição de igualdade de variância. 


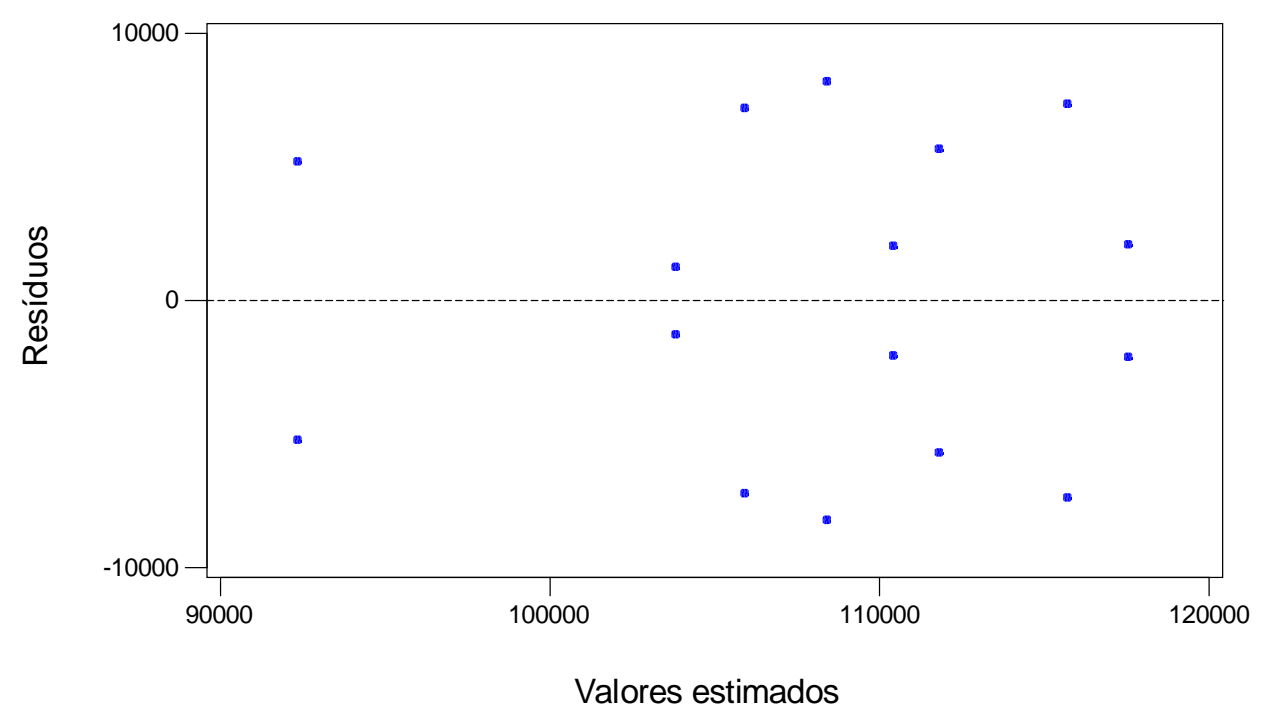

Figura 48 - Gráfico dos resíduos contra valores estimados da tabela 17

Pela observação da figura 48, pode-se dizer que os dados apresentam equivalência de variância, uma vez que a dispersão dos resíduos não revela um padrão óbvio e também não apresenta características da variância diminuir ou aumentar, como os gráficos que apresentam forma de "funil".

Para a verificação da distribuição normal, são feitos os gráficos de probabilidade normal e também de escores normais, como nas figuras seguintes: 


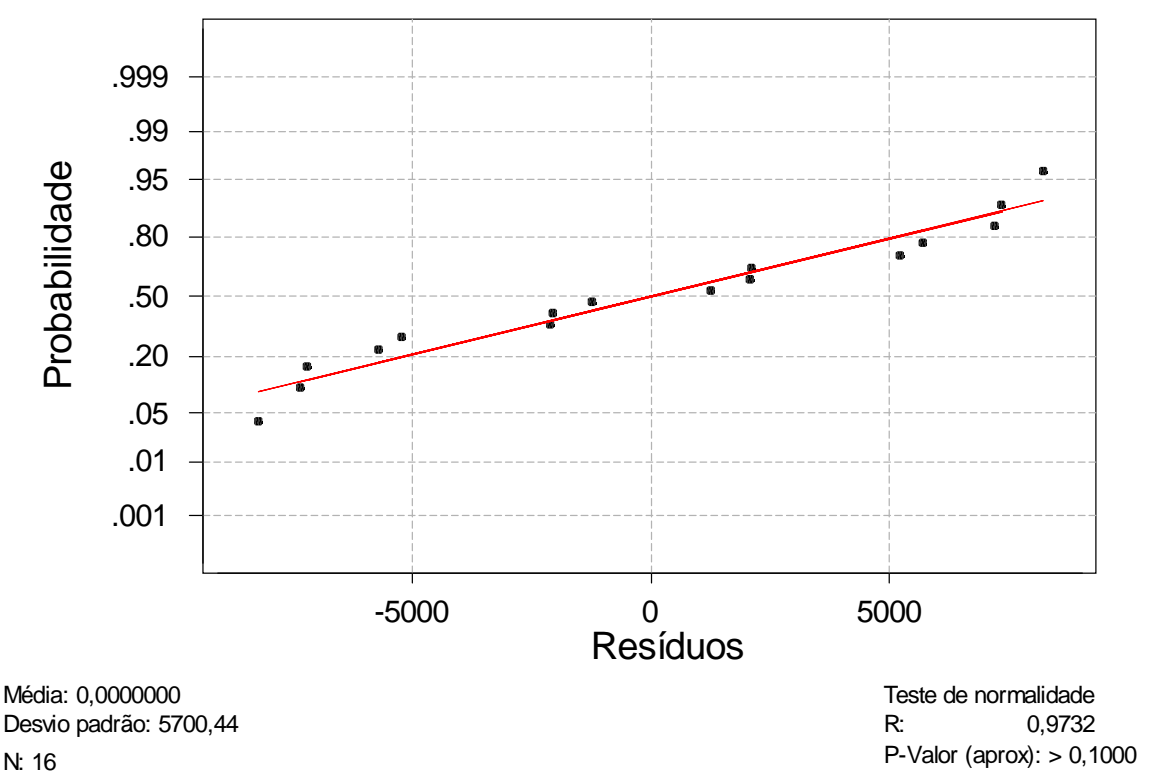

Figura 49 - Gráfico de probabilidade normal para os resíduos da tabela 17

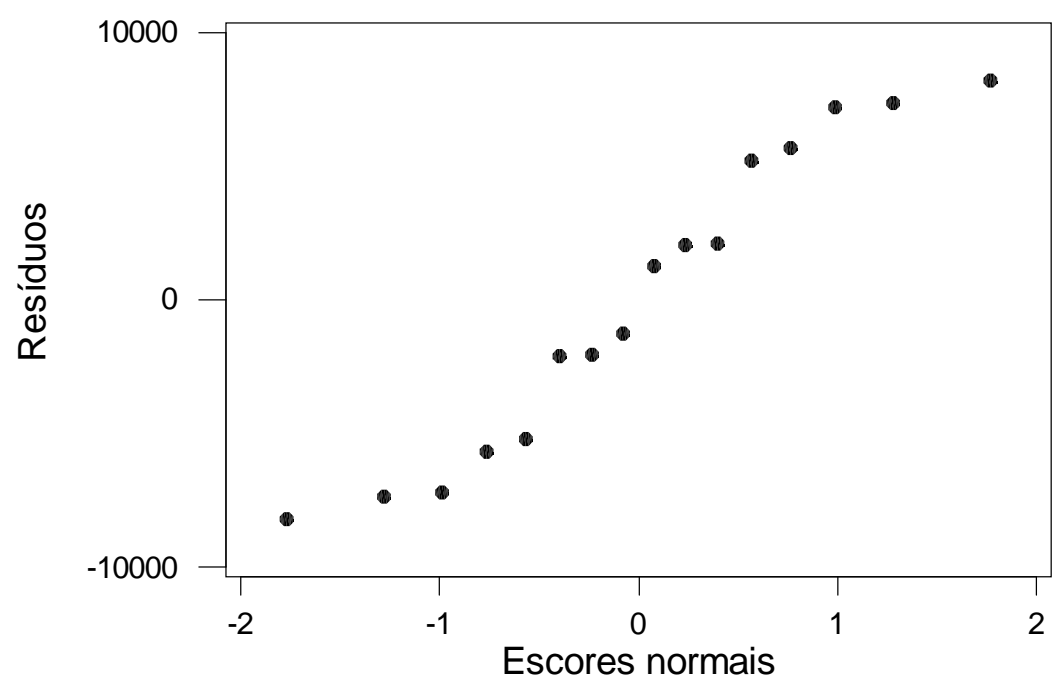

Figura 50 - Gráfico dos resíduos contra os escores normais (tabela 17)

Nas figuras anteriores, pode-se observar comportamento tendendo a linear, apontando que os resíduos seguem uma distribuição normal aproximada. 
Verificado o modelo, foi feita a análise dos efeitos das variáveis.

\begin{tabular}{|lcc|}
\hline \multicolumn{2}{|c|}{ Resposta versus distribuição, adesivo, pressão } \\
\hline Termo & Efeito & p-valor \\
\hline Distribuição & -9547 & 0,040 \\
Adesivo & -5344 & 0,208 \\
Pressão & -5303 & 0,211 \\
Distribuição * adesivo & -5438 & 0,201 \\
Distribuição * pressão & -3380 & 0,412 \\
Adesivo * pressão & 2230 & 0,583 \\
Distribuição * adesivo * pressão & -4999 & 0,236 \\
\end{tabular}

\section{Figura 51- Dados obtidos na análise fatorial}

A partir da figura 51, pode-se afirmar que somente o efeito principal "distribuição" influenciou na resposta, uma vez que seu p-valor é o único menor que 0,05. Os demais (adesivo, pressão e suas combinações, inclusive com a distribuição) não se enquadraram nessa condição, sendo seus efeitos não-significativos nas respostas. Isso permite concluir que ambos os adesivos (Cascophen e mamona) e ambas as pressões de colagem $(0,8$ e 1,2 $\mathrm{MPa})$ tiveram um comportamento tal que não influenciaram nas respostas finais dos módulos de elasticidade. Quanto à distribuição, seu efeito negativo (-9547) indica que ao passar o ensaio do nível baixo (-1) para o nível alto (1), o valor da resposta diminui. É possível afirmar que as distribuições nãoaleatórias (NA) levaram uma certa vantagem em relação às distribuições aleatórias (A), observando os valores estimados. Tal situação pode ser explicada pelo fato da média dos módulos de elasticidade das vigas com distribuição NA ter sido maior que a média das vigas com distribuição tipo A, o que após os ensaios resultou numa diferença de aproximadamente $9 \%$ em favor das não-aleatórias. 


\subsubsection{Correlações e análises de variância}

Aqui são feitas as correlações dos valores dos módulos obtidos nos ensaios destrutivos e não destrutivos e as análises de variância das médias obtidas nos ensaios e calculadas. A tabela a seguir apresenta os resultados determinados a partir dos três tipos de ensaios realizados.

Tabela 18 - Valores de $\mathbf{E}$ obtidos nos ensaios de flexão estática e vibração transversal e de $C_{L L}$ obtidos nos ensaios de ultra-som

\begin{tabular}{|c|c|c|c|}
\cline { 2 - 4 } \multicolumn{1}{c|}{} & Flexão estática & Vibração transversal & Ultra-som \\
\hline NA 1 C 0,8 & 115435 & 109300 & 112950 \\
\hline NA 2 C 0,8 & 119658 & 108500 & 116583 \\
\hline NA 1 C 1,2 & 116615 & 110900 & 119731 \\
\hline NA 2 C 1,2 & 100174 & 104300 & 107552 \\
\hline NA 1 M 0,8 & 108349 & 100200 & 105815 \\
\hline NA 2 M 0,8 & 112474 & 98300 & 111753 \\
\hline NA 1 M 1,2 & 123071 & 114300 & 123333 \\
\hline NA 2 M 1,2 & 108364 & 98900 & 110902 \\
\hline A 1 C 0,8 & 106119 & 108700 & 126856 \\
\hline A 2 C 0,8 & 117518 & 117600 & 130978 \\
\hline A 1 C 1,2 & 113120 & 115800 & 113506 \\
\hline A 2 C 1,2 & 98689 & 99900 & 107986 \\
\hline A 1 M 0,8 & 102557 & 107900 & 117472 \\
\hline A 2 M 0,8 & 105055 & 102100 & 132385 \\
\hline A 1 M 1,2 & 87134 & 92300 & 110104 \\
\hline A 2 M 1,2 & 97574 & 105400 & 106346 \\
\hline \multicolumn{2}{|c|}{} & 105900 & 115891 \\
\hline Médias & 108244 & 7015 & 8593 \\
\hline DP & 9531 & 0,07 & 0,07 \\
\hline CV & 0,09 & \multicolumn{2}{c}{} \\
\hline
\end{tabular}

Valores em daN/cm ${ }^{2}$

São apresentados, na seqüência, os resultados das correlações dos números dos ensaios de flexão estática versus vibração transversal, flexão estática versus ultrasom e vibração transversal versus ultra-som. 
Correlação entre módulos de elasticidade das vigas utilizando ensaios de flexão estática e de vibração transversal

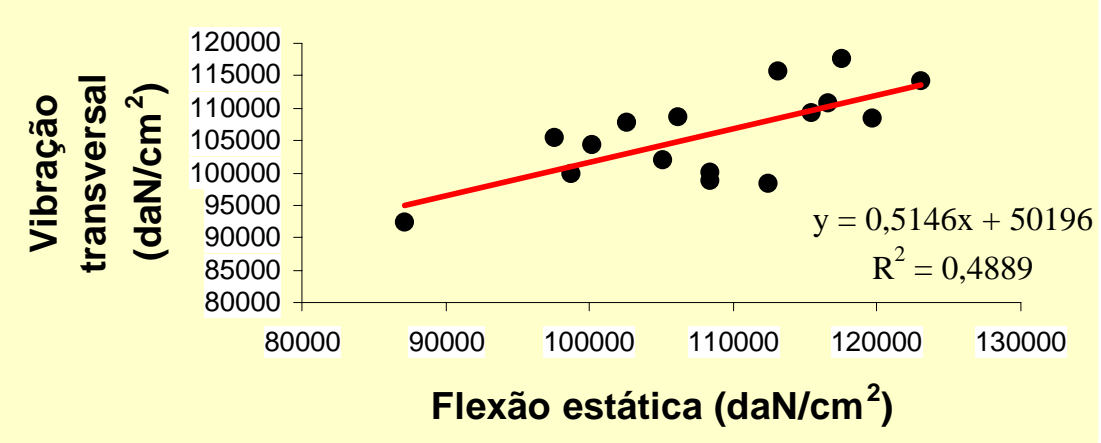

Figura 52 - Correlação para as vigas: flexão $x$ vibração

Correlação entre módulos das vigas utilizando ensaio de flexão estática e ultra-som

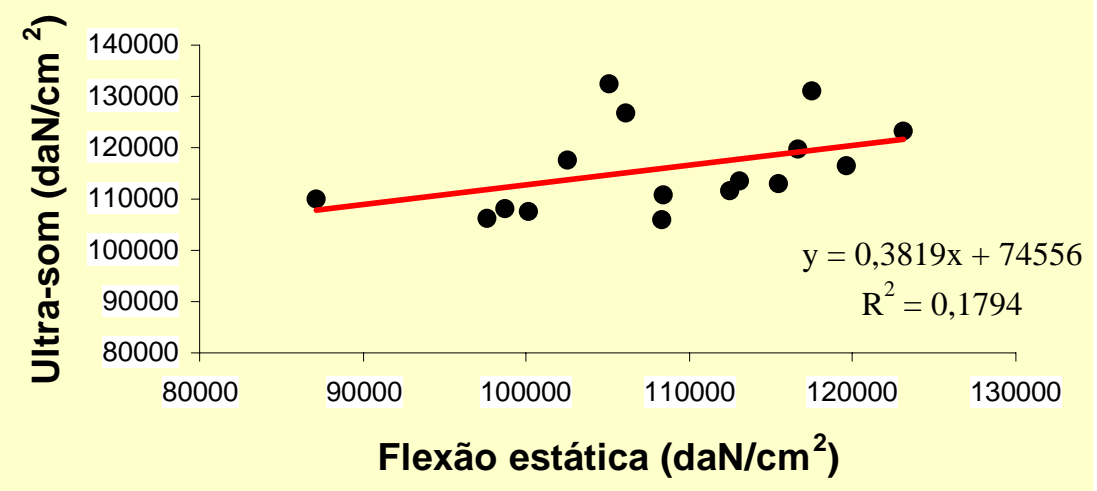

Figura 53 - Correlação para as vigas: flexão x ultra-som 


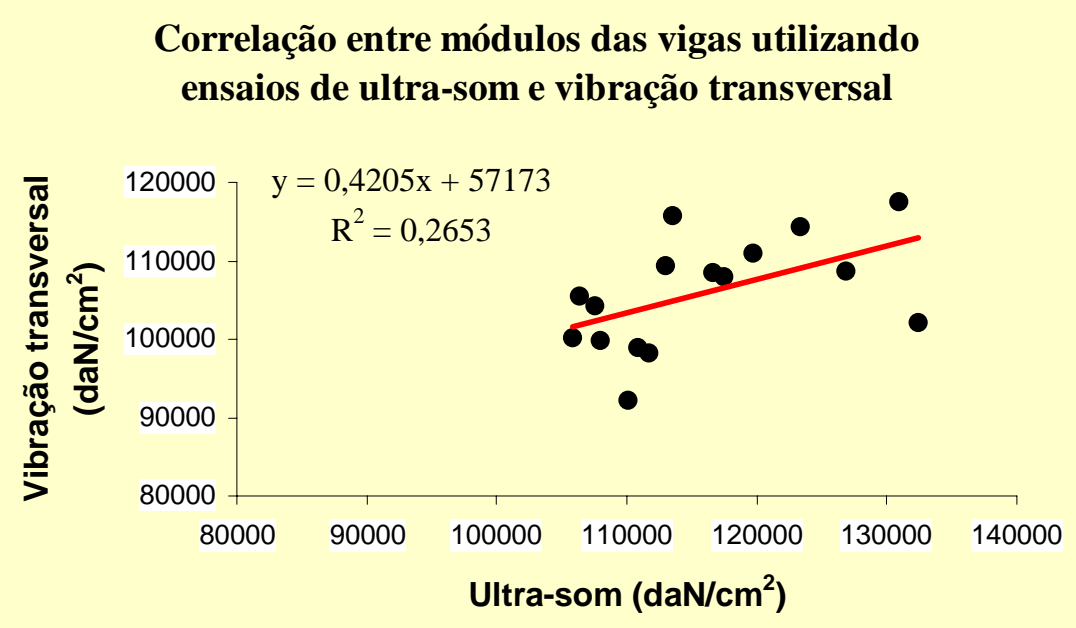

Figura 54 - Correlação para as vigas: ultra-som x vibração

Os resultados das correlações apresentadas nas figuras anteriores apontam para valores baixos se comparados com os valores obtidos nas correlações das lâminas. Para flexão estática versus vibração transversal obteve-se $\mathrm{R}^{2}$ igual a 0,4889 , para flexão estática versus ultra-som o $\mathrm{R}^{2}$ foi de 0,1794 e para vibração transversal versus ultra-som obteve-se o valor de 0,2653 para $\mathrm{R}^{2}$. Percebe-se que os menores valores são oriundos de correlações com ensaios de ultra-som. Uma possível explicação para este fato é o de os transdutores do aparelho Sylvatest terem sido posicionados nas vigas de uma maneira não alinhada, ocorrendo desvios de leitura.

Uma verificação da estimativa do módulo de elasticidade final a partir de valores calculados também foi feita pela análise de variância das médias. Neste caso, o grupo de controle foi o dos valores obtidos nos ensaios estáticos, que foram, então, comparados com os valores calculados. Foram feitas as comparações da média dos ensaios de flexão estática versus valores da média aritmética, e flexão estática versus média ponderada. Também foram feitas as comparações: vibração transversal versus médias aritmética e ponderada, e ultra-som versus médias aritmética e ponderada. Os resultados são mostrados na tabela 19. 
Tabela 19 - Análises de variância das médias dos ensaios versus calculados

\begin{tabular}{|c|c|c|c|c|c|c|}
\hline & Média 1 & Média 2 & $\mathrm{~F}_{\text {observado }}$ & $\mathrm{f}_{\mathrm{c}}$ & $\mathrm{p}$ & Diferença \\
\hline Flexão $^{1} \mathrm{x}$ aritmética ${ }^{2}$ & 108244 & 106921 & 0,15 & 4,171 & 0,705 & $-1,2 \%$ \\
\hline Flexão $^{1}$ x ponderada ${ }^{2}$ & 108244 & 112285 & 0,90 & 4,171 & 0,351 & $3,7 \%$ \\
\hline Vibração $^{1} \mathrm{x}$ aritmética ${ }^{2}$ & 105900 & 106921 & 0,11 & 4,171 & 0,741 & $1,0 \%$ \\
\hline Vibração $^{1}$ x ponderada ${ }^{2}$ & 105900 & 112285 & 2,61 & 4,171 & 0,117 & $6,0 \%$ \\
\hline Ultra-som $^{1} \mathrm{x}$ aritmética ${ }^{2}$ & 115891 & 106921 & 7,37 & 4,171 & 0,011 & $-7,7 \%$ \\
\hline Ultra-som $^{1} \times$ ponderada ${ }^{2}$ & 115891 & 112285 & 0,76 & 4,171 & 0,391 & $-3,1 \%$ \\
\hline
\end{tabular}

Em todas as análises feitas com as médias aritméticas e ponderadas, e com os ensaios de flexão estática e vibração transversal os resultados apontaram estas como sendo

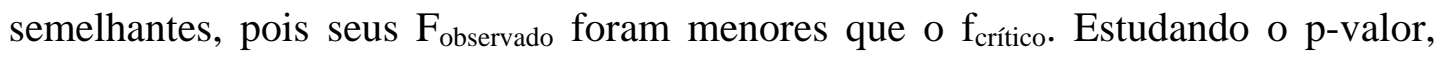
afirma-se que as que mais se aproximam são as médias dos ensaios de vibração transversal e aritmética simples. Quando se observa ultra-som versus ponderada, percebe-se que estas também apresentam uma semelhança significativa (pvalor=0,391), o mesmo não ocorrendo com ultra-som versus aritmética, que apresenta p-valor menor que 0,05, apesar da diferença percentual ser de 7,7\%. No entanto, cabe ressaltar que os valores de ultra-som que estão sendo comparados são os valores das constantes dinâmicas, e não os módulos de elasticidade das vigas, uma vez que estes dependem do coeficiente de Poisson. 


\section{$\mathrm{C}_{\text {A } \mathrm{s} \text { trulo }} 6$}

"Senhoras e senhores estamos aqui, pedindo uma ajuda por necessidade, pois 'temo' um irmão doente em casa, qualquer trocadinho é bem recebido. (...) Bom dia passageiros, é o que lhes deseja, a Miséria S.A. que acabou de chegar".

O Rappa

\section{CONCLUSÕES}

A partir da discussão dos resultados apresentados nos capítulos anteriores, conclui-se que:

- Para a produção de elementos estruturais de madeira laminada colada não basta que a espécie apresente densidade entre 0,5 a $0,75 \mathrm{~g} / \mathrm{cm}^{3}$. Tão importante quanto a densidade é a permeabilidade da espécie em relação aos adesivos disponíveis para a produção de MLC.

- Existem espécies tropicais, de densidade entre 0,5 e $0,75 \mathrm{~g} / \mathrm{cm}^{3}$, com permeabilidade adequada para a produção de elementos estruturais de madeira laminada colada, utilizando-se os adesivos Cascophen e à base de mamona. Neste trabalho merece destaque o potencial da espécie Cedrinho, entre as estudadas. 
- É possível efetuar uma adequada estimativa das propriedades de rigidez de vigas de MLC utilizando-se as expressões (3) e (4).

- As propriedades de rigidez de vigas de MLC, obtidas nos ensaios de flexão estática, não são influenciadas pela pressão de colagem variando entre 0,8 e 1,2 $\mathrm{MPa}$.

- As propriedades de rigidez de vigas de MLC, obtidas nos ensaios de flexão estática, não são influenciadas pelos dois adesivos estudados, o Cascophen e o à base de mamona.

- As propriedades de rigidez de vigas de MLC, obtidas nos ensaios de flexão estática, podem ser influenciadas pela disposição das lâminas ao longo da altura da seção transversal. Vigas com distribuição não aleatória de lâminas podem apresentar propriedades de rigidez superiores às de vigas montadas com distribuição aleatória de lâminas.

- É possível obter elementos compatíveis para emprego estrutural, de MLC, utilizando-se, como matéria prima, tábuas de espécies tropicais alternativas, empregadas com os adesivos estudados no presente trabalho. 


\section{Capítulo 7}

"Seria um crime mostrar os lados bons da guerra, ainda que ela os tivesse."

Henry Barbuse

\subsection{REFERÊNCIAS BIBLIOGRÁFICAS}

ASSOCIAÇÃO BRASILEIRA DE NORMAS TÉCNICAS, NBR 7190:1997 Projeto de Estruturas de Madeira.

AMERICAN SOCIETY FOR TESTING AND MATERIALS - D198:1984

BONO, C. T. (1996). Madeira Laminada Colada na arquitetura: sistematização de obras executadas no Brasil. São Carlos. Dissertação (Mestrado) - EESC/ USP.

CAlliA, V. W. (1958). Madeira laminada colada de Pinho do Paraná, seu emprego nas estruturas. São Paulo, Instituto de Pesquisas Tecnológicas. Boletim n47, Publicação n571. 60p.

CHAHUD, E.; ROCCO LAHR, F. A. (1983). Estudo da viabilidade do emprego de arcos de madeira laminada para estruturas principais de pontes. São Carlos. Relatórios de Iniciação Científica ${ }^{\circ} 1$ a 4 apresentados ao LaMEM/ EESC/ USP.

CHUGG, W. A. (1964). Glulam: The theory and pratice of the manufacture of gluedlaminated timber structures. London: Ernest Benn,. 423 p.

DIAS, A. A.; ROCCO LAHR, F. A. (1983). Estudo experimental do modelo reduzido de uma ponte pênsil com viga de rigidez de madeira laminada. São 
Carlos. Relatórios de Iniciação Científica $\mathrm{n}^{\circ} 1$ a 4 apresentados ao LaMEM/ $\mathrm{EESC} / \mathrm{USP}$.

DIAS, A. A.; ROCCO LAHR, F. A. (1999). Brazilian Tropical Timbers: Alternative Suggestions for Supplying European Economical Community. In: Encontro da Sociedade Portuguesa de Materiais, 9, Guimarães, Portugal. Anais: v.2, p. 21652170.

DEUTSCHES INSTITUT FÜR NORMUNG (1971). Keilzinkenverbindung Von Holz. Berlin, Alemanha. 3p.

JESUS, J.M.H. (2000). Estudo do adesivo poliuretano à base de mamona em madeira laminada colada (MLC). São Carlos. Tese (Doutorado). Escola de Engenharia de São Carlos - Instituto de Física de São Carlos - Instituto de Química de São Carlos. Universidade de São Paulo. 106p.

INSTITUTO NACIONAL DE PESQUISAS ESPACIAIS (1998). INPE Notícias. São José dos Campos, SP, Brasil, v. 4, n²13, jan/ fev.

MACÊDO, A. N. (1997). Madeiras tropicais da Amazônia em madeira laminada colada $(M L C)$. São Carlos. EESC-USP (Trabalho apresentado à disciplina "SAP 802” - Madeiras e suas aplicações).

MAINIERI,C.; CHIMELLO, J.P. (1983). Fichas de características das madeiras brasileiras. 2 ed - São Paulo: IPT , Divisão de Madeiras, Publicação IPT, n. 1791.

MARTÍNEZ, E. M. (2001). Desenvolvimento de um modelo estatístico para aplicação no estudo de fadiga em emendas dentadas de madeira. São Carlos. Tese (Doutorado). Escola de Engenharia de São Carlos - Instituto de Física de São Carlos - Instituto de Química de São Carlos. Universidade de São Paulo. $160 \mathrm{p}$.

MOODY, R. C. (1970). Glued-laminated timber research at the Forest Products Laboratory. Mad., Wis.: USDA-FS-FPL. 20 p.

NATTERER, J. (1991). Quality criteria for timber design. In: International Timber Engineering Conference, London. Proceedings, v.2, p.19-26. 
OLIVEIRA, F. G. R. (2001). Estudo de propriedades mecânicas de dicotiledôneas por meio de ensaio não-destrutivo utilizando equipamentos de ultra-som. São Carlos. Dissertação (Mestrado). Escola de Engenharia de São Carlos - Instituto de Física de São Carlos - Instituto de Química de São Carlos. Universidade de São Paulo. 55p.

ROCCO LAHR, F. A. (1992). Contribuição ao estudo de vigas retas de madeira laminada colada $(M L C)$. In: Encontro Brasileiro em Madeiras e em Estruturas de Madeiras, 4., São Carlos. Anais, v.3, p.13-20.

SANTOS, E. (1987). Nossas Madeiras. Belo Horizonte, Editora Itatiaia Ltda., Coleção Vis Mea in Labore, 313 p.

SELBO, M. L.; FREAS, A. D. (1954). Fabrication and Design of Glued Laminated Wood Structural Members. USDA-FS-FPL, Washington, DC., 220 p.

SIMIONI, A. (1978). Sobre a viabilidade técnica da confecção de vigas laminadas com madeira juvenil de Pinus elliottii Engelm. Curitiba. Dissertação (Mestrado em Engenharia Florestal), Universidade Federal do Paraná.

ZANDER, J. R. T. (1979). Cálculo e fabricação de peças de madeira laminada. São Carlos. Dissertação (Mestrado) - EESC/ USP. 


\subsection{OBRAS CONSULTADAS}

FEDALTO, L. C.; MENDES, I. C. A.; CORADIN, V. T. R. (1989). Madeiras da Amazônia: descrição do lenho de 40 espécies ocorrentes na Floresta Nacional dos Tapajós. Brasília: IBAMA, 156 p. (tabela A1 - Fonte II).

FOREST PRODUCTS LABORATORY. 1999. Wood Handbook - Wood as an engineering material. General Technical Report. FPL-GTR-113. Madison, WI: USDA. United States Department of Agriculture, Forest Service. 463p.

LOUREIRO, A.A.; FREITAS, J.A.; FREITAS, C.A.A. (1997). Essências madeireiras da Amazônia. Manaus: MCT/INPA - CPPF. (tabela A1 - Fonte V).

MAGAlhãES, M. N.; LIMA, A. C. P. (2002). Noções de probabilidade e estatística. 4 ed. - São Paulo: Editora da Universidade de São Paulo. 392p.

MAINIERI,C.; CHIMELLO, J. P. (1983). Fichas de características das madeiras brasileiras. 2 ed - São Paulo: IPT, Divisão de Madeiras, Publicação IPT, n. 1791. (tabela A1 - Fonte IV).

MARQUES, M. H. B.; MELO, J.E. (1997). Madeiras da Amazônia: Características e utilização. Brasília: IBAMA, 141p. (tabela A1 - Fonte III).

ROCCO LAHR, F.A. Características da madeira de trinta espécies nativas da Amazônia. São Carlos, EESC-USP, no prelo. (tabela A1 - Fonte VI).

SOUZA, M. H. (1997). Madeiras tropicais brasileiras. Brasília, IBAMA Laboratório de Produtos Florestais. 152 p. (tabela A1 - Fonte I).

ZANGIACOMO, A. L.; DIAS, A. A.; RADAIK, C. E. (1999). Caracterização de madeiras tropicais alternativas para aplicação na construção civil. In: CONGRESSO DE INICIAÇÃO CIENTÍFICA DA UNIVERSIDADE FEDERAL DE SÃO CARLOS, 7., São Carlos, 1999. Resumos. São Carlos: UFSCar, 1999.

ZANGIÁCOMO, A. L.; ROCCO LAHR, F. A. (2000). Espécies tropicais alternativas na produção de madeira laminada colada. In: SIMPÓSIO INTERNACIONAL DE INICIAÇÃO CIENTÍFICA DA UNIVERSIDADE DE SÃO PAULO, 8., São Carlos, 2000. Resumos. São Paulo: USP, 2000. 


\section{$A^{\text {PÊndICE }}$}


Tabela A1 - Espécies consultadas

\begin{tabular}{|c|c|c|c|c|c|c|}
\hline & Nome Comum & Nome Científico & Família & $\rho_{12}\left(\mathrm{~g} / \mathrm{cm}^{3}\right)$ & Outros Nomes & Fonte* \\
\hline 1 & Açacu & Hura crepitans $L$. & Euphorbiaceae & 0.48 & $\begin{array}{l}\text { açacu (branco, vermelho, } \\
\text { preto), areeiro, uçacu }\end{array}$ & III \\
\hline 2 & Aguano & (ver Mogno) & & & & IV \\
\hline 3 & Almecegueira & Protium heptaphyllum March. & Burseraceae & 0.73 & $\begin{array}{l}\text { almesca, almécega, mesclão, } \\
\text { breu, breu-branco, breu-preto }\end{array}$ & IV \\
\hline 4 & Amapá-Amargoso & Parahancornia amapa (Huber) Ducke & Apocynaceae & 0.56 & $\begin{array}{l}\text { amapá, amapá-amargo, amar- } \\
\text { goso, mogno-dourado. }\end{array}$ & III \\
\hline 5 & Amapá-Doce & Brosimum parinarioides Ducke subsp. & Moraceae & 0.64 & & II - IV \\
\hline 6 & Amapá-Doce & Brosimum potabile Ducke & Moraceae & 0.59 & & II \\
\hline 7 & Amesclão & Trattinnickia burseraefolia (Mart.) Willd. & Burseraceae & 0.52 & $\begin{array}{l}\text { amescla, breu, breu-preto, } \\
\text { mangue, sucuruba }\end{array}$ & I \\
\hline 8 & Anani & (ver Pitiá-de-Lagoa) & & & & IV \\
\hline 9 & Andiroba & Carapa guianensis Aubl. & Meliaceae & 0.7 & $\begin{array}{l}\text { andiroba-aruba, andiroba- } \\
\text { vermelha, carapa, caropá }\end{array}$ & I - II - IV \\
\hline 11 & Angelim-Pedra & Hymenolobium paetrum & & 0.69 & & $\mathrm{VI}$ \\
\hline 12 & Aruá-da-Terra-Firme & (ver Freijó) & & & & V \\
\hline 13 & Axixá & Sterculia apeibophylla Ducke & Sterculiaceae & 0.61 & couro-de-sapo & III \\
\hline 14 & Axixá & (ver Tacacazeiro) & & & & V \\
\hline 15 & Breu-Sucuruba & (ver Amesclão) & & & & $\mathrm{V}$ \\
\hline 16 & Burra-Leiteira & Sapium marmieri Huber & Euphorbiaceae & 0.48 & leiteira, murupita, seringueira & III \\
\hline 17 & Cafearana & Andira sp & & 0.68 & & $\mathrm{VI}$ \\
\hline 18 & Cajuaçú & Anacardium spp & Anacardiaceae & 0.51 & $\begin{array}{l}\text { caju, caju-da-mata, cajuí, } \\
\text { cajuí-da-mata, caracol }\end{array}$ & I - II - IV \\
\hline 19 & Castanheira & Bertholletia excelsa Humb. \& Bonpl. & Lecythidaceae & 0.71 & & II - IV \\
\hline
\end{tabular}


Tabela A1 - Espécies consultadas

\begin{tabular}{|c|c|c|c|c|c|c|}
\hline 20 & Cedrinho & Erisma sp & Vochysiaceae & 0,57 & $\begin{array}{l}\text { bruteiro, cambará, jaboti-da- } \\
\text { terra-firme, quarubatinga }\end{array}$ & I \\
\hline 21 & Cedro-Amargo & Cedrella odorata & & 0,51 & & $\mathrm{VI}$ \\
\hline 22 & Cedro-Doce & Cedrella sp & & 0,5 & & $\mathrm{VI}$ \\
\hline 23 & Cedrorana & Cedrelinga catenaeformis Ducke & $\begin{array}{l}\text { Leguminosae } \\
\text { Mimosoideae }\end{array}$ & $0,52-0,57$ & $\begin{array}{l}\text { cedrarana, cedro-branco, } \\
\text { cedromara, taperibá-açú }\end{array}$ & $\mathrm{I}-\mathrm{VI}$ \\
\hline 24 & Copaíba & Copaifera spp. & $\begin{array}{c}\text { Leguminosae } \\
\text { Caesalpinoideae }\end{array}$ & $0,5-0,75$ & $\begin{array}{l}\text { copaíba-preta, óleo, óleo- } \\
\text { de-copaíba, óleo-pardo }\end{array}$ & $I-I I-V I$ \\
\hline 25 & Copaíba-Jutaí & Copaifera duckei Dwyer & Caesalpiniaceae & 0,69 & & $\mathrm{~V}$ \\
\hline 26 & Envira-Bobó & Guatteria olivacea R. E. Fries & Annonaceae & 0,57 & & V \\
\hline 27 & Envira-Branca & Xylopia nitida Dun. & Annonaceae & 0,63 & & $\mathrm{~V}$ \\
\hline 28 & Envira-Brava & Rollinia exsucca (Dun.) A. DC. & Annonaceae & 0,58 & & $\mathrm{~V}$ \\
\hline 29 & Envira-Preta & Diclinanona calycina (Diels) R. E. Fries & Annonaceae & 0,53 & & II \\
\hline 30 & Fava-Bolota & (ver Faveira-Bolota) & & & & II - IV \\
\hline 31 & Faveira-Bolota & Parkia pendula (Willd.) Benth. ex Walp. & $\begin{array}{l}\text { Leguminosae } \\
\text { Mimosoideae }\end{array}$ & 0,6 & $\begin{array}{l}\text { angelim-bolota, fava-bolota, } \\
\text { faveira, paricá-grande }\end{array}$ & I - IV \\
\hline 33 & Faveira-Branca & Parkia spp. & $\begin{array}{l}\text { Leguminosae } \\
\text { Mimosoideae }\end{array}$ & $0,50-0,52$ & $\begin{array}{l}\text { atanã, arara-tucupi, camurim } \\
\text { visgueiro }\end{array}$ & I \\
\hline 34 & Faveira-Tamboril & Enterolobium maximum Ducke & Mimosaceae & 0,47 & & II \\
\hline 35 & Faveira-Vermelha & Dimorphandra sp & Caesalpiniaceae & 0,62 & $\begin{array}{l}\text { fava-vermelha, faveira-camu- } \\
\text { rim }\end{array}$ & IV \\
\hline 36 & Freijó & Cordia bicolor A. DC. ex D.C. & Boraginaceae & 0,55 & & $\mathrm{II}-\mathrm{V}$ \\
\hline 37 & Freijó & Cordia goeldiana Huber & Boraginaceae & 0,54 & & II - IV \\
\hline 38 & Freijó & Cordia sagotii I. M. Johnston & Boraginaceae & 0,56 & aruá-da-terra-firme & II \\
\hline
\end{tabular}


Tabela A1 - Espécies consultadas

\begin{tabular}{|c|c|c|c|c|c|c|}
\hline 39 & Guariúba & Clarisia racemosa Ruíz \& Pav. & Moraceae & 0,7 & $\begin{array}{l}\text { catruz, gameleiro, oiticica, } \\
\text { oiti, guariúba-amarela, aji }\end{array}$ & I - IV \\
\hline 40 & Imburana-de-Cheiro & Torresea acreana Ducke & Fabaceae & 0,58 & cumaru-de-cheiro & IV \\
\hline 41 & Ingá-Chi-Chi & Inga alba(Sw.) Willd. & Mimosaceae & 0,61 & ingá & IV \\
\hline 42 & Ingá-de-Porco & Macrosamanea pedicellaris (DC.) Kleinh & $\begin{array}{l}\text { Leguminosae } \\
\text { Mimosoideae }\end{array}$ & 0,61 & $\begin{array}{l}\text { carrapatinho, cazenza, ingá- } \\
\text { favo, jaguarana, jueirana. }\end{array}$ & III \\
\hline 43 & Jacareúba & Calophyllum brasiliense Camb & Clusiaceae & 0,6 & & IV \\
\hline 44 & Leiteiro & Sapium aereum Klotzsch & Euphorbiaceae & 0,52 & burra-leiteira, sorva & III \\
\hline 45 & Louro & Ocotea spp. & Lauraceae & 0,7 & louro-canela & 1 \\
\hline 46 & Louro-Amarelo & Ocotea sp & Lauraceae & 0,52 & louro & IV \\
\hline 47 & Louro-Faia & Euplassa spp. & Proteaceae & 0,67 & $\begin{array}{l}\text { faia, cedro-bordado, catu- } \\
\text { caém, carvalho-brasileiro }\end{array}$ & I \\
\hline 48 & Louro-Inamuí & Ocotea cymbarum H.B.K. & Lauraceae & 0,64 & $\begin{array}{l}\text { inamuí-louro, louro-mamorim, } \\
\text { sassafrás }\end{array}$ & IV \\
\hline 49 & Louro-Preto & Ocotea sp & Lauraceae & $0,61-0,68$ & louro & IV - VI \\
\hline 51 & Maminha-de-porca & ZanthoxyIn regnelianum Engl. & Rutacea & 0,6 & & III \\
\hline 52 & Mandioqueira & Qualea albiflora Warm. & Vochysiaceae & 0,68 & $\begin{array}{l}\text { mandioqueira-áspera, man- } \\
\text { dioqueira lisa }\end{array}$ & I \\
\hline 53 & Mandioqueira & Ruizterania albiflora Marcano Bert & Vochysiaceae & 0,63 & & IV \\
\hline 54 & $\begin{array}{l}\text { Mandioqueira-Esca- } \\
\text { mosa }\end{array}$ & Qualea dinizii Ducke & Vochysiaceae & 0,69 & $\begin{array}{l}\text { amarelão, mandioqueira-ro- } \\
\text { as, pau-mulato, quaruba }\end{array}$ & III \\
\hline 55 & Melancieira & Alexa grandiflora Ducke & Fabaceae & 0,67 & & II \\
\hline 56 & Mogno & Swietenia macrophyla King & Meliaceae & 0,61 & mogno-aguano, cedro I & IV \\
\hline
\end{tabular}


Tabela A1 - Espécies consultadas

\begin{tabular}{|c|c|c|c|c|c|c|}
\hline 57 & Morototó & Schefflera morototoni (Aubl.) & Araliaceae & 0,57 & $\begin{array}{l}\text { caxeta, imbaubão, man- } \\
\text { diocão-do-mato, mucututu }\end{array}$ & I \\
\hline 58 & Muiratinga & Maquira sclerophylla (Ducke) C.C. Berg & Moraceae & 0,64 & & II \\
\hline 59 & $\begin{array}{l}\text { Munguba-Grande- } \\
\text { da-Terra-Firme }\end{array}$ & Eriotheca longipedicellata (Ducke) A. R. & Bombacaceae & 0,54 & $\begin{array}{l}\text { mamorana-da-terra-firme, } \\
\text { munguba,sumaúma-vermelha }\end{array}$ & $\mathrm{I}-\mathrm{V}$ \\
\hline 60 & Mururé & Brosimum acutifolium Huber subsp. & Moraceae & 0,62 & & II \\
\hline 61 & Oiticica-Amarela & (ver Guariúba) & & & & I - IV \\
\hline 62 & Paricá & Enterolobium contortisiliquum (vell.) M. & Mimosaceae & 0,52 & timbuva & IV \\
\hline 63 & Pitiá-de-Lagoa & Symphonia globulifera L. & Guttiferae & 0,72 & anani, guanandi & IV \\
\hline 64 & Quaruba & Vochysia spp. & Vochysiaceae & 0,6 & $\begin{array}{l}\text { cedrorana, guaruba, quaruba- } \\
\text { cedro, quaruba-vermelha }\end{array}$ & 1 \\
\hline 65 & Quarubarana & Moquinia polymorpha & Compositae & 0,7 & cambará, candeia, cedrilho & IV \\
\hline 66 & Rabo-de-Arraia & (ver Quaruba) & & & & VI \\
\hline 67 & Simbiúva & Hirtellasp & Chrysobalanaceae & 0,7 & ajururama, caraipé-vermelho & IV \\
\hline 68 & Sorva & Malouetia ducke Mgf. & Apocynaceae & 0,64 & & $\mathrm{~V}$ \\
\hline 70 & Tacacazeiro & Sterculia speciosa K. Schum. & Sterculiaceae & 0,59 & & $\mathrm{II}-\mathrm{V}$ \\
\hline 71 & Tachi-Vermelho & Sclerolobium chrysophyllum Poepp. \& E. & Caesalpiniaceae & 0,56 & & $\mathrm{~V}$ \\
\hline 72 & Tamboril & (ver Paricá) & & & & IV \\
\hline 73 & Tatapiririca & Tapirira guianensis Aubl. & Anacardiaceae & 0,56 & & II \\
\hline 74 & Tauari & Couratari oblongifolia Ducke \& Knuth & Lecythidaceae & 0,56 & & $\mathrm{~V}$ \\
\hline 75 & Tauari & Couratari spp. & Lecythidaceae & $0,59-0,64$ & $\begin{array}{l}\text { imbirema, tauari-amarelo, } \\
\text { tauari-morrão, estopeiro }\end{array}$ & I - II - IV \\
\hline 76 & Taxi & Tachigali myrmecophila Ducke & $\begin{array}{c}\text { Leguminosae } \\
\text { Caesalpinoideae }\end{array}$ & 0,67 & $\begin{array}{l}\text { taxi-pitomba, taxi-preto, taxi- } \\
\text { preto-da-mata, taxizeiro }\end{array}$ & I- II \\
\hline
\end{tabular}


Tabela A1 - Espécies consultadas

\begin{tabular}{|c|l|l|c|c|c|}
\hline 77 & $\begin{array}{l}\text { Ucuuba-da-Terra- } \\
\text { Firme }\end{array}$ & Virola michellii Heckel & Myristicaceae & 0,56 & II \\
\hline 78 & Ucuubarana & Iryanthera grandis Ducke & Myristicaceae & 0,7 & II \\
\hline 79 & Ucuubarana & Osteophloeum platyspermum (A. DC.) W. & Myristicaceae & 0,59 & $\begin{array}{l}\text { arurá-branco, pajurá, ucuúba- } \\
\text { branca, ucuubão. }\end{array}$ \\
\hline 80 & Umirana & Qualea retusa & & 0,71 & \\
\hline
\end{tabular}

* Ver obras consultadas 


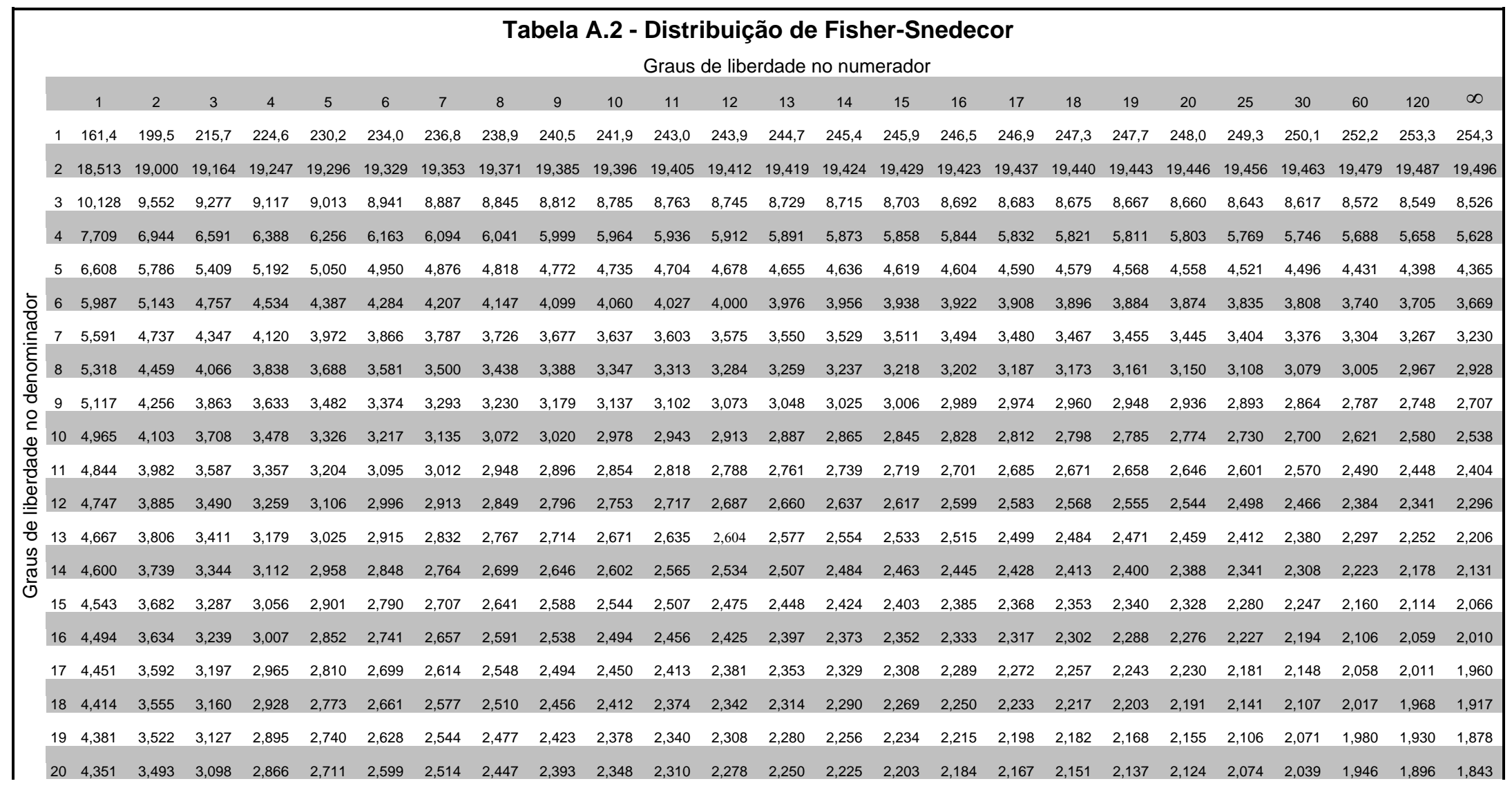




\section{Tabela A.2 - Distribuição de Fisher-Snedecor}

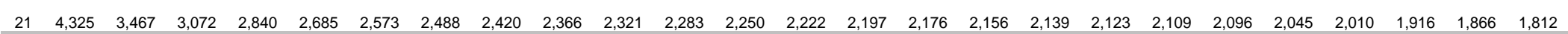
\begin{tabular}{lllllllllllllllllllllllllllllll}
22 & 4,301 & 3,443 & 3,049 & 2,817 & 2,661 & 2,549 & 2,464 & 2,397 & 2,342 & 2,297 & 2,259 & 2,226 & 2,198 & 2,173 & 2,151 & 2,131 & 2,114 & 2,098 & 2,084 & 2,071 & 2,020 & 1,984 & 1,889 & 1,838 & 1,783 \\
\hline
\end{tabular} \begin{tabular}{lllllllllllllllllllllllllllll} 
흉 & 23 & 4,279 & 3,422 & 3,028 & 2,796 & 2,640 & 2,528 & 2,442 & 2,375 & 2,320 & 2,275 & 2,236 & 2,204 & 2,175 & 2,150 & 2,128 & 2,109 & 2,091 & 2,075 & 2,061 & 2,048 & 1,996 & 1,961 & 1,865 & 1,813 & 1,757 \\
\hline & 24 & 4,260 & 3,40 & 3,00 & 2,776 & 2,621 & 2,508 & 2,423 & 2,35 & 2,300 & 2,25 & 2,216 & 2,83 & 2,55 & 2,130 & 2,108 & 2,088 & 2,070 & 2,054 & 2,040 & 2,027 & 1,975 & 1,929 & 1,842 & 1,790 & 1,733 \\
\hline
\end{tabular}

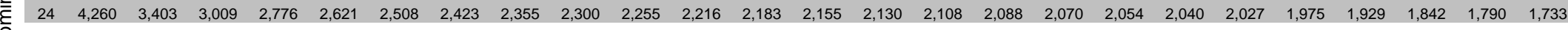

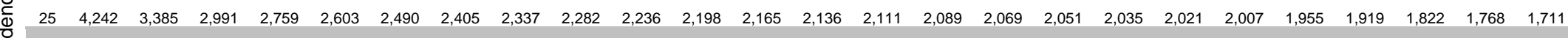

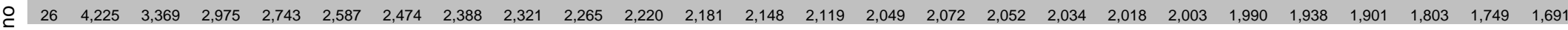

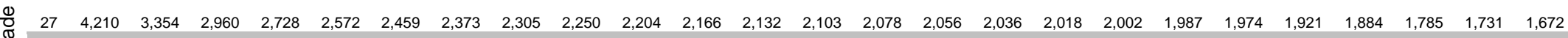

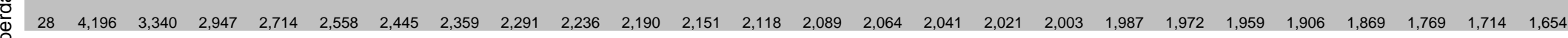
\begin{tabular}{lllllllllllllllllllllllllll}
\hline \% & 29 & 4,183 & 3,328 & 2,934 & 2,701 & 2,545 & 2,432 & 2,346 & 2,278 & 2,223 & 2,177 & 2,138 & 2,104 & 2,075 & 2,050 & 2,027 & 2,007 & 1,989 & 1,973 & 1,958 & 1,945 & 1,891 & 1,854 & 1,754 & 1,698 & 1,638 \\
\hline
\end{tabular}

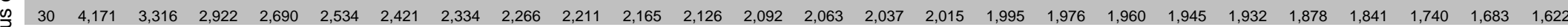

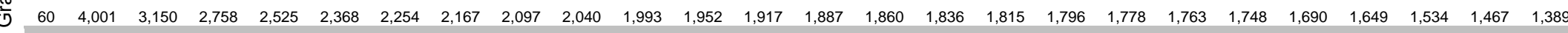

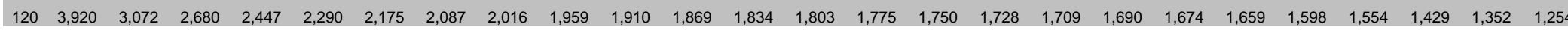
$\begin{array}{lllllllllllllllllllllllllll}\infty & 3,842 & 2,996 & 2,605 & 2,372 & 2,214 & 2,099 & 2,010 & 1,938 & 1,880 & 1,831 & 1,789 & 1,752 & 1,720 & 1,692 & 1,666 & 1,644 & 1,623 & 1,604 & 1,587 & 1,571 & 1,507 & 1,459 & 1,318 & 1,221 & 1,000\end{array}$ 